\title{
Studies on the influence of heparin and heparin derivatives on the generation of thrombin
}

Citation for published version (APA):

Baruch, D. (1986). Studies on the influence of heparin and heparin derivatives on the generation of thrombin. [Doctoral Thesis, Maastricht University]. Rijksuniversiteit Limburg. https://doi.org/10.26481/dis.19860314db

Document status and date:

Published: 01/01/1986

DOI:

10.26481/dis.19860314db

Document Version:

Publisher's PDF, also known as Version of record

\section{Please check the document version of this publication:}

- A submitted manuscript is the version of the article upon submission and before peer-review. There can be important differences between the submitted version and the official published version of record.

People interested in the research are advised to contact the author for the final version of the publication, or visit the DOI to the publisher's website.

- The final author version and the galley proof are versions of the publication after peer review.

- The final published version features the final layout of the paper including the volume, issue and page numbers.

Link to publication

\footnotetext{
General rights rights.

- You may freely distribute the URL identifying the publication in the public portal. please follow below link for the End User Agreement:

www.umlib.nl/taverne-license

Take down policy

If you believe that this document breaches copyright please contact us at:

repository@maastrichtuniversity.nl

providing details and we will investigate your claim.
}

Copyright and moral rights for the publications made accessible in the public portal are retained by the authors and/or other copyright owners and it is a condition of accessing publications that users recognise and abide by the legal requirements associated with these

- Users may download and print one copy of any publication from the public portal for the purpose of private study or research.

- You may not further distribute the material or use it for any profit-making activity or commercial gain

If the publication is distributed under the terms of Article $25 \mathrm{fa}$ of the Dutch Copyright Act, indicated by the "Taverne" license above, 


\title{
STUDIES ON THE INFLUENCE OF HEPARIN AND HEPARIN DERIVATIVES ON THE GENERATION OF THROMBIN
}

\author{
PROEFSCHRIFT
}

ter verkrijging van de graad van doctor in de geneeskunde aan de Rijksunivergiteit Limburg te Maastricht, op gezag van de Rector Magnificus, Prof. Dr. F.I.M. Bonke, volgens het besluit van het College van Dekanen, in het openbaar te verdedigen op vrijdag 14 maart 1986 on vier uur

door

Dominique Baruch

geboren te Suresnes (Frankri.jk) in 1954 
PROMOTOR : Prof. Dr. H.C. Hemker

CO-PROMOTOR : Dr. T. Lindhout

REFERENTEN :Prof. Dr. M.J. Larrieu, Paris

: Dr. Y. Legrand, Paris

: Prof. Dr. H. Struyker-Boudier, Mastricht

These Investigations were supported in part by the Institut National de la Sante et de la Recherche Medicale (Paris) 


\section{CONTENTS}

Abbreviations

Chapter I

INTRODUCTION

The influence of heparin on thrombin formation

Chapter II

RINEIICS OF THROMBIN-INDUCED RELEASE AND ACTIVATION OF PLATELET FACTOR $V$

based on:

Baruch, D., Hemker, H.C., and L1ndhout, T. Eur.J.Blochem. 154, 213-218 (1986)

Chapter III

THROMBIN-INDUCED PLATELET FACTOR Va FORMATION IN PATIENTS WITH A GRAY PLATELET SXNDROME

based on:

Baruch, D., Lindhout, T., Dupuy, E., and Caen, J.P. Submitted for publication.

INHIBITION OF THROMBIN-CATALYZED REACTIONS IN BLOOD COAGULATION AND PLATELET ACTIVATION

Effect of heparin and low molecular weight heparins in the absence of antithrombin III based on:

Baruch, D., Franssen, J., Hemker, H.C., and Lindhout, T. Thromb. Res. 38, 447-458 (1985)

Baruch, D., Lindhout, T., Wagenwoord, R*, and Hemker, H.C. Haemostasis (1986) in press 
Chapter $\mathrm{V}$

Chapter VI

Chapter VII

SUMMARY

RESUME

SAMENVATT ING

ACKNOWLEDGEMENTS

CURR I CULUM VITAE
THE ROLE OF HEPARIN CHARGE DENSITY IN THE ANTITHROMB IN III DEPENDENT AND INDEPENDENT INACTIVATION OF THROMBIN

based on:

Baruch, D., Franssen, I., Hemker, H.C., and Lindhout, T. Submitted for publication.

THROMBIN GENERATION AND INACTIVATION IN THE PRESENCE OF ANTITHROMBIN III AND HEPARTN based on:

Lindhout, T., Baruch, D., Schoen, P., Fransisen, J., and Hemker, H.C.

Submitted for publication

GENERAL DISCUSSION 


\section{ABBREVIATIONS}

DEAE Diethylami noet hyl

EDTA Ethylenediamine tetracetic acid

Hepes 4-2-(hydroxyethyl)-1-pipperazine-echanesulfonic ficid dimethylsulfoxide

HSA Human serum albumin

p-NPGB P-nitrophenyl-p-guanidinobenzoate hydrochloride

PC Phosphatidylcholine

PS Phosphatidylserine

PPCA Platelet prothrombin converting activity

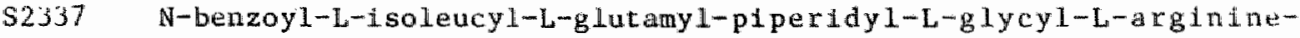
paranitroanilide hydrochloride

S 2238 HD-pheny Lallanyl-L-pipecolyl- L-arginine- paranitroandide hydrochloride

SDS $\quad$ Sodiun-dodecyl-sulfate

Tris Tris (hydroxymethyl) aminomethane

USP United States Pharmacopeia 
$-6-$ 
CHAPTER I

THE INFLUENCE OF HEPARIN UN THROMBIN FURMATION

* Thrombin formation and its regulation.

- Thrombin formation

- The regulation of thrombin formation by thrombin dependent posttive Eeedback reactions.

1. Factor VIII:C activation

2. Factor V activacion

3. Platelet factor $V$ release and activation

4. Procoagulant activity of platelets in factor $x$ and prothrombin activation.

The function of heparin in the regulation of thrombin formation.

- Intraduction

- The inactivation of thrombin by natural inhibitors.

1. Antithrombin III

2. Heparin cofactor II

- Biosynthesis and structure of heparin

- Heparin-antithrombin III interaction

- Heparin-protease interaction

- Kinerics of the heparin-catalyzed antithrombin III/protease reactions

- Kinetics of the heparin-catalyzed antichrombin IIL/protease reactions in prothrombin activation by the prothrombinase complex

- The antithrombin III-independent effect of heparin

- Heparin-platelet interaction

* The present study. 


$$
-8-
$$


THROMBIN FORMATION AND ITS REGULATION

\section{Thrombin formation}

The process that goverms the guneration of thrombin lis a series of proteolytic proenzyme actiwations that occur at a phospholipid-solute interface. In addition, the limited proteolysts of non-enzymatic proteins provides specific cofactors for some of the enzymes of blood coagulation. The sequence of the proteolytic activation reactions can be simplified to a main activation triangle with three relnforcement loops (1). The activation of factor $X$ occurs by two different pathways: activated factor VII (facto VII ) activates factor $X$ or factor VII activates first factor IX which in turn activates factor $X$. The intrinsic pathway consists of factor IX activation by the contact factors (factor XI, which is activated by factor XII and prekallikrein). Reinforcement loops are formed by positive feed back reactions such as activation of factor VII by factor $x_{a}$ or factor ix (2), the mutual activation of prekallikrein and factor XII and the activation of factor VII by factor XII (3) [Figure 1 taken from reference (1)). In addition thrombin mediates other positive feedback reactions as will be discussed in the next section.

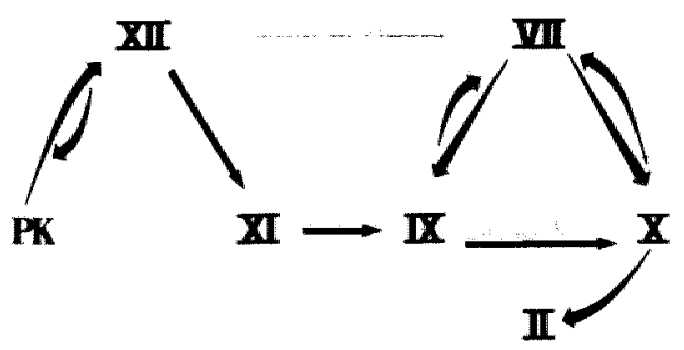

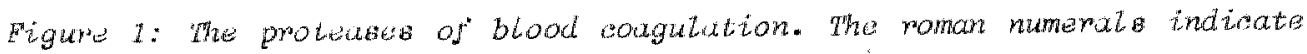
the respective coagulation jactors. PK = prekaltikrein. The arrowa indicate wetivation by 2 imited proteolysis. For example, $x \rightarrow$ II means that activated factor $X$ exerts its proteolytic action upon factor II so as to activate it (taken from reference 1$)$. 


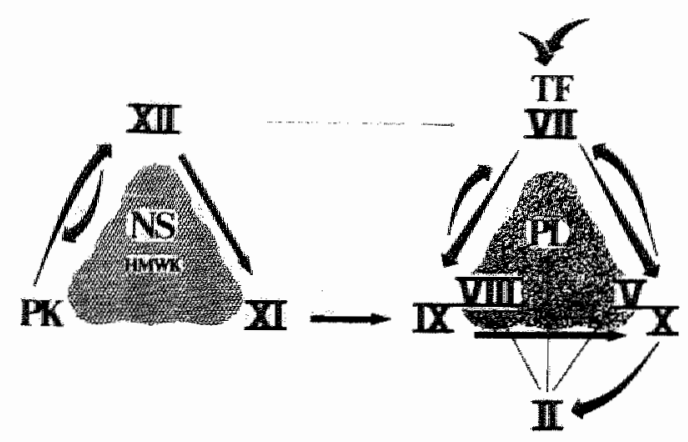

Figure 2: The overall coagulation procesa. In addition to figure 1 the non-enzymatic cofactors and the kurfaces at which the reaction takes place are indicated. $N S=$ negattwety-charged surface. HMW = High Molecultar Weight Kinimogen; $T N=$ tissue foctor; $P L=$ phospholtpid.

Each of the activation reactions has its specific non-enzymatic protein cofactor: factor WII which activates factor $X$ and factor IX needs the

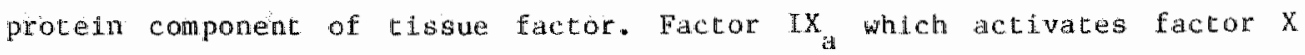
needs ictivated finctor VIIL. Prothrombin activation by faccor $x_{\text {dil }}$ requires activated factor $V$. Contact activation reactions require high molecular weight kininogen. Thus each stage in the process of blood coagulation can be viswed as a dssociable three component enzyme (enzyme-cofactor-surface) acting on a substrate bound to the same surface. Whereas the physlological surface involved in the so-called contact activation (activation of factor XIL, factor XI and prekal1lkrein) has yet to be established, wounded cells and/or activated platelets provide the procoagulant surfaces for the activation of factor $\mathrm{LX}$, factor $\mathrm{X}$, factor VII and prothrombin. The overall. schene of blood coagulation is depleted in Figure 2.

The regulation of thrombin formation by thrombin-dependent positive feedback reactions

Thrombin is responstble for positive feedback reactions that lead to an amplification of its own formation. Four specific reactions are catalyzed by thrombin. 
1. Factor VIII:C activation. Activated factor VIII:C (VIII ) is the cofactor of the factor-X-activating complex. Factor VIll a forms a stoichiometric complex with factor $I_{a}$ and promotes factor IX binding to phospholipid by lowering the dissociation constant $(4,5)$. Non-activated human factor VIL consists of a single polypeptide chaln, $M_{r}=100,000$ to 210,000 , this heterogeneity is presumably due to proteolysis (6). Thrombin-catalyzed factor VIII activation results in the formation of a heavy chain of $M_{r}=92,000$ and a 11 ght chain of $M_{r}=71,000-72,000(7)$. This is analogous to the active forms shown for muman and bovine factor $V(8,9)$. There is evidence that thrombin activated factor WII is labile and chat stabilization is achleved by performing the activation in the presence of phospholipid and factor $\mathrm{IX}_{\mathrm{a}}(10)$. Whether thrombin is responsible for the inactivation of factor VIII (6) or whether factor VIII undergoes both thrombin dependent activation and thrombin independent inactivation (11) is still unknown.

2. Factor V activation. Factor $V$ from bovine or human origin is a single chain glycoprotein with $M_{r}=330,000$. The activation process of either molecule by thrombin yields factor $\mathrm{V}_{\mathrm{a}}$, a two-subunit protein. The two subunits togecher represent about one-half of the mass of factor $v$, and the remaining mass represents activation fragments. Bovine factor $v_{a}$ consists of a light chain of $M_{r}=80,000$ and a heavy chain of $M_{r}=94,000$. Both chains are non-covalently linked by cat lons $(9,12)$. Factor $V_{a}$ increases the maximal rate of thrombin formation about 2000-fold (13). With factor $x_{a}$ it forms a stoichiometric complex with a $k_{d}$ of $3.10^{-9} \mathrm{M}$. Phospholipids promote factor $x_{a}$-factor $V_{a}$ complex formation by decreasing the $k_{d}$ from $10^{-9} \mathrm{M}$ to $10^{-11} \mathrm{M}$. The $\mathrm{K}_{\mathrm{d}}$ of the factor $\mathrm{x}_{\mathrm{a}}-\mathrm{f} a \mathrm{ctor}$ $V_{a}$ complex for phosphollipids is dependent on the phosphatidylserine content of the latter ( 9 ). The phospholipid binding site of factor $V_{a}$ is located on the factor $v_{a}$ light chain. The interaction is primartiy electrostatic and does not requfre $\mathrm{Ca}^{++}$lons (14) although hydrophobtic interactions cannot be ruled out. Factor $x_{a}$ and prothrombin bind to intact factor $V_{a}$. That is, binding occurs when the factor $V_{a} 11 \mathrm{ght}$ chain and heavy chain are associated via $\mathrm{Ca}^{++}$ions (15). 
3. Platelet factor V release and activation. Factor V localization in platelers was firgt show by Breederveld (16), using immonofluorescence techniques. Immonological and functional studies, as well as studies of partial granule deficiencies in platelet, have established that factor $V$ is stored $1 \mathrm{n}$ a-granules $(17-23)$. Osterud et al. (18) reported that the protein was stored in 1 ts activated form because no increase in factor $V_{a}$ activity was observed when frozen-thaved platelet suspensions were incubated with thrombin. However, it is generally accepted now that factor $V$ fs stored in its non-activated form and can be released by a variety of agents (thrombin, collagen, ADP, ionophore A 23187). The findings of: Osterud et al. (18) can be explained by the presence of a platelet factor $V$ activator (19). Several reports suggested that collagen induced the incomplete release of factor $V$ present in plate1.ts (20-22). In contrast with these studies, kane et al. (23) showed that vircually all factor present in platelets could be released by the action of thrombin. This discrepancy, as well as the one existing for the assessment of platelet factor $V$ concentration relies on the absence of a well-defined factor $V$ bioassay. Based on the radiolmmunoasay described by Tracy et a1. (24) human platelet factor $v$ represents $10-20 \%$ of human plasma factor $V(25 \mathrm{nM})$.

The importance of platelet factor $V$ in maintaining normal hemostasis has been suggested by Miletich et al. (25) who demonstrated that among pacients with a factor $V$ deficiency the severity of bleeding correlated wh the extent of platelet factor $V$ defictency. Tracy et al. (26) reported a sewere familial bleeding disorder related to the almost complece absence of functionally active platelet factor $V$ with a ratio activicy/antigen of $2 \%$. This compares with a ratio of $70 \%$ in plasma. This abnormally was not caused by an impaired rellease reaction, nur by a defect in the assembly or functioning of the prothrombinase complex In the presence of exogenous factor $V_{a}$.

4. Procoagulant activity of platelets in factor $X$ and prothrombia activation. Extensive studles from our laboratory have demonstrated the need for the comblned action of collagen and thrombin in the generation of platelet procoagulant activity in factor $x$ and prochromin 
activation $(27-29)$. This activity results from the exposure at the surface of activated platelets, of the negatively-charged phospholipids, phosphatidylserine and phosphatidylethanolamine. The physiological importance of platelet procaagulant activity was confitrued by the study of a patient with a bleeding disorder ascribed to an isolated deficiency of platelet procoagulant activity in prothrombin activation (29) and presumed to be due to the selective lack of a membrane protein (receptor) required for factor $V_{a}$ binding (30). However, the results of: a recent study showed an equally Impaired ability of the patient's platelets to promote prothrombin and factor $X$ activation after stimulation of platelets by collagen and thrombin. The decreased stimulatory effect of the patient"s platelets was accompanied by a reduced exposure of phosphatidylserine as assessed by treatment of the membranes with phospholipases (29).

THE FUNCTION OF HEPARIN IN THE REGULATION OF THROMBIN FORMATION

\section{Intraduction}

Heparin is one of the most important drugs for the treatment and prevention of venous thrombosis. However it still raises many puzzilng questions on different levels for clinicians and cilnical chemists, biologists and biochemists. Clinicians and clinical chemists know that the major drawback to the therapeutic use of heparin is the absence of any reliable laboratory test to keep the patient in the narrow range that ensures an efflclent antithrombotic action but without causing a hemorrhagic tendency. Research over the last few years has led to the preparation of heparin fractions which allowed considerable progress in understanding the structure function relationships. The main in vitro and ex vivo anticoagulant function of heparin occurs by accelerating the inactivation of serine proteases by antithrombia III. However the properties of heparin to catalyze factor $x_{a}$ or thrombin inactivation by antithrombin III in vitro do not necessarily reflect the complexicy of heparin actions in blood coagulation reactions ex vivo, and are far from being sufficient to explain the in vivo effects. 
1. Antithrombin 1II. Antehrombin II is the main inhibitor of thrombin. It is present in human plasma at a concentration of $2.5 \mu M$ (31). The correlation between thrombotic disorders and plasta antithrombin III deficlency suggests that antichrombin III lis essential in the regulation of hemostasis.

Antithrombin IT from human or bovine plasma is a single-chain $a_{2}$-glycoprotein with $M_{r}=56,000-57,000$ and $M_{r}=56,600$ as determined by SDS-gelelectrophoresis and equilibrium sedimentation techniques, respectively (32). It concains about $10 \%$ carbohydrates. The complete primary structure of human antithrombin III has been reported and showed a pronounced sequence homology with a -antitrypsin (33), histidine-rich glycoprotein (34) and ovalbumin (35).

Antthrombin ILL Inhiblts proteases by ineans of the formation of it scable 1 : 1 molar complex between the active site of the enzyme and the reactive site of antithrombin. III (36). This reactive site, the antithrombin III ( $\mathrm{Arg} 385$ - Ser 386) peptide bond, appears to be the same for thrombin (37), factor $I X_{a}$ and factor $X_{a}$ (38).

The mechanism of thrombin inhibition by antithrombin III has been extensively studied. It resembles the mechanism described for the formation of a stable bond between a protease and a substrate and is bhown in Figure 3. The first step of the reaction involves the formation of a non covalent enzyme-substrate (Michaelis) complex, which after Internal bondshifts leads to the formation of a covalent tetrahedral complex. The third step of the reaction involves the breakdown of a peptide bond in the tetrahedral complex, leading to an acylenzyme intermediate and an amine product. The reverse reaction mlght occur, but very slowly. Water replaces the peptide leaving group in the reaction sequence (39). Evidence for the formation of an aeylenzyme incermediate in the reaction between antithrombin III and proteases came from studies of the dissociation pattern of these complexes under the denaturing conditions of sDs polyacrylamide electrophoresis. Whereas Rosenberg and Damus (36) showed the formation 


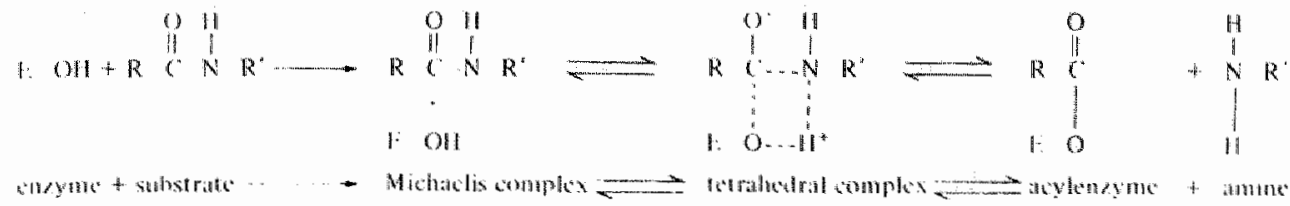

Figure 3: The reaction sequence for serine protease and aubltate complex fomation. The enzyme is depicted by $E-O H,-O H$ being the reacting group of the serine residue in the active centre. The reverse of the three reactions ahown heme can take place with the exception that the acylenayme reacts with a water molecule to form a tetrahedral complex.

of a stable antithrombin III-thrombin complex, Jesty (40) demonstrated that the stability of the complexes (antichrombin II-thrombin and antithrombin III-factor $x_{a}$ ) was $p H$ dependent. They were dissociated at pH 9 and could be reassociated at pH 7.9. Upon dissoctation of the complexes a modified form of antithrombin III was produced. In a recent study it was shown that the equimolar thrombin-antithrombin III complex is the only product of the reaction of thrombin with antithrombin III over a wide range of lonic strengths $(0.01-0.5)$. The reactive sitecleaved antithrombin $\mathbb{I I}$ released at a slow rate from the complexes in the absence of heparin is identical to the proteolytically modifled antithrombin $\mathbb{I I}$ produced in the presence of heparin (41). Although the exact nature of the bonds involved in the stable enzyme-antithrombin III complex is not known, kinetic studies have demonstrated the in volvement of a rapid preequilibrium step with formation of a Michaelis complex. Studies by means of stopped-flow fluorimetry with thrombinbound-p-aminobenzamidine as a probe showed that the antithrombin IIIthrombin reaction followed saturation kinetics when the antithrombtn IIf concentration exceeded $70 \mu \mathrm{M}$. The overall process of thrombin inactivation by antithrombin III was described as a two-step reaction, where the formation of an intial weak thrombin-antithrombin III complex with a $\mathrm{K}_{\mathrm{d}}$ of $1.4 \times 10^{-3} \mathrm{M}$ is followed by the formation of a stable complex with a first onder rate constant of $10.4 \mathrm{~s}^{-1}$ (42). 
2. Heparin cofactor II. A second heparin-dependent inhibitor of thrombin, the heparin cofactor I has been demonstraced and purified rrom human plasma (43). The activity of this inhibitor is enhanced by high heparin concentration. The characteriscics of the mucopolysacharide structure requited to enhance the heparin cufactor II-thrombin reaction have not been established. Subspecies of heparin other than the ones catalyzing the antuthrombin $41-p r o t e a s e$ reaction seem to be lnvolved in this catalytic effect (see below, kinetics of the heparin-catalyzed antithrombin $\mathbb{1} \mathrm{I}$-protease reaction) (44). Dermatan sulfate, which is a poor accelerator of the antithrombin III-thrombin reaction appears to be the maln mucopolysaccharide able to catalyze the heparin cofactor II thrombin reaction (45). The mechanism by which dermatan sulfate catalyzes the hepartin cofactor II-thrombin reaction seems essentially identical to the reaction mechanism described for the heparin-catalyzed antithrombin III-thrombin reaction (46). The physiological role of heparin cofactor II is not known. Its protease speciflcity seems to be restricted to thrombin, and in the presence of dermatan sulfate heparith cofactor II binds to thrombin as $1 \mathrm{t}$ is being generated in plasma (47). Rapid inhibition of thrombin by heparin cofactor II may occur in vivo only in the immediate vicinity of dermatan sulfate, which is the main proteoglycan of the intima and media of large arteries.

\section{Blosyrithesis and structure of heparin}

Heparin is a highly sulfated mucopolysaccharide widely distributed throughout a variety of organs within mamalian species. The bilosynthesis of heparin is inttiated by the attachment of a carbohydratemprotein linkage region to the serine residues of a specific polypeptide chatin (48). The polymer chatn of the mucopolysaccharide is assembled by the alternate attachment of the N-acetylglucosamine and glucuronte acid (Figure 4). Thereafter this simple copolymer structure is modifled by a multiscep process that takes place to a varying extent, apparently at random places, whin different segments af the mucopolysacehuride chain. These series of post-synthetic modifications are depicted in Figure 5. Each stage in the process is under the 


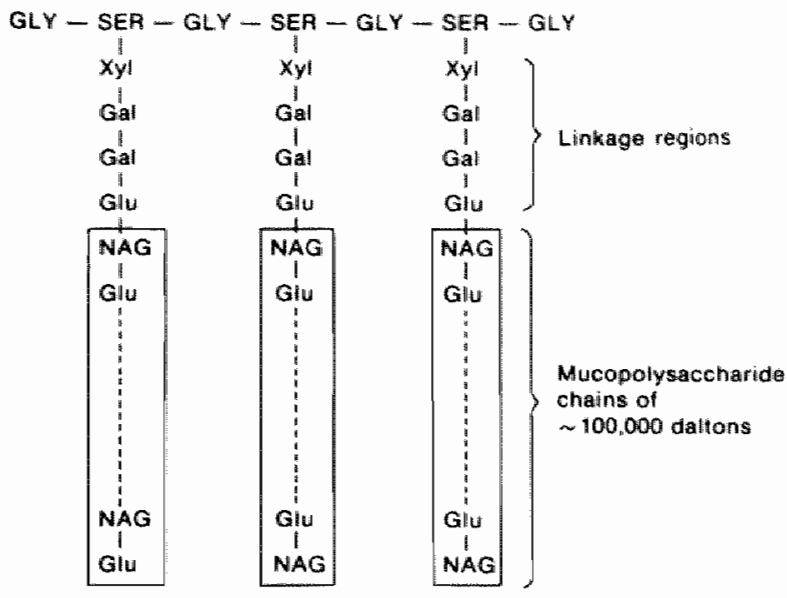

Figure 4: Initiation of the synthesis of hepamin. The semine mesidues of a specific polypeptide chain (heparin proteoglycan) bear aarbohydrateprotein linkage regions. The potymer chain of the mucopotybaccharide is assembled by the altemate attachment of N-acetyitglucosamine (NAG) and gLucuronic acid (CLu).

control of a specific enzyme and is only intiated when the preceding transformation has been completed. Of partictlar interest for the development of the anticoagulant activity of heparin 18 the epimerization of glucuronic acid residues into iduronic residues at the C-2 position. Within the tissues a degradative process by different types of lysosomal enzymes takes place leading to single polysaccharide chains with molecular weights of approximately 3,000 to 35,000 daltons (49). They are composed of alternating residues of uronic acid and glucosamine, linked by alternating $\alpha-D$ and $\beta-D 1,4$ bonds. The uronic acid groups may exist as iduronic acid-2 sulfate, glucuronic actd or non-sulfated iduronic acid. The glucosamine restdues way be N-sulfated, N-acetylated or have free amino groups. They nay have a free hydroxyl. group at $\mathrm{C}-6$ or bear an ester sulfate at this position (50). This mode of biosynthesis explains why commerclal heparin preparations that are extracted fron animal sources without further fractionation, exhibit a wide range of molecular weight, ratios of glucuronic acld over lduronic acid, degree of sulfation and $N$-acetylation ( 51$)$. 


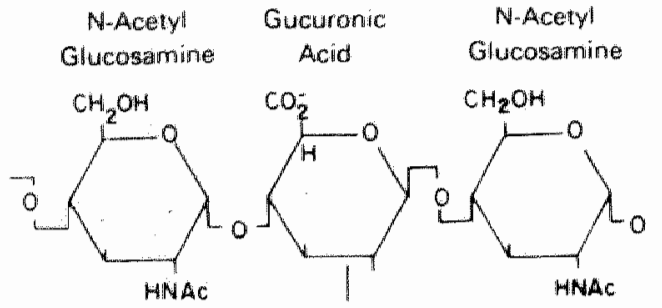

N-Deacenylase

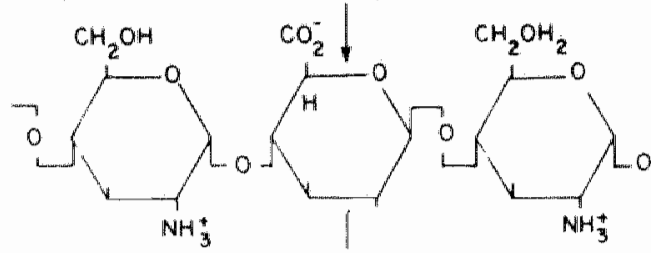

N-Sulfatransferase
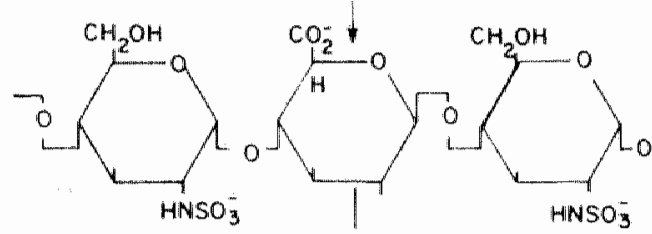

Epimerase
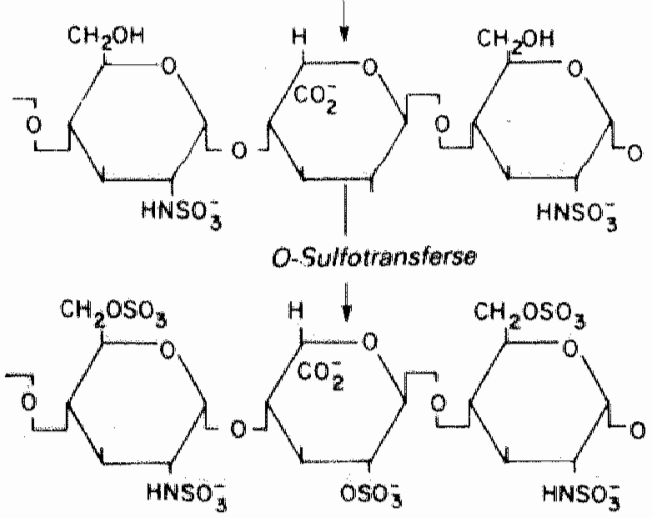

Disulfared Hexósamine
Sulfiated

Disulfated Iduronic Acid Hexosamino
Future 5 :

The biosynthesis of the mueopolysaccharide chains. Four major post-aynthetic modifications of the simple copolymer structure (N-acetylgluoosamine atternating with glucuronic acid lead to the completed heparin moleaule. They consist of:

(1) deacetylation;

(2) N-oulfation;

(3) 5-epimerization of the D-glucumonosyl moieties;

(4) 0-sulfation at position 2 of the iduronosyl moieties and o-sulfation at position 6 of the giucosamine residues. 


\section{Heparin-antithrombin III Interactions}

Heparin has been fractionated on the basis of its affinity for antithrombin III. Antithrombin III high affinity material represents only one third of unfractionated heparin $(52,53)$. Preparation of heparin fragments by chemical or enzymatic degradation have led to the isolation of a polysaccharide sequence required for the heparin-antithrombin III interaction. The antithrombin III binding donatn has been identified as a hexa-, penta-, or tetrastacharide sequence $(54,55,56)$. The pentasaccharide structure is shown in figure 6 .

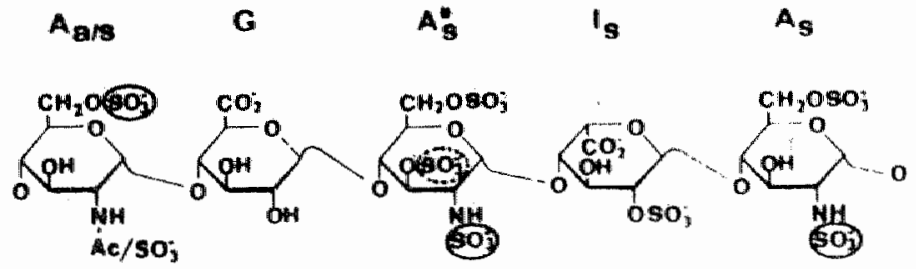

Figure 6: The pentosachamide sequence responaible for the binding to antithrombin IIT. $A_{a / s}:$ N-acetyl-6-o-sulfate-a-D-glucosumine $\left(A_{a}\right)$ or $N$-suljate-6-0-sulfate-a-D-glucosamine $\left(A_{B}\right) ; G: \beta-D-g l u c u r o n i a ~ a c i d ;$ $A_{g}^{*}: N$-sulfate-3, 6-di-0-sulfate-a-b-glucosamine; $I_{8}: 2-0-3 u l f a t e-$ a-L-iduronic acid; A: N-Bulfate-6-0-sulfate-a-D-glucosomine. Full chroles indicate essential sulfate groups, the dotted circle indicates a sulfate group whose role has not been proved essential (taken from reference 55 ).

Rosenberg and Damus (36) demonstrated that the action of heparin in the antithrombin III thrombin-reaction could be removed by nodiflication of the lysyl residues of the inhibttor. However, these alterations did not affect thrombin inhibition by antithrombin III in the absence of heparin. In addition, Longas et al. (57) demonstrated that disruption of a single disulfide bridge in antlthrombin III leads to a reduced affinity for heparin and a corresponding loss of inhibitory activity in the prew sence, but not in the absence of heparin. This indlcates that liepurin and thrombin bind at different sites of the antitirombin Ill molecule. 
Structural studles have provided evidence for two functional domains of the antithrombin III molecule. Upon exposure to guanidinium chlorlde, a blphasic denaturation behaviour was observed, suggesting a two-step folding echanism of different parts of the molecule $(58,59)$. However, correlation with the binding properties of antithrombin III differed in the two studies: whereas the irreversible loss of activity upon folding was accompanted by a parallel loss of heparin-binding properties and not of protease-binding in one study (58), opposite results were found In the other report concerning the simultaneous loss of binding properties, that were found to be strongly dependent on an aggregation of the thrombin-antithrombin III complexes (59). A hereditary abnormal antithrombin III characterized by a loss of heparin-enhanced activity, was blochemically 1dentifled as a single substitution of an arginine in the amino-teminal end (position 47) by a cystelne residue (60). The role of arginine residues in the heparin binding properties of antithrombin III has diso been demonstrated in studies using chenical modiflcations of the argintne groups of the inhibitor $(61,62)$. A loss of heparin binding was found independently from the loss of protease binding. Seven arglnine residues are thought to be required for heparin bluding, and a model was proposed where one or several arginine groups would accomodate the sulfate groups in the pentasaccharide stucture of heparin, through positive charge clusters at the binding site of antichrombin III (62).

The involvement of tryptophan residues in the binding of heparin by antithrombin LII has been shown by structural studles as well as with chemically modifled antithrombin III. Using UV double difference spectral analysis, Elmarsson (63) found that unfractionated heparin bound to antithrombin III with a molar stolchiometry of $2: 1$, and an average dissociation constant of $4.3 \times 10^{-6} \mathrm{M}$, suggesting a strong and specific interaction. Fluorescence studies allowed determination of the respectlve dissociation constants for heparin fractions with high and low affintty for antithrombtn III. High affinity hepardn binds to antithrombin III with a $K_{d}$ of $4.5 \times 10^{-7} \mathrm{M}(64)$, or $8 \times 10^{-7} \mathrm{M}(65)$ whereas low affinity heparin binds to the same site of antithrombin III with a $\mathbb{K}_{\mathrm{d}}$ of $8 \times 10^{-4} \mathrm{M}(66)$. A general conformation change of the 
antithrombin III molecule on its binding to heparin was suggested from these fluorescence studies. After binding to antithrombin III of the fluorophor probe 1-anilino-8-naphtalene sulfonate (ANS), a quenching of the antithrombin II emission fluorescence was obsecved, suggesting a thydrophobic interaction region in near location of the tryptophanyl residues (66). Thus upon heparin binding, changes in the local microenvironment of buried tryptophan residues accurred (64). This was confirmed by circular dichrolsm spectral analysis in the presence of heparin (67). Chemical modification of the tryptophan residues of antithrombin IIf resulted in an impaired heparin enhancement of the rate of thrombin inactivation by antithrombin III (68). A recent study of the amino acid sequence of such modified antithrombin III led to the identification of a tryptophan residue in position 49 that is critical for heparin binding. The amino terminal sequence may constitute part of the heparin-binding domaln that is widely separated from the proteasebinding domain locatex on the carboxyl terminal end (69).

\section{Heparin-protease interaction}

The interaction between heparin and some activated blood coagulation faccors has been established by direct binding techniques. However, most of the binding data were obtained from kinetic studies, as will be discussed later. It appears that the factors $X_{a}, X_{a}$ and kallikrein have little, if any, affinity for hepartn, whereas thrombin, factor $L_{\text {a }}$ and $X I_{a}$ bind strongly to heparin. The heparin-thrombin interaction $\mathbb{l}$ s the best defined one Besides the antithrombin IIL-binding site of heparin there appear to be additional structural properties of heparin that are related to 1 ts anticoagulant activity. Fractions with increasing molecular weight have been shown to exhibit increasing antithrombin activity $(70-72)$. A minimum octadecasaccharide sequence $1 \mathrm{~s}$ required for the action of heparin in the antithrombin III-thrombin reaction (73). Furthermore, heparin binding to thrombin in the heparincatalyzed antithrombin lilf-thrombin reaction occurs via electosotatic interactions that Increase with the degree of sulfation, $1 . e$. the anionic charge density of heparin (74). Hurst at id. (75) found a 
correlation between charge density and the anti-thrombin activity of efther unfractonated heparin or antithrombin III high affinity fractons geparalied by a phate partition techique so that they systematcally varted in antontc charge density. Thus the antithrombin III-binding domain of heparin appeared functionally independent of the protease-binding domain. However, ho sequence has been identified for the latter and it seems that heparin binding to thrombin occurs along the whole dimension of the heparin chain.

Kinetics of the heparin-catalyzed antithrombin III/protease reactions

It has been sthown that the kinetics of the heparin-catalyzed factor $x_{a}$ inhibition by antithrombin III differ significantly from those of chrombin and factor $\mathbb{I X}_{a}$ inhlbition. It 1 s at present generally assumed that the apparent differences in the kinetics of the varlous antithrombin III/protease reactions are caused by the different affinities of the proteases for their binding to heparin.

Because heparin brings together the reactants and is released from the antithrombin III-protease complex once the reaction has occurred, heparin can be compared to an enzyme that catalyzes a two-substrate reaction. Elther heparin blnds simulaneously to both antithrombin III and the protease (random order bireactant model) or heparin binding reaults in conformational change of antithrombin III that increases 1 ts affintty for the protease (ordered bireactant model).

The inftal reaction velocities in each of the antithrombin IIIprotease reaction can be described by the general rate equation for a randon order bireactant system (ref. 76 and references herein). In this model (the so-called template model) the reaction was first order with respect to the concentition of the ternary complex, with an apparent flrst order rate constant value of $13 \mathrm{~s}^{-1}$, over a thousand-fold range of heparin concentrations (77). The heparin-catalyzed antithrombin IIIthrombin reaction was shown to be saturable with respect to both antithrombin III $\left(\mathrm{K}_{\mathrm{d}}=10^{-7} \mathrm{M}\right)$ and thrombin $\left(\mathrm{K}_{\mathrm{d}}=3.6 \times 10^{-8} \mathrm{M}\right)(78)$. Hoylaerts et al. (79) were able to simplify the kinetic analysis by preparing covalent complex of heparin-antithrombin IIT. 


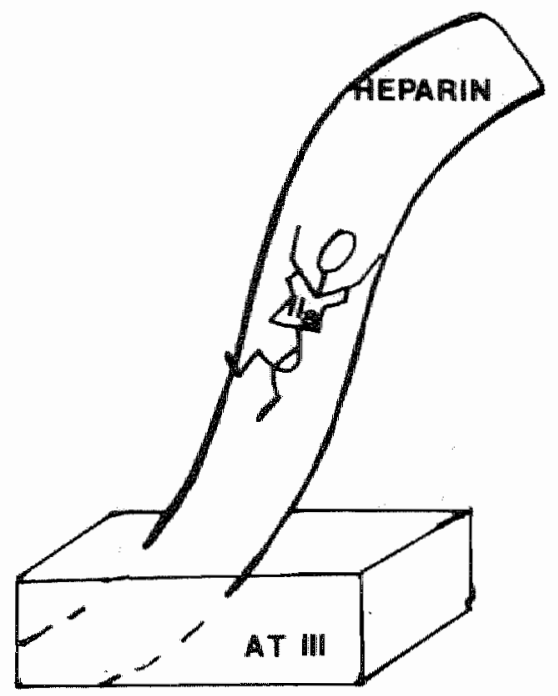

Figure 7: A "gilitug" moded for heparin-ant thrombin TIT-thrombin interation acomding to Hoyldewte et at. (79). Antithrombin TrT binds to the pentasacoharide sequence of the hepatin thatn. Thrombin heparin interactione oceur along the heparin chatn tength, allowing thrombin to diffuse towards the antithmombin III molecule.

The rate of thrombin inhtbition was saturable with respect to the concentration of the covalent complex. Comparison of a high affinity heparin with $M_{r}=15,000$, and fragments of $M_{r}=4,300$ and $M_{r}=3,200$ revealed that the apparent dissociation constants for the interaction between thrombin and the covalent heparin-antithrombin IIT complexes were 7 nM, $100 \mathrm{nM}$ and $6 \mathrm{\mu M}$ respectively. However, the apparent first order rate constant value, $2 \mathrm{~s}^{-1}$, was independent of the heparin size. These findings are conslstent with the random order model for the meckanism of heparin action. Ln addftion, they showed that the binding of thrombin to heparin was of an electrostatic nature and was strangly dependent on the heparin chain length. Thus, the bound throibin is able to diffuse along the heparin chain to interact with the bound antichrombin III as schematically represented in Figure 7.

Evidence has been presented that the heparin-calalyzed atituronbin III-protease reaction can also be described by the general rate equation for an ordered bireactant reaction mechanism. Bleteher and Nelsestuen (80) described a model in which the direct binding of 
heparin to thrombin results in a decrease in the affinity of thrombin for the heparia-antithrombin III complex and thus in a decrease in the indial reaction velocity at high heparin concentrations. At low heparin concentrations, the rate-determining step was independent of thrombin but dependent on the antithrombin III concentration, while at high heparin concentrations, the reaction was dependent on both ancithrombin III and thrombin. It was shown that fractionation of heparin by affintey for antithombin III increases the maximum specific velocity of the reaction, not because the fractions had different $k_{m}$ values for antithrombin III but due to the removal of polysaccharides with low affinity to antithrombin III (81). This moded is essentially identical to the one proposed by Jordan et al. (82) where the interactions are nalyzed as sequential events with firsty, direct binding of heparin to antithrombin III (allosteric effect) and secondly, interactions between the free enzyme and the heparin bound to antithrombin III (approximation effect). The second order rate constant for thrombin inactivation by the antithrombin III-heparin complex was $1.7 \times 10^{9} \mathrm{M}^{-1} \cdot \mathrm{min}^{-1}$, in contrast with a value in the absence of heparin of $4.25 \times 10^{5} \mathrm{M}^{-1} \cdot \mathrm{min}^{-1}$. Comparisons of the vartous kinetic constants Indicated that the direct binding of heparin to antithrombin III is responsible for a 1000-fold acceleration of thrombin-antithrombin III complex formation whereas interaction between thrombin and heparinantithrombln III provides an additlonal. 4 to 15-fold increase in the rate of inactivation: (83).

However, the heparin-antithrombin III-protease interaction does not seen to be restricted to etther an ordered reaction sequence or a random reaction pathway, as underlined by Griffith (77) and Hoylaerts et al. (79). Upon saturation of thrombin with heparin, the formation of the ternary complex shtfts from a random to a sequential pathway in which hepatin-thrombin ts intubted by antithrombin III. Intecesting Ly, when both thromblin and antithromblo $1 \mathrm{Ll}$ are saturated wht heparin, the reaction rate minimizes to a rate which is only sllightly slower than the rate of inhHbition of factor $x_{a}$ by antithrombln III-heparin. In addition, the rate of inhibition of factor $x_{a}$ by antithrombin IIIheparin is insensitive to the heparin chain length inasmuch as the antithrombin III-binding domain fs present (46). 
Kinetics of the heparin catalyzed antithrombin 114 protease reactions in prothrombin activation by the prothrombinase complex.

In discussing the heparin-catalyzed antithrombin III-protease reaction, an important difference was found when factor $x_{a}$ was studied th the presence of the accessory components (factor $V_{a}$ and phospholiplds) of the prothrombinase complex. It has already been known for several years that factor $x_{a}$ bound to phospholipids is much less susceptible to the inactivation by antithrombin III-heparin than free factor $x_{a}(84,85)$. Ellis et al. (86) reported that this effect was observed in the presence of the procoagulant surface of activated platelets or in the presence of phospholipid vesicles either in the absence or in the presence of factor $\mathrm{V}_{a}$. However, Barrowcliffe et al. (87) reported that the protective effect of phospholipid and factor $V_{a}$ could be eliminated at high concentrations of unfractionated heparin, whereas a fragment with $M_{r}=3,000$ was unable to overcome this protective effect. These authors suggested that in the presence of the components of the prothrombinase complex, an interaction between heparin and factor $x_{a}$ occurred that required an additional sequence of the heparin molecule distinct from the saccharide sequence inwolved in the binding to antithrombin ILI.

In addition, an activation peptide from prothrombin (prothrombin fragment 2) was found to inhibit the antithrombin III inactivation of thrombin by altering the reversible binding of thrombin to antithrombin III. However, fragment 2 had no inhfbitcory effect on the formation of the stable antithrombin III-thrombin complex. This observation was interpreted as a potential protection mechanism against inactivation by antithrombin III of the formed thrombin (88).

The ant Ithrombin III-independent effect of heparin.

Evidence for an antithrombin III-independent effect of hepartn in reactions of blood coagulation and hemostasis is two-fold:

- Some heparin fractions with low affinity for antethrombin III and thus virtually devold of any in vitro anti-thrombin or anti-factor $x_{a}$ 
activty glgaflcantly lacreased hemorrhage without influencing the in wivo ant thrombotic effect in animal experimental models (89). Furthernoce this antithrombin III Low affinity heparin fraction potentlated the antithrombotic action of a high affinity heparin ollgosaccharide of mollecular weight lower than 3,500 , which had an in vitro ant-factor $x_{a}$ activity but no anti-thrombin activity $(90)$.

- In a system consisting of purified coagulation factors and synthetic phospholiplds, heparin can inhibit prothrombin and factor $X$ activation. This effect was attributed to the displacement of the bound proteins from the phospholipid surface $(91-93)$. However, these experimental results can alternatively be explained by an effect of heparin on the thrombin-catalyzed factor VIII activation. The effect of heparin in these experiments was practically eliminated if activated factor VIII was present. Furthermore, in an antithrombin III depleted plasma the inhibitory effect of heparin on factor $x_{a}$ or thrombin generation is almost negligible (94). Comparison of crude heparin and low affinity heparin in prothrombin activation in antithrombin III depleted plasma showed that the inhibitory effect of both heparins was similar (95). However, these experiments do not exclude an effect due to other protease inhibitors.

\section{Heparin-placelet inceractions}

The effect of heparin on platelet functions is rather unclear. Two main actions can be contrasted. Clinically, the most mportant one is the hepartinassoctated thrombocytopenta, that occurs either in lsolation or with arterial thrombosis, but rarely leads to bleeding complications (for a review see reference 96). It represents the most serious adverse effect of heparin therapy for two reasons. It is encounted in $5 \%$ of patients recelving heparin therapy. Arterial thrombosis has a much lower frequency than isolated thrombocytopenia, but is a very severe complication with about $30 \%$ mortality being reported in patients $(97,98)$. The onset of heparin-induced thrombocytopenia (plus arterial chrombosis) takes place between the $8^{\text {th }}$ and $15^{\text {th }}$ day of heparin 
therapy, which is consistent with an anamestic response. A heparindependent platelet aggregating factor has been isolated from the serum of the patients, and shown to be an antiplatelet antibody that caused increased platelet destruction (99). However, several arguments suggest that heparin-induced thrombocytopenia is not a typical drug-induced thrombocytopenia. Recovery of platelet count can occur despite the heparin type and dosage beling maintained in the same patient. Patients with a history of heparin-induced thrombocytopenia can be rechallenged with heparin without recurrence of the thrombocytopenia (100) and heparin-dependent binding of the IgG from the patients" serum to normal platelets is not always convincingly demonstrated (101). The substitution of low molecular welght heparin preparations to treat the patients has been reported to be successful in some cases (102) and not in others (103). It is not yet known whether there are heparin preparations which have a negligible risk of thrombocytopenia.

The second type of heparin-platelet interaction is distinguished clinically by its immediate time of onset and does not seen to be an immunological process. It is not clear whether the different reactions are of clinical relevance. They include in vitro heparin-induced aggregation that can occur to a varying degree in almost every individual, and an impairment of the release reactions (104). The original observation of Salzman et al. (105) that high molecular weight heparin fractions irrespective of their affinity for antithrombin III, were more reactive on platelets than low molecular weight, antithrombin III high affinity fractions, suggested a correlation between the hemorrhagic effect of heparin and the anticoagulant propertieg in vitro. This was confirmed by in vivo animal studies, showing that the bleeding risk of heparin could be dissoclated from its antithrombotic activity (106). 


\section{THE PRESENT STUDY}

Although the anticoagulant action of heparin has been the subject of extensive investigations, two matn problems energe in the analysis of these studies. Flrsty, the anti-thrombin activity has been almost exclubively studied in a simple in vitro bireactant system, where heparia catalyzes the interaction between thrombin and antithrombin III, whereas the sttuation In clotting plasma is much more complicated. Secondly, heparin is simply too heterogeneous to expect that the experimental results obtained in different laboratories, using different heparin preparations and fractions, would necessarily lead to a unique interpretation of data and identical conclusions regarding the rechandsin of action. Our purpose was to focus on the interaction of heparin with reactions that can be considered as relevant for in vivo hemostasis and thrombosis, such as the thrombin-dependent feedback reactions. The interactions were analyzed by using purified proteins and washed platelets under wel1-defined conditions.

In chapter II we describe a kinetic study on platelet factor $V_{a}$ formation from washed human platelets upon their activation by thrombin. The use of a prostacyctin analogte provides a way of analyzing the effect of thrombin on the release of factor $V$ separately from its effect on the formation of activated factor $V$. This study raised the question of the relative importance of platelet factor $W_{a}$ and plasma factor $V_{a}$ formation in hernostasis. The study of patients with a moderate bleeding disorder ascribed to a Gray platelet syndrome, was undertaken in order to appraach this question by determining whether the expected factor $V$ storage defect would resilt in an impairment of platelet factor $V_{a}$ formation (chapter III).

Platelet and plasma factor $v_{\text {a }}$ formation are reactions involved in the feedback mechanism of thrombin formution, as are the generation of a negatively-charged surface from activated platelets and the activation of plasma factor VIII:C. The effect of heparin and heparin fractions in the absence of antithrombin III on these thrombin-dependent reactions is described in chapter IV. The interaction of heparin and thrombin can be quantitatively assessed as it results in an inhibition of the 
catalytic action of thrombin towards its macromolecular substrates. The Low molecular weight heparin fractions proved to be less effective in inhlbiting the thrombin-dependent reactions than unfractionated heparin. Because heparin binding to chrombin is thought to be of an electrostatle nature, we have lnvestigated whether and to what extent the antithrombin ITI-independent action of heparin on the inhibition of chrombin is a function of its charge density (chapter V). Studying the antithrombin III-dependent inactivation of proteases, we were interested to assess this effect on thrombin formation when it occurs in the presence of prothombinase complexes of different compositions. Our aim was to simultaneously determine the rate of inactivation by antithrombin III and heparin of factor $x_{a}$ bound to phospholipid and/or factor $v_{a}$ and the rate of inactivation of thrombin formed under these different conditions. We compared these kinetics with those obtained for free enzyme inhibition by antithrombin TIL and neparin (Chapter VI).

\section{REFERENCES}

1. Hemker, H.C., Lindhout, Th.: A clotting scheme for 1984. Nouv. Rev. Fr. Hemato1. 26, 222-231 (1984)

2. Jesty, J., Silverberg, S.A.: Kinetics of the tissue factor-dependent activation of blood coagulation factors $\mathrm{IX}$ and $\mathrm{X}$ in a bovine plasmat Bystem. J. Blol. Chew. 254, 12337-12345 (1979)

3. Cochrane, C.G., Griffin, J.H.: The blochentstry and pathophysiology of the contact system of plasme. Adv. Immunol. 33, 241-306 (1982)

4. Wan Dieijen, G*, Tans, G., Rosing, J., Hemker, H.C.: The role of: phospholipid and factor VIIIa in the activation of bovine factor $X$. J. Biol . Chem. 256, 3433-3442 (1981)

5. Van Dieijen, G., van Rijn, J.L.M.L., Govers-Riemslag, J.W.P., Henker, H.C., Rosing, J.: Assembly of the intrinsic factor $X$ activating complex. Interactions between factor IXa, factor VIILa and phospholfpid. Thromb. Haen. 53, 396-400 (1985)

6. Fulcher, C.A., Roberts, J.R., Zimmerman, T.S.: Thromblu proteolysis of purified factor VIIT procoagulant protein: correlation of activation with generation of a specitic polypeptide. Blood 61 , $807-811$ (1983)

7. Fulcher, C.A., Zimmerman, T.S.: Structure and function of factor VIII procoagulant protein. Ir. Progress in Clinieal and Biological Research Vol 150 Factor VIIL Intibitors. Hoyer L. W. ed. Alan, R., Lissi Inc. Ny pp. $57-71(1984)$ 
8. Suzuki, K. Dahlbăck, B., Scenflo, J.: Thrombin catalyzed activation of human coagulation factor V. J. Biol. Chem. 257, 6556-6564 (1982).

9. Lindhout, T." Govers-R.iemslag, J.W.P., van de Waart, P., Hemker, H.C., Rosing, J.: Factor Va-factor Xa inceraction. Effects of phospholipid vesicles of varying composition. Biochemistry $2 \mathbb{1}$, $5494-5502(1982)$

10. Lollar, P., Knutson, G.J., Fass, D.N.: Stabilization of thrombin activated porcine factor VIII:C by factor IXa and phospholipid. Blood $63,1303-1308(1984)$

11. Hultin, M.B., Jesty, J.: The activation and inactivation of human. factor VIII by thrombin. Effect of inhibitors of thrombin. Blood 54 , $476-482(1981)$

12. Nesheit, M.E., Foster, W.B., Hewick, R., Mann, K.G.: Characterization of factor $V$ activation intermediates. J. Biol.Chem. 259, 3187-3196 (1984)

13. RosLing, J., Tans, G., Govers-Ritemslag, J.W.P., Zwatl, R.F.A., Henker, H.C.: The role of phospholipids and factor Va in the prothrombinase complex. J. Blol. Chem. 255, 274-283 (1980)

14. van de Waart, P., Bruls, H., Hemker, H.C., Lindhout, T.: Interaction of bovine blood clotting factor Va and its subunits with phospholipid ves1cles. BLochenistry, 22, 2427-2432 (1983)

15. van de Waart, P., Hemker, H.C., Lindhout, T.: The interaction of prothrombin with factor Va-phosphollpid complexes. Biochemistry, 23, $2838-2842(1984)$

16. Breederveld, K., Giddings, J.C., ten Cate, J.W., Bloom, A.L.: The localization of factor $V$ within normal human platelets and the demonstration of a platelet factor $V$ antigen in congenital factor $V$ deficlency. Br. J. Haemato1. 29, 405-412 (1975)

17. Ittyerah, T.R., Rawala, R., Colman, R. W.: Immunochemical studies of factor $V$ of bovine platelets. Eur. J. Biochem. 120, 235-241 (1981)

18. Osterud, B.S., Rapaport, S.I., Lavine, K.K.: Factor V activity of platelets. Evidence for an activated factor $V$ molecule and for a platelet activator. Blood 49, 819-834 (1977)

19. Kane, W.H., Mruk, J.S., Majerus P.W.: Activation of coagulation factor $V$ by a platelet protease. J. Clin. Invest. 70, 1092-1100 (1982)

20. Vicle, W.J., Lages, B., Weiss, H.J.: Release of human platelet factor $V$ activicy is induced by both collagen and ADP and is inhibited by aspirin. Blood $56,448-455$ (1980)

21. Chesney, C.M., Pifer, D., Colman, R.W.: Subcellular localization and acretion of factor $V$ from human platelets. Proc. Nat1. Acad. Scl 78 , $5180-5184(1981)$

22. Chesney, C.M., Pifer, D.D., Colman, R.W.: The role of platelet factor $\mathrm{V}$ in prothrombin conversion. Thromb. Res. 29, 75-84 (1983)

23. Kane, W.H., Lindhout, T., Jackson, C.M., Majerus, P.W.: Factor Va. dependent binding of factor Xa to human platelets. J. Biol. Chem. $255,1170-1174(1980)$

24. Tracy, P.B., Ellde, L.L., Bowle, E.J.W., Mann, K.G.: Radioimmunoassay of factor $V$ in human plasma and platelets. Blood 60, 59-63 (1982)

25. Miletich, J.P., Majerus, D.W., Majerus, P.W.: Patlents with congenital factor $V$ deficiency have decreased factor Xa binding sites on thelr platelets. J. Clin. Invest. 62, 824-831 (1978) 
26. Tracy, P.B., Giles, A.R., Mann, K.G., Eide, L.L., Hoogendootri, H., Rivard, G.E.: Factor V (Quebec): a bleeding diathesis associated with a qualitative platelet factor $V$ deficiency. J. Clin. Invest. 74, $1221-1228(1984)$

27. Bevers, E.M., Comfurius, P., van Rijn, J.L.M.L. , Hemker, H.C., Zwaal, R. F.A.: Generation of prothrombin converting activity and the exposure of phosphatidylserine at the outer surface of platelats. Eur. J. Biochem. 122, 429-436 (1982)

28. Rosing, J., van Rijn, J.L.M.L., Bevers, E.M., van Dieljen, G., Comfurius, P., Zwall, R.F.A.: The role of activated platelets 1n prothrombin and factor X activation. Blood $65,319-322$ (1985)

29. Rosing, J., Bevers, E.M. Comfurius, P., Hemker, H.C., van Dieljen, G., Weiss, H.J., Zwal, R.F.A.: Impaired factor X and prothrombin activation associated with decreased phospholipld exposure in platelets from a patient with a bleeding disorder. Blood 65 , $1557-1561$ (1985)

30. Miletich, J.P., Kane, W.H., Hofman, S.L., Stanford, N., Majerus, P.W.: Deficiency of factor Xa-factor Va binding site on the platelets of a patient with a bleeding disorder. Blood 54, 1015-1022 (1979)

31. Conrad, J., Brosstad, F., Larsen, M.L., Samama, M., Abilgadrd, U. * Molar antithrombiln concentration in normal human plasma. Haemostasis $13,363-368(1983)$

32. Kurachi, K., Schmer, G., Hermodson, M.A., Teller, D.G., Davie, E.W.: Characterization of human, bowine and horse antiturombin III. Biochemistry 15, 368-373 (1976)

33. Petersen, E.E., Dudek-Wojclechowska, G., Sottrup-Jensen, L., Magnusson, S.: The primary structure of antithrombin III (heparincofactor). Partial homology between alpha 1 -antitrypsin and antithrombin III. Collen, D., Wiman, B., Verstrate, M., eds. The physiological inhibitors of coagulation and fibrinolysis. Amsterdam: Elsevier North-Holland 43-54 (1979)

34. Lijnen, H.R., Hoylaerts, M., Collen, D.: Neutrallzation of heparin activity by binding to human histidine-rich glycoprotein. Thromb. Res. 29, 443-446 (1983)

35. Mac Reynolds, L., OMalley, B.W., NLbet, A.D., Fothergl11, J.E., Givol, D., Field, S., Robertson, M., Browlee, G.G.: Sequence of chicken ovalbumin mRNA. Nature (London) $273,723-728$ (1978)

36. Rosenberg, R.D., Damus, P.S.: The purification and mechanism of action of human antithrombin-heparin cofactor. J. Biol. Chem. 24.8, 6490-6505 (1973)

37. Björk, I., Danielsson, A., Fenton, J.W.II, Jornvall, H.: The ste in human antichrombin for functional proteolytic cleavage by human thrombin. FEBS Letter 126, 257-260 (1981)

38. Björk, I., Jackson, C.M., Jornvall, H., Lavine, K.K., Nordling, K., Salsgiver, W.J.: The active site of antithrombin. Release of the same proteolytically cleaved form of the Inhubitor from complexes with factor IXa, Xa and thrombin. J. Blol. Chem. 257, 2406-2411 (1982)

39. Hemker, H.C." Handbook of synthetic susbtrates for the coagulation and fibrinolytic system. Mertinus Nijhoff eds, p. 12-15 (1983)

40. Jesty, J.: Dissoclation of complexes and their derivatives formed during inhibition of bovine thrombin and activated factor $X$ by antithrombin III. I. Biol. Cherl. 254, 1044-1049 (1979). 
41. Olson, S.T.: Heparin and ionic strength-dependent conversion of antuthrobin LIL from an inhibltor to a substrate of a-thrombin. I. B1ol. Chem. 260, 10153-10160 (1985)

42. Olson, S.I., Shore, J.D. Demonstration of a two step reaction mechantsm for inhibition of $a$-thrombin by antithrombin III and identification of the step affected by heparin. J. Biol. Chem. 257. $14891-14895(1982)$

43. Tollefsen, D.M., Majerus, D.W., Blank, M.K.: Heparin cofactor II purlfteation and propertles of a heparin dependent inhibitor of thrombin in human plasma. J. B1ol. Chen. 257, 2162-2169 (1982)

44. Hurst, R.E., Settine, J.M., Poon, M.C., Lurle, A.: Heterogeneity in the composition of comercial heparins: comparison of anticoagulant activities and biochemical compositions of anionic density fractionated heparins. Throub. Res. 25, 255-265 (1982)

45. Tollefsen, D.M*, Pestka, C.A., Monafo, W.J.: Activation of heparin cofactor II by dermatan sulfate. J. Biol. Chem. 258, 6713-6716 (1983)

46. Griffith, M.J.: Heparin-catalyzed inhibitor/protease reactions: Kunetic evidence for a common mechanism of action of heparin. Proc. Wat l. Arad. Sci. USA. 80, 5460-5465 (1983)

47. Parker, K.A., Tollefsen, D.M.: The protease specificity of heparin cofactor II. Inhybition of thrombin generated during coagulation. J. Blo1. Chem. 260, 3501-3505 (1982)

48. Lindahl, U., Höök, M., Backström, G., Jacobsson, I., Riesenfeld, J., Malmstrom, A., Roden, L., Feingold, D.S.: Structure and blosynthesis of heparin-like polysaccharides. Fed. Proc. 36, 19-24 (1977)

49. Robinson, H.C., Horner, A.A., Höök, M., Ogren, S., Lindah1, U.: A proteoglycan form of heparin and its degradation to single chain molecules. J. Biol. Chem. 253, 6687-6693 (1978)

50. Jacobsson, I., Lindahl, U.: Biosynthesis of heparin. Concerted action of late polymer-modification reactions. I. Biol. Chem. 255, $5094-5100,(1980)$

51. Cifonelli, J.A., King, J.: Structural studies on heparin with unusually high $\mathrm{N}$-acety Iglueosamine contents. Blochim. Blophys. Acta $320,331-341(1973)$

52. Lam, L.H., SLlbert, J.E., Rosenberg, R.D.: The separation of active and Inactive forms of heparjn. Bioch. Biophys. Res. Commun. 69, $570-577(1976)$

53. Hopwood, J., Höök, M., Linker, A., Lindahl, U.: Anticoagulant activity of heparin: isolation of antithrombin binding sites. FEBS Leter $69,51-54(1979)$

54. Lindahl, U., Backstrom, G., Thunberg, L.: The antithrombin-binding sequence in heparin. J. Biol. Chem. 258, 9826-9830 (1983)

55. Choay, J., Petitou, M. Lormeau, J.C., Sinay, P., Casu, P., Gatti, G.: structure activity relationships in heparin: a synthetic pentasaccharide with high affinity for antithrombin III and ellciting high anti factor Xa activity. Biochem. Biophys. Res. Comm. 116 , 492-499(1983)

56. Lindthardt, R.J., Grant, A., Cooney, C.L., Langer, R.: Differential Anticoagulant activity of heparin fragment prepared using microbial heparinase. I. Biol. Chem. 257, 7310-7313 (1982)

57. Longas, M.O., Ferguson, W.S., Finlay, T.H.: A disulfide bond in antithrombin is required for heparin accelerated thrombin inactivation. J. Btol. Chem. 255, 3436-3441 (1980) 
58. Villanueva, G.B., Allen, N.: Refolding properties of antithrombin III. Mechanism of binding to heparin. J. Biol. Chem. 258, 14048-14053 (1983)

59. Fish, W.H., Danielsson, A., Nordling, K., Miller, S.H., Lam, C.F., Björk, I.: Denaturation behaviour of antithrombin in guandinium chloride. Irreversibility of unfolding caused by aggregation. Biochemistry 24, 1510-1517 (1985)

60. Koide, T., Odiani, S., Takahashi, K., Ono, T., Sakuragawa, N.: Ancithrombin IIl Toyama: Replacement of arginine-47 by cysteine in hereditary abnormal antithrombin III that lacks heparin-binding ability. Proc. Natl. Acad. Sci. USA 81, 289-293 (1984)

61. Pecon, J.M., Blackburn, M.N.: Pyridoxylation of essential 1ysines in the heparin-binding site of antithrombin IIL. J. Biol. Chem. 259, $935-938$ (1984)

62. Jorgensen, A.M., Borders, C.L., Fish, W.W.: Arginine residues are critical for the heparin cofactor activity of antithrombin III. Blochem. J. 231, 59-63 (1985)

63. Einarsson, R.: The binding of l-anlilno-8-napthalene sulfonate, heparin, salicylate and caprylate by human antithrombin $\mathbb{I I}$. Blochim. Biophys. Acta 446, 124-133(1976)

64. Elnarsson, R., Andersson, L.O.: Binding of heparin to human antithrombin III as studied by measurements of tryptophan fluorescence. Biochim. Biophys. Acta. 490, 104-111 (1977)

65. Nordenman, B., Danielsson, A., Björk, I.: The biading of low affinity and high affinity heparin to antithrombin. Fluorescence studies. Eur. J. Biochem. 90, 1-6 (1978)

66. Danielsson, A., Bjork, I.: The binding of low affintty and high affinity heparin to antithrombin III. Competition for the same binding site on the proteln. Eur. I. Biochem. 90,7-12 (1978)

67. Villanueva, G.B., Danishefsky, I.: Evidence for a heparin induced conformational change of AT III. Biochem. Biophys. Res. Comm.74, $803-809$ (1977)

68. Blackburn, M.N., Stbley, C.C.: The heparin binding site of antithrombin III. Evidence for a critical residue. J. Biol. Chem. 255, $824-826(1980)$

69. Blackburn, M.N., Smith, R.J.", Carson, J. "Sibley, C.C.: The heparin binding site of antithrombin ILI. Identffication of a critical. tryptophan in the amino acid sequence. J. Biol. Chem. 259, 939-941. (1984)

70. Lane, D.A., MacGregor, I.R., Michalski, R., Kakker, V.J.: Anticoagulant activitles of four unfractlonated and fractionated heparins. Thromb. Res. 12, 257-271 (1978)

71. Holmer, E., Kurachi, K., Soderstrom, G.: The mollecular weight dependence of the rate enhancing effect of heparin on the inhlbition of thrombln, factor Xa, factor IXa, factor XIa, factor XIIa and kalilkrein by antithrombin III. Biochem. J. 193, 395-400 (1981)

72. Rosenberg, R.D., Jordan, R.E., Favreau, L.V., Lam, L.H.: Highdy active heparin species with multiple binding sites for antithrombin. Bioch. Blophys. Res. Commun. 86, 1319-1324 (1979)

73. Lane, D.A., Denton, J., Flynn, A.M., Thunberg, L., Lindahl, U.: Ant1coagulant activities of heparin oligosaccharides and their neutralization by platelet factor 4. Biochem.J. 218,725-732 (1984) 
74. Heuck, C.C., Schiele, U., Horn, D., Eronda, D., Ritz, E.: The role of surface charge in the accelerating action of heparin on the antithrombin III inhiblted activity of a-thrombin. T. Biol. Chem. 260, $4598-4603(1985)$

75. Hurst, R.E. Poon, M.C., Griffith, M.J.: Structure activity relationship of heparin. Independence of heparin charge density and antithrombin bialing domalng in heparin inhibition by antithrombin III and hepartin cofactor II. J. Clin. Invest. 72, 1042-1045 (1983)

76. Nesheim, M.E.: A simple rate lab that describes the kinetics of the heparin catalyzed reaction between antithrombin III and thrombin. I. B101. Chent, 258, 14708-14717 (1983)

77. Griffith, M.J.: Kinetics of the heparin-enhanced antithrombin IIIthrombin reaction. Evidence for a template model for the mechanism of action of hepar1n. J. Biol. Chem. 257, 7360-7365 (1982)

78. Grifftth, M.J.: The heparin enhariced antithrombin III-thrombin reaction is saturable with respect to both thrombin and antithrombin III. J. B101. Chem. 257, 13899-13902 (1982)

79. Hoylaerts, M., Owen, W.G., Collen, D.: Involvement of heparin chain length In the heparin-catalyzed inhibition of thrombin by antithrombin III. J. B1ol. Chem. 259, 5670-5677 (1984)

80. Pletcher, C.H., Nelsestuen, G.L.: Two-substrate reaction model for the heparti-catalyzed bovine ant ithrombin/protease reaction. J. Biol. Chem. 258, 1086-1091 (1981)

Bl. Pletcher, C.H., Cuningham, M., Melsestuen, G.L.: Kinetic analysis of varlous fractions and heparin substitutes in the thrombin inhibition reaction. Blochdm. Biophys. Acta 838, 106-113 (1985)

82. Jordan, R.E., Dosta, G.M., Gardner, W.T., Rosenberg, R.D.: The kinetics of hemostatic enzyme-antithrombin luteractions in the presence of low molecular weight heparin. J. Biol. Chem. 255, $10081-10090$ (1980)

83. Jordan, R.E., Oosta, G.M., Gardner, W.T., Rosenberg, R.D. The binding of low molecular weight heparin to hemostatic enzymes. J. Biol. Chem. $255,10073-10080(1980)$

84. Marclniak, E.: Factor Xa inactivation by antithrombin III. Evidence for blological stabilization of factor Xa by factor V-phospholipid complex. Br. J. Haem. 24, 391-400 (1973)

85. Josso, F., Beguin, S.: Changes in the antithrombin III activity at the interface plasma-phospholipids. Thromb. Haenost. 46: 285 (Abstract) (1981)

86. Ellis, V., Scully, M.F., Kakkar, V.V.: Inhibition of prothrombinase complex by plasma proteluase inhlbitors. Blochemistry 23, 5882-5887 $(1984)$

87. Barrowcliffe, T.W., Havercroft, S.J., Lindahl, v.: Effect of calcium Lons, phospholipid and factor $V$ on the anci-Xa activity of heparin. Thrombos. Haemost. 54, 111 (abstract) (1985)

88. Walker, F.J., Esmon, C.T.: The effect of prothrombin fragment 2 on the tuhtbition of thrombin by antithrombin III. J. Biol. Chem. 254 , $5618-5622(1979)$

89. ockelford, P., Carter, C.J., Cerskus, A., Smith, C.A., Hirsh, J.: Compartion of the in vivo haemorrhagic and antithrombotic effects of a low antithrombin III affinity heparin fraction. Thromb. Res. 27, $679-690(1982)$ 
90. Barrowcliffe, T.W., Merton, R.E., Havercroft, S.J., Thumberg, U., Thomas, D.P.: Low affinity heparin potentiates the action of high affinity heparin oligasaccharides. Thromb. Res. 34, 125-133 (1984)

91. Walker, F.J., Esmon, C.T.: Interactions between heparin and factor Xa. Inhibition of prothrombin activation. Blochim. Biophys. Acca 585, $405-415$ (1979)

92. Brown, J.E., Baugh, R.F., Hougie, C.: The inhibition of the Intrinsic: generation of activated factor $X$ by heparin and hitudin. thromb. Res. 17, 267-272 (1980)

93. Ofosu, F.A., Blajchnan, M.A., Hitsh, J.: The inhibition by heparin of the intrinste pathway activation of factor $x$ in the absence of antithrombin III. Thromb. Res. 20, 391-403 (1980)

94. Ofosu, F.A., Blajchman M.A., ModL, G. Cerskus, A.L., Hirsh, J.: Activation of factor $X$ and prothromin in antithrombin Iil depleted plasma: the effects of heparin. Thromb. Res. 23, 331-345 (1981)

95. Ofosu, F.A., Modi, G., Cerskus, A.L., Hirsh, J., Blajchman, M.A." Heparin with low affinity to antithrombin III inhibits the activation of prothrombin in normal plasma. Thromb. Res. 28, 487-497 (1982)

96. Kelton, J.G.: Heparin-Induced thrombocytopenia. Hemostasls. In press (1986)

97. Powers, P.J., Kelton, J.G., Carter, C.J.: Studies on the frequency of hepartn-assoclated thrombocytopenta. Thromb. Res. 33, 439-443 (1984)

98. King, D.J., Kelton, J.G.: Heparin associated thrombocytopenia. Ann. Intern. Med. 100, 535-540 (1984)

99. Kelton, J.G., Sheridan, D., Braln, H. Powers, P.J., Turple, A.G., Carter, C.J.: Clinical usefulness of testing for a heparin dependent platelet-aggregating factor in patients with suspected heparinassoclated thrombocytopenia. J. Lab. Clin. Med. 103, 606-612 (1984)

100. Eika, C., Godal, H.C., Laake, K., Hamborg, T.: Low incidence of thrombocytopenia during treatment with hog mucosa and beef lung heparin. Scand. J. Haematol. 25, 19-24 (1980)

101. Howe S.E., Lynch, D.M.: An enzyme linked immunosorbent assay for the evaluation of thrombocytopenla induced by heparin. J. Lab. Clin. Med. $105,554-559(1985)$

102. Harenberg, J. Zimmerman, R., Schwarz, F., Kubler, W.: Treatment of heparin-induced thrombocytopenta with thrombosis by new hepartuold. Lancet $1,986-987$ (1983)

103. Horrelou, M.H., Conrad, J., Lecrubler, C., Samama, M., Roque d'Orbcastel, 0. , de Fenoy $1,0 .$, DI Marla, G., Bernadou, A.: Persistent heparia induced thrombocytopenia desplte therapy wth low molecular weight heparin. Thromb. Haemostas. 51, 134 (1984)

104. Harker, L.A. "Molpass, T.W., Branson, H.E., Hessel, E.A., Slichter, S.J.: Mechanism of abnormal bleeding in patients undergoing cardiom pulmonary by-pass: acquired transient dysfunction assoclated with selective allpha-granule release. Blood $56,824-834$ (1980)

105. Salzman, E.W., Rosenberg, R.D., Snith, M.H., LIndon, J.N., Favreau, L.: Effect of heparin and heparin fractions on platelet aggregation. J. Clin. Invest. 65, 64-73 (1980)

106. Carter, C.J. Kelton, J.G., Hirsh, J. Cerskus, A., Santos, A.V., Gent, M.: The relationship between the hemorrhaglic and antithrombotic properties of low molecular weight heparin in rabbits. Blood, 59, $1239-1245(1982)$ 
CHAPTER II

KLNETLCS OF THROMBIN-INDUCED RELEASE AND ACTLVATION OE PLATELET FACTOR $V$

\author{
SUMMARY
}

The kinetics of thrombin-induced platelet factor $\mathrm{V}$ activation were studied in suspension of washed tuman platelets. The effect of thrombin in stimulating the release reaction could be separated from its effect on factor $v$ activation by use of a potent inhibitor of the release reaction, the prostacyclin analogue $Z K$ 36374 . When platelets were incubated with $2 K 36374$ prior to stimulation with thrombin, the amount of ZK 36374 requlred to inhibit $50 \%$ of factor $V_{a}$ formation was $15 \mathrm{pM}$. ZK 36374 at a final concentration of $1 \mathrm{nM}$ was found to block instantaneously and completely the release of factor $V$, whereas it has no effect neither on platelet factor $V$ activation wor on the fiactor $V_{a}$ assay. By varying the time interval between the addition of thrombin $(0.5 \mathrm{nM})$ and $\mathrm{ZK} 36374$ to suspensions of $4.6 \times 10^{6}$ platelets/m1 the rate of factor $V$ release was found to be $12 \mathrm{pM}$ factor $\mathrm{V} / \mathrm{min}$. In the absence of $Z K$ 36374, the total amount of factor $V$ released was $8 \mathrm{pM}$, whereas Triton $X$-100-treated platelets gave $13 \mathrm{pM}$ factor $V$. It appeared that the amount of factor $V$ that could be released was dependent on the thrombin concentration. Maximum release was obtained at 1 nM thrombin. The rate of factor $W$ release increased in proportion to the thrombin concentration. The rate of factor $V$ activation was found to be proportonal to the thrombin concentration as well as to the amount of released factor $V$. When $4.6 \times 10^{6}$ platelets/nil were actirated by $0.5 \mathrm{nM}$ thrombin, the rates of factor $V$ activation were found to be 0.3 and 1.2 pH factor Va/min at $20 \%$ and $90 \%$ completion of the release reaction. Therefore, the rate of factor $V$ release was at least one order of magnitude faster than the rate of factor $V$ activation. The kinetics of thrombin-induced platelet factor $V$ activation were compared to those of plasma factor $V$ activation in platelet-rich and platelet-free plasma. The results clearly demonstrate that platelets have no effect on the rate of factor $V$ activation and that the kinetics of plasma factor $V$ activation are identical to those of platelet factor $V$ activation. 
INTRODUCTION

Thrombiamctivated platelets are essentlal to the normal hemostatic mechanlist. Two types of procoaguiant activity from activated platelets have been recognized. In the first place factor $V$ is released and activated during stimulation by thrombin $(1,2)$ and secondly the altered membrame of platelets activated by thrombin plus collagen provides a procoagulant surface $(3,4)$. These two events enable factor $x_{a}$ to function in a platelet bound complex of factor $V_{a}$ and factor $x_{a}$, the so-called prothromblnase, thus causing a dramatic amplification of the thrombin-generating capacity of factor $X_{a}(5,6)$. Factor $V$ occurs as a plasma protein as well as a protein present in the alpha-granules of platelets.

The question of the physiological importance of platelet factor $V$ over plasma factor $V$ in affecting the effictency of the hemostatic process has been recently adressed by Tracy et a1. (7). These authors described an inherited factor $V$ disorder and the association of a significant bleding diathesis with a qualitative abnormality predominantly in platelet factor $V$. As yet the kinetics of thrombin-induced platelet factor $V$ release and activation were difficult to study, because the release reaction induced by thrombin could not be separated from the factor $V$ activation catalyzed by the same enzyme.

Here we report that a semi-synthetic prostacyclin analogue ( $Z \mathrm{~K} 36374$ ) is able instantaneously to block thrombin-induced platelet factor $V$ release during the time course of the reaction. This enabled us to study separately the kinetics of factor $V$ release and thrombin-catalyzed activation of platelet factor $V$.

\section{MATERLALS AND METHODS}

Materlals. $\$ 2238$ was purchased from AB Kabi Diagnostica. Human serum albumin (fatty acld free) and 1,2 -dioleoyl-sn-glycero-3-phosphocholine (PC) were obtained from sigma. $2 \mathrm{~K}$ 36374, a stable carbacyclin derivative of prostacyclin, was obtained froin Schering AG (Berlin) as a $0.5 \mathrm{mg} / \mathrm{ml}$ solution of Tris-saline. All reagents used were of the highest grade commercially available. 
Proteins. Human thrombin was prepared from prothrombin by the method of Pletcher and Nelsestuen (8). Bovine prothrombin, factor $x_{a}$ and factor $V_{a}$ were obtalned as described by Lindhout et al. (9). The proteins were stored at $-80{ }^{\circ} \mathrm{C}$ in $50 \mathrm{mM}$ Tris $\mathrm{HCl}, 175 \mathrm{mM} \mathrm{NaCl}$, and $0.5 \mathrm{mg} / \mathrm{mil}$ human serum alburin, pH 7.9 .

Protein concentrations. The molar concentration of thrombin was determined by active site titration with p-NPGB according to Chase and shaw (10). Prothrombin concentration was determined by the same method after complete activation with E. carinatus venom. The concentration of factor v was determined by kinetic analysis as described by Lindhout et al. (9). Factor $x_{a}$ concentrations were determined by active site titration according to Smith $(11)$.

Phospholipid and phospholipid vesicle preparation. 1,2-Dioleoyl-sa-glycero-3-phosphoserine (PS) was prepared from 1,2-doleoy1-sn-glycerom-phosphocholine (PC) by enzymatic synthesis as described by Comfurius \& Zwaal (12). single-bilayer phospholipid vesicles. were prepared according to the nethod of De Kruijff et al. (13). Phospholipid concentrations were determined by phosphate analysis as described by Böttcher et al. (14).

Isolation of human platelecs. Blood was drawn by venepuncture from healthy volunteers directly into acid citrate-dextrase $60.18 \mathrm{M}$ glucose-0.08 $\mathrm{M}$ sodium citrate-0.052 M citric acid), in the ratio of 5 volumes of whole blood to 1 volume of anticoagulant. Platelet-rich plasma was obtalned by centrifugation at $220 \mathrm{xg}$ for $15 \mathrm{~min}$. Platelets were isolated by centrifugation at $600 \mathrm{xg}$ for $20 \mathrm{~min}$ and the pellet was resuspended in $10 \mathrm{mM}$ Hepes, $136 \mathrm{mM} \mathrm{NaCl,} 2.7$ mM $\mathrm{KCl}, 2 \mathrm{mM} \mathrm{MgCl}_{2}, 5 \mathrm{mM}$ glucose and $4 \mathrm{mg}$ human serum albumin (HSA)/m, pH 6.7. The platelets were washed twice in this buffer by centrifugatton at $350 \times g$ for 15 min. Before centrifugation one volume of acid citrate-dextrose was added to 14 volumes of the platelet suspension. Flablly, the platelets wre resuspended in Hepes buffer, i mg HSA/ml, pH 7.5. Platelet concentration was determined with a coulter counter. Platelets were kept at room temprature and no loss of platejet functions was found for at least loh.

Measurement of platelet factor Va formation. Washed human platelets were suspended in $10 \mathrm{mM}$ Hepes, $136 \mathrm{mM} \mathrm{NaCl}, 2.7 \mathrm{mM} \mathrm{KCl}, 2 \mathrm{mM} \mathrm{MgCl}$, $5 \mathrm{mM} \mathrm{glucose,}$ $1 \mathrm{mg} H S A / m l, \mathrm{pH} 7.5$. The platelet suspension $\left(292 \mu 1,4.6 \times 10^{6}\right.$ platelets/ ml) was incubated with $3 \mathrm{mM} \mathrm{CaCl} 2$ and stirred ( $350 \mathrm{rev} / \mathrm{min})$ for 4 min at $37{ }^{\circ}$. Subsequently, 5 ul of a thrombin solution was added, resulting in a 
Final volume of $0.35 \mathrm{~m}$. Hefer different time Intervals samples (20 pl) were taken ard transferted to cuvettes containing the factor $V_{\text {a }}$ assay mixture. The assay pilfture $(205 \mu 1)$ contained factor $\mathrm{X}_{\mathrm{a}}(13 \mathrm{pM}), 20 \% \mathrm{FS}-80 \% \mathrm{PC}(10 \mu \mathrm{M})$ and $\mathrm{CaCl}_{2}$ (10 mM). The assay buffer was composed of $50 \mathrm{mM}$ Tris, 175 mM NaCL, $0.5 \mathrm{mg} H S A / m$, pH 7.9. Thrombin formation was intiated by the addition of $25 \mu \mathrm{L}$ of prothrombin $(2 \mu \mathrm{M})$. After $2 \mathrm{~min}, 0.65$ ml buffer containing $50 \mathrm{mM}$ Tris, 75 mil NaCl, $20 \mathrm{mM}$ EDTA, $0.5 \mathrm{mg} \mathrm{HSA} / \mathrm{ml}, \mathrm{pH} 7.9$ and $0.235 \mathrm{mM} \mathrm{S} 2338$ was added to the reaction mixture. The amount of thrombin formed was measured by the change in absorbance recorded on an Aminco DW-2 spectrophotometer operated in the dual wave-length mode $\left(\lambda_{s}=405 \mathrm{~nm}\right.$ and $\left.\lambda_{r}=500 \mathrm{~nm}\right)$. The procedure was performed at $37{ }^{\circ} \mathrm{C}$. Standard curves were constructed by assaying dilutions of a bovine factor $v_{a}$ preparation whose concentration was determined using active site titrated factor $X_{\text {a }}$ (9). The assay had a functional range from $2 \times 10^{-14} \mathrm{M}$ to $5 \times 10^{-12} \mathrm{M}$ of factor $V_{a}$. Non-activated factor $V$ had in this assay $1.2 \%$ of the activity of activated factor $V$. Factor V release studies. At different time intervals, $2 K 36374$ was added as a small aliquot $(10 \mu 1)$ to pliatelet suspensions incubated with thrombin. Factor $V_{a}$ generation was monitored by the factor $V_{a}$ assay until completion. The maximal amount of factor $V_{a}$ formed was taken as the amount of factor $V$ released at the time $2 \mathrm{~K} 36374$ was added to the platelet suspension.

Plasma factor V activation. Platelet-free plasma was obtained by centrifugation of platelet-rich plasma at $2000 \mathrm{xg}$. Platelet-rich or platelet-free plasma wala diluted in $10 \mathrm{mM}$ Hepes, $136 \mathrm{mM} \mathrm{NaCl}, 2.7 \mathrm{mM} \mathrm{KCl}, 2 \mathrm{mM} \mathrm{MgCl}, 5 \mathrm{mM}$ glucose, $5 \mathrm{mM} \mathrm{CaCl} 2 \mathrm{lmg} H \mathrm{HA}_{2} \mathrm{ml}, \mathrm{pH} 7.5$. The plasma dilution was stirred 4 win at $37^{\circ} \mathrm{C}$ followed by addition of thrombin $(0.5 \mathrm{nM})$, resulting in a final. volume of $500 \mu 1$. Subsequently, aliquots $(20 \mu 1)$ were taken for factor $v_{a}$ determination.

\section{RESULTS AND DISCUSSION}

Effect of $2 \mathrm{~K} 36374$ on thrombin-induced platelet factor Wa formation. Wh e $\mathrm{n}$ washed platelets $\left(4.6 \times 10^{6} / \mathrm{ml}\right)$ were preincubated with varying concentrations of $2 K 36374$ prior to stimulation with thrombin $(0.5 \mathrm{nM})$ the maximal amount of factor $W_{\mathrm{g}}$ that could be formed was found to be dependent on the $\mathrm{ZK}$ 36374 concentration (Figure 1 ). At $\mathrm{ZK} 36374$ concentrations of 1 nM platelet 


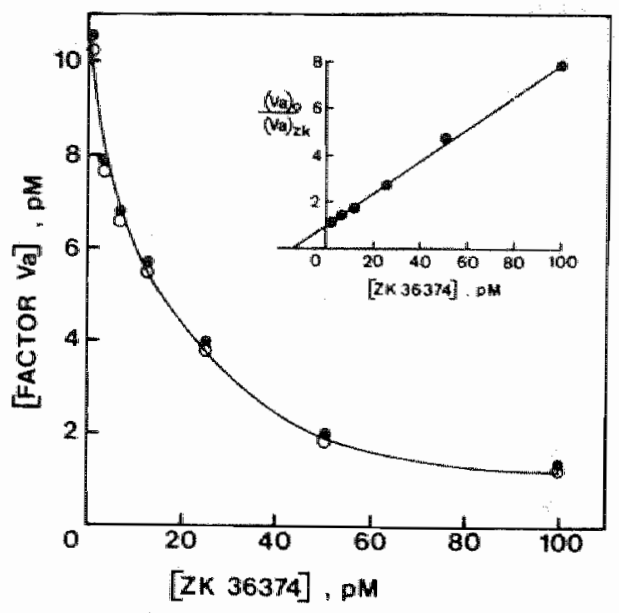

Figure 1: Effect of $2 K 36374$ on thrombin-induced platelet faotor $V$ release. Platelets $\left(4.6 \times 10^{6} / \mathrm{m}\right.$ ) were incubated with $2 K 36374(5-100$ pM) for 1 minute before at timulation with thrombin $10.5 \mathrm{mM})$. Factor $V_{a}$ was measured after 10 min $(0)$ or 20 min ( ) . Inset: ratio of factor $V_{a}$ generated in the absence of $2 K 36374$ over factor $V_{a}$ generated in the presence of $2 K 36374$ as a function of the ZKK 36374 concentration.

factor $V_{a}$ generation was diminished to a baseline of about $2 \%$ of the control walue in the absence of $\mathrm{ZK} 36374$. In unstimulated platelets the bageline factor $\mathrm{V}_{\mathrm{a}}$ activity was less than $1 \%$ of the control value. The $2 \mathrm{~K} 36374$ concentration required to diminish factor $V_{a}$ generation to $50 \%$ of the control value, $15 \mathrm{pM}$, was determined fron the intercept with the abcissa of a plot of ZK 36374 concentration versus the ratio of factor V formed in the absence of $\mathrm{ZK} 36374$ over factor $V_{a}$ formed in the presence of $2 \mathrm{~K} 36374$ (Figure 1, inset). In further release studies used a $2 \mathrm{~K} 36374$ concentration of $1 \mathrm{nM}$.

Release of platelet factor V. Platelets $\left(4.6 \times 10^{6} / \mathrm{ml}\right)$ were stimulated with thrombin (0.5 nM). $2 K 36374$ wiss added in separate experintents pror to and at different time intervals after the addition of thrombin. The corres-

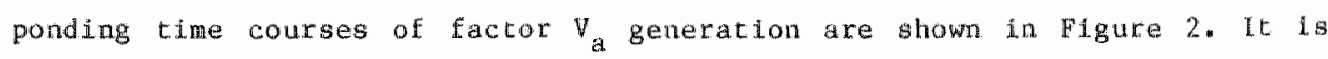
demonstrated that the final level of factor $V_{a}$ activity increased with the time interwal between thromin and $\mathrm{ZK} 36374$ addition to the platelet suspension. Because $2 K 36374$ at this concentration ( 1 nM) was able to block the release reaction when preincubated with the platelet suspension, this result suggests that when $Z K 36374$ is added during the time course of thromblninduced platelet factor $V$ release, factor $V$ release was instantaneously and completely inhibited. The increase in factor W formation after the addition of ZK. 36374 therefore must be the result of activation of factor $V$ that was 

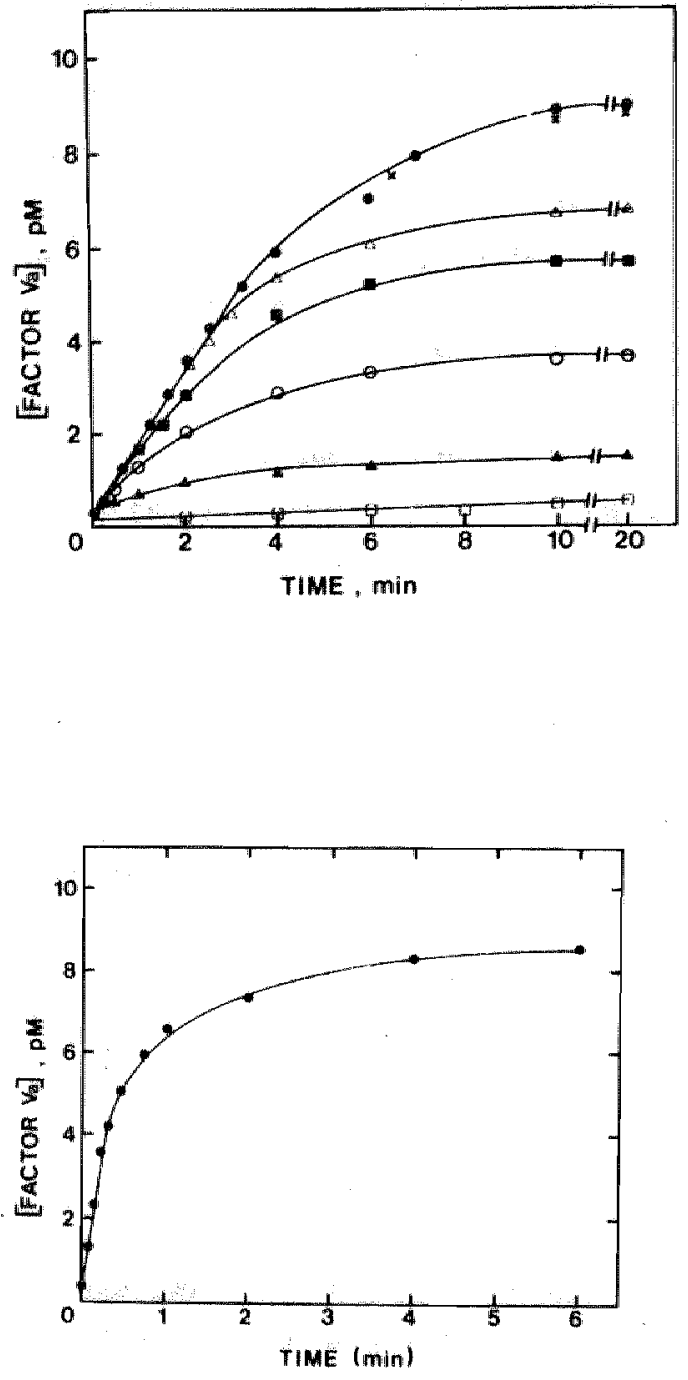

Eigure 2: Effect of the time of 2KK 36374 addition on the time course of factor $V_{a}$ generation. Platelets $\left(4.6 \times 10^{6} / \mathrm{ml}\right)$ were stimulated with thrombin $(0.5 \mathrm{nM}$ ) at $37^{\circ} \mathrm{C} .2 K 36374$ was added 2 min prior to ( $\square$ ) or at different time intervals after thrombin stimulation: (4) $5 \mathrm{~g}$, (O) $15 \mathrm{~s}$, (घ) $456,(\Delta) 2 \min ,(\mathrm{X}) 6 \mathrm{~min}$ (-) no $Z K$ 36374. Factor $V_{a}$ was assayed as described under Materials and Methods.

Figure 3: Time course of thrombin-induced factor $V$ release. platelets were incubated at $37{ }^{\circ} \mathrm{C}$ with thrombin $(0.5 \mathrm{nM})$ at aifferent time intervals followed by the addition of $2 K 36374$ (1 nM). Factor $V$ was assayed as described in the text.

released, but not yet actlvated. Thus, the rate of factor $V$ release can be estinated from a plot of the maximal amount of factor $V_{a}$, obtained 20 min after the addition of thrombin, versus the time of addition of $Z \mathrm{~K} 36374$ (Figure 3). The amount of released factor $V$ showed a linear increase in time 
during the first $30 \mathrm{~s}$ of the reaction. This enables us to astimate a true initial. rate of factor $v$ release of $12 \mathrm{pM}$ factor $\mathrm{V} / \mathrm{min}$ by $4.6 \times 10^{6}$ platelets/al. It can be questioned whether $2 \mathrm{~K} 36374$ at a concentration of 1 nM affects placelet factor $V$ activation and/or the factor $V_{a}$ assay. To this and $2 \mathrm{~K} 36374$ was added at a final concentration of 100 nM to the factor $\mathrm{V}_{\mathrm{a}}$ assay. We found that $\mathrm{zK} 36374$ had no effect on the determination of factor $V_{a}$ activity. Because the rate of factor $V_{a}$ generation, once the release reaction was completed, was identical whether or not $2 K 36374$ was present, we conclude that $2 K 36374$ had no effect on the platelet factor $V$ activation reaction (Figure 2 ).

Obviously, our method to assess the amount of released factor $V$ has clear advantages over other methods, where a separation is required between platelets and their supernatants. The method, however, is only applicable if there is no other effect of activated platelet constituants on our factor $V_{\text {a }}$ assay, i.e. activated platelets provide a procoagulant surface by their ability to assemble the componencs of the prothrombinuse complex. In ordit: to avold this effect phospholipid was present at a concentration that Ls suffictent to make the assay virtually insensitive for the procoagulant platelet surface. In addition, to assess the amount of platelet-bound factor $V_{a}$, platelets $\left(4.6 \times 10^{6} / \mathrm{ml}\right)$ were treated with $0.5 \mathrm{nM}$ thrombin for 4 inin and centrifuged for $\mathbb{l}$ min at $7000 \mathrm{xg}$. Before and after the centrifugation, factor W activity was determined in the suspension and the supernatant respectively. We found that both the suspension and the supernatant contained virtually identical amounts of factor $V_{a}(5 \mathrm{pH}$ ). This observation Indicates that pitatelet-bound factor $V_{a}$ must be a very small fraction of total factor $V_{a}$.

Whereas $50 \%$ of the platelet factor $V$ it released within $20 \mathrm{~s}$, half-maxtmall factor $V_{a}$ formation was obtatined only after a reacton time of 1 min (figure 2). Apparently, the rate of thrombin-iaduced platelet factor $v$ release is much faster than the rate of thrombin-catalyzed factor W activation.

Placelet factor $V$ activation. Because the rate of factor $V$ release is faster than the rate of factor $V$ activation, the amount of non-activated factor $V$ will increase rapidly during the time course of the release reaction. One can conceive that under our experimental conditions, i.e. high enzyme over substrate ratios, the rate of factor $V$ activation is dependent on the factor $\checkmark$ concentration. Thus, during the initial phase of the release reaction, the 
rate of factor $V$ actlwatlon wil increase up to an optimal value when the release reaction is nearly completed.

Therefore, we studied the rate of factor $V$ activation as a function of the factor $V$ concentration. The different initial factor $V$ concentrations were obtained by terminating the release reaction at different time intervals in thrombin-stimulated platelet suspensions of different platelet counts. When the prostacyciln analogue was added 10 or 20 s after thrombin $(0.5$ nil), a linear increase in factor $V_{\text {a }}$ formation was observed during a subsequent time perlod, sufficlent to release most of the platelet factor $V$ when the release was not blocked. During that time interval, about 1 min for the different platelet concentrations, $20 \pm 5 \%$ of the intial factor $V$ was converted into

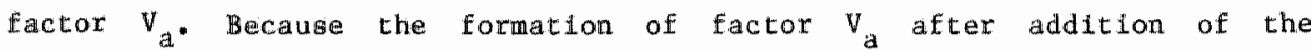
prostacyclin analogue was linear in time, we have additional proof that the release reaction was instantaneously and completely blocked when $2 K 36374$ was added.

Figure $4 \mathrm{~A}$ gives the amount of released, but yet not activated factor $V$ as a function of the release time for the different platelet concentrations. These values were taken as the difference between total factor $V_{a}$ formed (1.e. released factor $V$ ) and factor $V$ formed during the release t1me. The rates of factor $V$ activation at the corresponding factor $V$ concentrations are depicted in Flgure 4B. As was expected, the rates of factor $V$ activation increased with the comcentration of factor V (Figure 5). Thus, opt Imal rates were obtalned when the relewse reaction reached completion. Independent of the platelet concentration we found that $10 \mathrm{~s}$ after inftating the reaction, the rate of factor $V$ release was 20 -fold higher than the rate of factor $V$ activation. At the time the release reaction was nearly completed (90\%) a 6-fold difference was observed.

Platelet factor V release and factor Va generation as a function of thrombin concentration. Washed platelets $\left(4.6 \times 10^{6} / \mathrm{ml}\right)$ were incubated with varying concentrations of thrombin. $\mathrm{ZK} 36374$ was added $2 \mathrm{~min}$ prior to thrombin or $3,6,10$ and 15 after thrombin. Initial rates of factor $V$ release were estimated from plots of factor $V_{a}$ concentration measured 20 min after the addition of thrombin, versus time of addition of $2 \mathrm{~K} 36374$. The initial rates of platelet factor $V$ release as a function of thrombin concentration are given in Table $I$. It is apparent that the initial rate of release and rate of factor $V$ activation are proportional to the thrombin concentration. When 

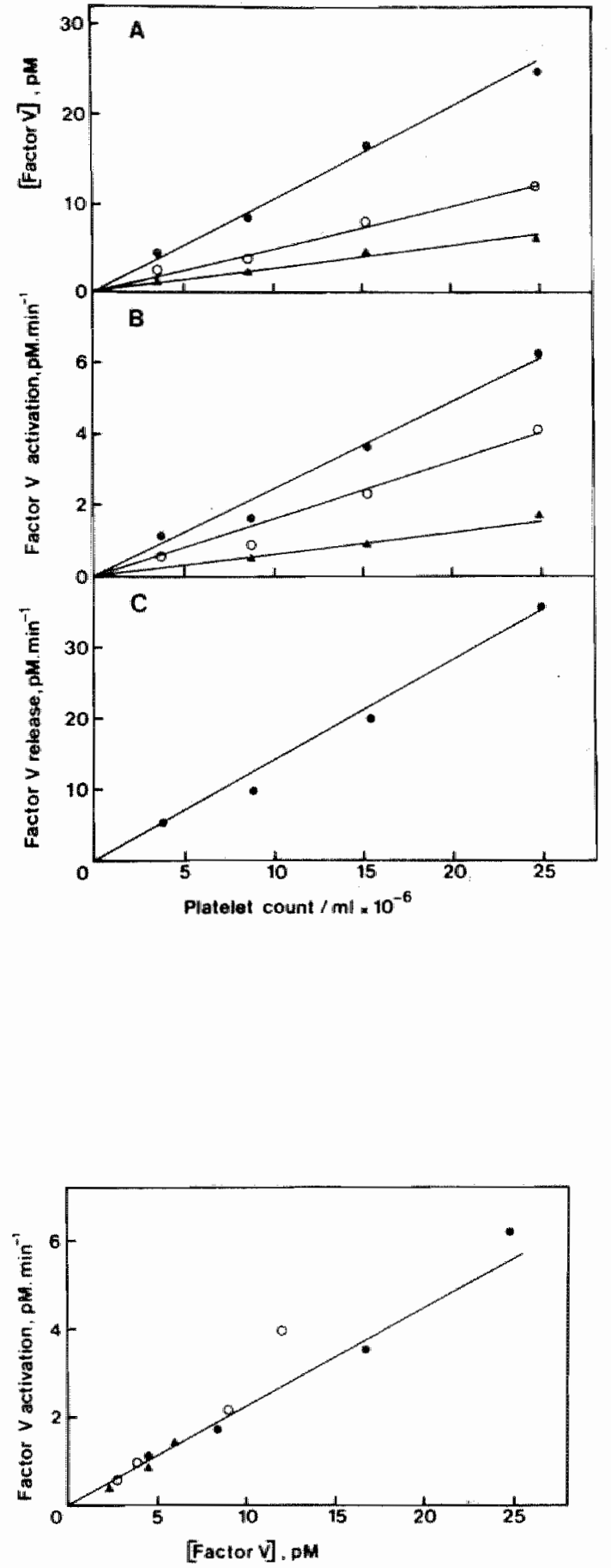

Figure 4: Relationship between platelet factor $V$ ralease and platelet factor $V$ activation. Platelets $\left(3.8-25 \times 10^{6} / \mathrm{mL}\right)$ were stimulated with thrombin $(0.5 \mathrm{nM})$ at $37^{\circ} \mathrm{C}$.

$A$, the amount of released factor $V$ after 10 a $(4) 20$ \& $(0)$ and nearly completion (90\%) of the release reaction $(\bullet)$.

$B$, rates of factor $V_{a}$ formation after blocking the retease reartion at $10 \mathrm{~s}(\mathbf{4}), 20 \mathrm{a}(\mathrm{O})$ and at nearly completion (90\%) of the release reaction $(\bullet)$.

$C$, rates of factor $V$ relectae. Experimental details are described in the text.

Figure 5: Rate of factor $V$ activation as a function of factor $V$ concentration. The rates of factor $V$ activation from figure $4 B$ were ptotted versus the corresponding initial factor $V$ concentration from Eigure $4 \mathrm{~A}$. 
platelets were incubated with varylng concentrations of thrombin in the absence of $Z K 36374$ we found that the final level of factor $V_{a}$ increased proportionally to the chrombin concentration, reaching a maximum, $13 \mathrm{pM}$ factor $V_{\text {a }}$, at about 1 nM thrombin (Table $I$ ).

When platelets $\left(4.6 \times 10^{6} / \mathrm{ml}\right)$ were exposed to $0.2 \%$ Triton $\mathrm{x}$ - 100 followed by an incubation with $0.5 \mathrm{nM}$ thrombin, $13 \mathrm{pM}$ factor $\mathrm{V}_{\mathrm{a}}$ was obtained. Thus at the optimal thrombin concentration ( $1 \mathrm{nM}$ ) all factor $V$ present in the platelets was released.

It is apparent that at thrombin concentrations up to $0.6 \mathrm{nM}$ a fraction of the total platelet factor $V$ content can be released proportionally to the thrombin concentration.

Table $I$. Platelet factor $V$ release and activation as a function of thrombin concentration

Platelets $\left(4.6 \times 10^{6} / \mathrm{ml}\right)$ were incubated with varying thrombln concentrations, at different time intervals before the addition of ZK 36374 (InM), and in the absence of $2 \mathrm{~K} 36374$. The rates of factor $V$ release, factor $V$ activation and the amount of factor $V$ released are measured as described in the text.

\begin{tabular}{cccc}
\hline Thrombin & $\begin{array}{l}\text { Rate of factor V } \\
\text { release }\end{array}$ & $\begin{array}{c}\text { Rate of factor } V \\
\text { activation }\end{array}$ & $\begin{array}{c}\text { Factor V } \\
\text { relieased }\end{array}$ \\
\hline nM & pM.min $^{-1}$ & pM.min $^{-1}$ & $\mathrm{pM}$ \\
0.2 & 2.5 & & 4.2 \\
0.4 & 8.0 & 0.7 & 8.5 \\
0.6 & 16.5 & 1.2 & 12.0 \\
0.8 & 27 & 3.0 & 12.5 \\
1.0 & 35 & 4.0 & 13.0 \\
1.5 & 58 & 5.0 & 13.2 \\
\hline
\end{tabular}


Plasma factor $V$ activation. An interesting question is whether the kinetics of plasma factor $V$ activation, estimated under the conditions of platelet factor $V$ activation, differ from those of platelet factor $V$ activation. To this end different dilutions of platelet-free and platelet-rich plisma were incubated with $0.5 \mathrm{nM}$ thrombin. At $30-\mathrm{s}$ intervals up to $5 \mathrm{~m} \mathrm{~m}_{\mathrm{n}}$ samples were

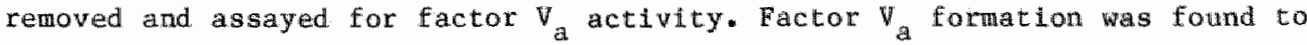
be limear in time up to 2 min. The corresponding factor $V$ concentrations 1 th the dilutions were estimated from the factor $V_{a}$ activities after complete activation. The results are deplcted In Table II. Human plasma factor V concentration as determined by our factor $V_{a}$ assay was found to be 6 nM. This value is $30-40 \%$ of that reported by Tracy et al. (15).

Table II. Rate of plasma factor $V$ activation.

Platelet rich playma (PRP) containing $2 \times 10^{8}$ phatelets/ml and platelet frete plasma (PFP) were dlluted in $10 \mathrm{mM} \mathrm{HEPES,} 136 \mathrm{mM} \mathrm{NaCl}, 2.7 \mathrm{mM} \mathrm{KCl,} 2 \mathrm{mM}$ $\mathrm{MgCl}_{2}$, $5 \mathrm{mM} \mathrm{CaCl} 2,5 \mathrm{mM}$ glucose and $1 \mathrm{mg} \mathrm{HSA} / \mathrm{ml}$, $\mathrm{pH} 7.5$. Factor $V$ activation was inltiated by adding thrombin $(0.5 \mathrm{nM})$.

\begin{tabular}{|c|c|c|c|c|c|c|}
\hline \multirow[b]{3}{*}{$\begin{array}{l}\text { Plasma } \\
\text { dilution }\end{array}$} & \multirow{2}{*}{\multicolumn{2}{|c|}{$\begin{array}{l}\text { Factor } V \\
\text { concenteatton } \\
(\mathrm{pM})\end{array}$}} & \multicolumn{2}{|c|}{$\begin{array}{c}\text { Rate of factor } \\
\text { activation }\end{array}$} & \multicolumn{2}{|c|}{ Rate. $[V]^{-1}$} \\
\hline & & & CpM. & -1 ) & (mi & \\
\hline & PRP & $\mathrm{PEP}$ & PRP & PFP & PRP & Prp \\
\hline $1: 113$ & 50 & 40 & 15.0 & 12.1 & 0.30 & 0.30 \\
\hline $1: 300$ & 16 & 19 & 6.0 & 5.6 & 0.37 & 0.30 \\
\hline $1: 600$ & 11 & 9 & 3.4 & 2.6 & 0.27 & 0.29 \\
\hline $1: 1200$ & 5.4 & 4.5 & 1.9 & 1.5 & 0.35 & 0.33 \\
\hline
\end{tabular}

It is also show that the rate of factor $V$ activation is proportional to the plasma factor $V$ concentration. Apparently the rate of factor $V$ activation in platelet-free plasma is identical to that in platelet-rich plasma. This 
fuludes a role of platelet constituants in factor $V$ activation. Because of inter-1ndividual variations we compared the kinetics of plasma factor $W$ activation to those of platelet factor v activation using washed platelets from the same donor. The results show that the rates of platelet factor $V$ activation, wen normalized for the factor $V$ concentration, were similar to those of plasma factor $V$ activation (Table III). According to our bioassay, the amount of factor that is provided by the platelets in platelet-rich plasida 18 about 10\% of the total factor $\mathrm{V}$ concentration. This value is gomewhat lower than that reported by Tracy et al. (15) and is in agreement with the findings of Chiu et al. (16).

Immonological identity between platelet and plasma factor $V$ has been shown In human spectes $(15,17,18)$, bovine species $(19,20)$ and recenty in guinea plg between plasma factor $W$ and a precursor form synthesized in the megakaryocytes (16). Whereas in the latter case functional differences were found after exposure to thrombin, in other reports the same quotient of activation by thrombin was found between platelet and plasma factor $v(1,2)$.

Table III. Rate of platelet factor V activation.

Washed platelets were prepared from the platelet rich plasma of Table 2. The rate of factor $V$ activation by $0.5 \mathrm{nM}$ thrombin was determined at the time the release reaction was nearly completed (90\%). The factor $\nabla$ concentration at that time point was determined as described in the legends to Figure 4.

\begin{tabular}{|c|c|c|c|}
\hline $\begin{array}{c}\text { Platelet } \\
\text { concentration }\end{array}$ & $\begin{array}{c}\text { Factor V } \\
\text { concentration }\end{array}$ & $\begin{array}{c}\text { Rate of factor } V \\
\text { activation }\end{array}$ & Rate. $[\mathrm{V}]^{-1}$ \\
\hline $10^{-6}$ xeounts.m $\mathbb{1}^{-1}$ & $\mathrm{pM}$ & $p M \cdot m \mathbb{1} n^{-1}$ & $\min ^{-1}$ \\
\hline 31 & 45 & 10.0 & 0.22 \\
\hline 12 & 16 & 5.0 & 0.30 \\
\hline 6 & 10 & 3.0 & 0.31 \\
\hline 3 & 6 & 2.3 & 0.38 \\
\hline
\end{tabular}




\section{CONCLUSTON}

In order to assess the time course of platelet factor $v$ release by a bioassay it is important to separate the effect of thrombin on the release of platelet factor $V$ from its effect on factor V activation because the rate limiting step in thrombin-tuduced platelet factor $v_{\text {a }}$ formation fe the thrombin-catalyzed activation of the released non-activated factor $V$. By utilizing the stable prostacyclin analogue $2 \mathrm{~K} 36374$ we could demonstrate that, in contrast to previous reports $(1,2)$, the rate of platelet factor $V$ release is as fast as the rate of release of another protelu present in the platelet alpha-granules, i.e. beta-thromboglobulin (21). our method is useful in the assessment of the kinetics of release of other protelns present in the alpha-granules and in the investigation of placelet disorders charactertzed by an 1mpaired release process and/or storage defect.

our findings on the kinetics of platelet factor $V$ release and actlvation (platelet factor $V_{\text {a }}$ generation) and plasma factor $V_{a}$ formation rastise questions as to the role of platelet factor $V$ in the regulation of thrombin formation at the platelet surface. We found that the rate of activation of platelet factor $V$ once it is released is ldentical to that of plasma factor V. Taking into account that 1$)$ the rate of platelet factor $V$ release and the amount that can be released depend on the thrombin concentration and 2) factor $V$ present in the platelets is about $10 \%$ of that in plasma, 1 appears that factor $V_{a}$ formation from plasma factor $V$ is quantitatively far are important than factor $V_{a}$ formation from platelet factor $V$ *

However, one should bear in mind that at a ste of vascular injury platelets do aggregate and as a result might provide locally high platelet factor $V_{\text {(a) }}$ concentrations. It has been reported that the absence of platelet factor $V$ rather than plasma factor activity appeared to be associated with a severe bleding disorder $(7,22)$. On the other hand, patients with arey platelet syndrome have a moderate bleeding disorder desplte thrombocytopenta (23), a platelet factor $V$ content that is about $20 \%$ of normal when expressed as factor $V$ concentration per platelet count per $m I$ and a severely tmpalred platelet factor $V$ release reaction. However, those patients have an almost normal plasma factor $V$ level (D. Baruch, T. Llndhout, E. Dupuy and J. P. Caen, unpublished results). 


\section{REF FERENCES}

1. Chesney, C.M., Pifer, D., Colman, R.W." Subcellular localization and secretlon of factor V from human platelets. Proc.Nat1.Acad.Sci. U.S.A. $78,5180-5184(1981)$

2. Katre, W.H., Lindhout, T., Jickson, C.M., Majerus, P.W.: Factor va

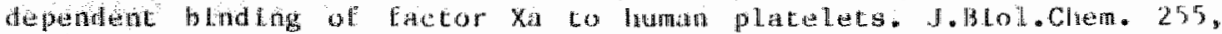
$1170-1174(1980)$

3. Bevers, E.M., Confurlus, P., wan Rijn, J.L.M.l., Henker, H.C., Zwaal, R. P.A.: Generation of prothrombin converting activity and the exposure of phosphatddylserine at the outer surface of platelets. Eur.J.Blochem. 122, $429-436(1982)$

4. Roglng, J., van RIjn, J.L.M.L., Bevers, E.M., van Dieijen, G., Comfutius, P., Zwaal, R.F.A.: The role of activated platelets in prothrombin and factor $X$ activation. Blood 65, 319-332 (1985)

5. Tracy, P.O., Nesheim, M.E., Mann, K.G.: Coordinate binding of factor Va and factor Xa to the unstimulated platelet. J.Btal. Chem. 256, 743-751 (1981)

6. Neshelm, M.E., Eid, S. Mann, K.G.: Assembly of the prothrombinase complex in the absence of prothrombin. J.Biol.Chem. 256, 9874-9882 (1981)

7. Tracy, P.B., Giles, A.R., Manm, K.G., Elde, L. L., Hoogendoorn, H., Rivard, G.E.: Factor W (Quebec); a bleeding diathesis assoctated with a qualitative factor V deficiency. J.c1in. Invest. $74,1221-1228$ (1984)

8. Pletcher, C.H., Nelsestuen, G.L.: The rate-determining step of the heparin-catalyzed antithrombin thrombin reaction is independent of thrombin. J.Biol. Chem., 257, 5342-5345 (1982)

9. Lindhout, T., Govers-Riemslag, J.W.P., van de Waart, P., Henker, H.C., Rosing, J.: Factor Va-factor Xa interaction. Effects of phospholipid vesicles of varying composition. Biochemistry 21, 5494-5502 (1982)

10. Chase, T., Shaw, E.: Comparison of the esterase activities of trypsin, plasmin and thrombin on guanldinobenzoate esters. Titration of the enzymes. Biochemistry 8, 2212-2227 (1969)

11. Smith, R.l.: Titration of activated bovine factor X. J.Biol. Chem. 248, $2418-2423(1973)$

12. Comfurlus, P., Zwaal, R.F.A.: The enzymatic synthesis of phosphatidylserine and purtfication by cri-cellulose colum chromatography. Blochim. Blophys Acta $488,36-42(1977)$

13. De Kruifff, H., CHIlls, P.R., Radda, J.K.: Differential scanning calorlmetry and $P$ NMR studies on sonlcated and unsonicated phosphatidyloholine liposomes. Biochim. Blophys.Acta 406, 6-20 (1975)

14. Böttoher, G.J.F., van Gent, C.M., Pries, C.: Rapld and sensitive submiero phosphorus determination. Anal.Clin. Acta 24, 203-207 (1961)

15. Tracy, P.B., Eide, L.L., Bowle E.J.W., Mann, K.G.: Radioimmunoassay of factor V in human plasma and platelets. Blood $60,59-63$ (1982)

16. Chiu, H.C., Schlck, P.K., Colman, R.W.: Blosynthesis of factor $V$ in isolated guinea pig megakaryocytes. J.C11n. Invest. 75, 339-346 (1985)

17. Breederveld, K., Giddings, J.C., Ten Cate, J.W., Bloom, A.L.: The localization of factor $V$ within normal human platellets and the demonstration of a platelet factor $V$ antigen ia congenital factor $V$ deficlency. Br.J.Haematol. 29, 405-412 (1975)

18. Osterud, B.S., Rappaport, S.I., Lavine, K.K.: Factor V activity of platelets. Evidence for an activated factor $v$ molecule and for a platelet activator. Bllood 49,819-834 (1977) 
19. Tracy, P.B., Peterson, J.M., Nesheim, M.E., MC Duffie, F.C., Mann, R.G.: Interaction of coagulation factor $V$ and factor Wa with platelets. J.B1ol.Chem. 254, 10354-10361 (1979)

20. Ittyerah, T.R., Rawala, R., Colman, R.W.: Immunochemical studies of factor $W$ of bovine platelets. Eur.J.Biochem. 120, 235-24l (1981)

21. Akkerman, J.W.N., Gorter, G., Kloprogge, E.: Kinetic analysis of alpha-granule secretion by platelets. Thromb.Res. 27, 59-64 (1982)

22. Miletich, J.P., Majerus, D.W., Majerus, P.W.: Patients with congenital factor $V$ deficiency have decreased factor Xa binding sites on their platelets. J.Clin. Invest. 62, 824-831 (1978)

23. Bellucci, S., Tobelem, G., Caen, J.P.: Inherited platelet disocders* Progress in Hematology XIII, 223-263 (1983) 
$-52-$ 
CHAPTER III

\section{THRORBIN-INDUCED PLATELET FACTOR $V$ FORMATION IN PAITENIS WITH A GRAY PLATELET SYNDROME}

\section{SUMMARY}

The contribution of human platellet factor generation to the regulation of thrombin formation is not yet clear. We report a study on factor $V_{\text {a }}$ formation in plasma and platelets of three patients with a mild bleeding disorder ascribed to a gray platelet syndrome. This inherited platelet disorder has been characterized by the absence of alpha-granules as observed by electron microscopy, and by specific deflciencles of alphagranule proteins.

We found that the concentration of plasma factor $V$ was slightly decreased (70\% of normal values) but the rate of thrombin-catalyzed factor $v$ activation was normal. In contrast, platelet factor $V_{a}$ formation was severely impaired. Besides a much lower factor $V$ content than in control platelets (6-20\% of normal), the dependency of platelet factor $v_{a}$ formation on thrombin concentration was altered. Increasing the thrombin concentration 4-fold compared to the concentration that results in optimal factor $V_{\text {a }}$ concentration in nomal platelets did not result in a maxtinall factor $V_{a}$ formation in gray platelets. However, we have demonstrated that this factor $V_{a}$ formation is the result of the thrombin-1nduced release reaction.

It 1 s our conclusion that the almost normal plasma factor vatoton in those patents compensates the abarkedly reduced cunctional platelet factor $W_{a}$ formation and as such could account for the absence of a severe impaiment of hemostasis. 


\section{INTRODUCTION}

Factor can be released from platelet alpha-granules after stimulation by a variety of agente like thrombin and collagen. In order to function as a coffactor in prothrombin activation, factor $W$ requires to be activated by thrombin $(1-3)$. The function of platelet factor $v$ is not yet clearly established. We have recently developped a bioassay that allowed us to aparately assess the klnetics of thrombln-induced platelet factor $V$ release from those of platelet factor $V$ activation (4). We have shown that all factor $V$ stored in normal platelet suspensions $\left(5 \times 10^{6} / \mathrm{m} 1\right)$ conld be released by an optimal thrombin concentration ( 1 nM). Human platelet factor $V$ represents 10 to $20 \%$ of plasma factor $V(3-5)$. We found that the kinetics of thrombin-catalyzed platelet factor $v$ activation were ldentical to those of plasma factor $V$ activation (4). However, the crucial importance of platelet factor $V$ in maintaining normal hemostasis was suggested by Miletich ec al. (6), who showed a close relationship between the severity of bleeding and the extent of platelet factor $V$ deficiency among a group of patients with a plasma factor $V$ deficlency.

The gray platelet syndrome is a hereditary platelet disorder characterized by the almost complete absence of alpha-granules in the megakaryocytes and In the platelets $(7,8)$. Cytochemical studies show that alpha-granules are present in the megakaryocytes at an immature state but are unable to mature. Thus, the compounds normally present in alpha-granules are synthetized but are discharged in distended demarcation membranes or vacuoles (9). Nurden et 1 . (10) demonstrated that up to $10 \%$ of the normal concentrations of the following proteins were present in the gray platelets: fibrinoger, fibronectin, thrombospondin, won Willebrand factor, platelet factor 4 and beta-thromboglobulin, whereas $50 \%$ of the normal albumin content was found.

The functional factor $V$ concentration is not clearly established In gray platelets. Victe et al. (3) showed in a patient with a combined deflciency of dense and alpha-granules, that platelet factor $V$ activity was $50 \%$ of control values in frozen-thawed platellets as well as after stimulation by collagen. In a recent study, nearly mormal amounts of factor $V$ antigen were detected in lyzed platelets of a patient with a gray platelet syndrome (11). However, the functional factor $V$ concentration was not determined in that study. 
The gray platellet syndrome is clinically characterized by a mild bleeding disorder, mainly of the type of a primary hemostasis abnormality of platelet adhesion or aggregation. However, two symptons that have not been clearly described suggest a coagulation abnormality: a questionable recurrent hemarthrosis in one patient (7) and spontaneous hematoma in towo others (12). This platelet disorder thus offers a possibility to further understand the contribution of platelet factor $V$ in the efficiency of the hemostatic process.

In the present study we report on factor $V$ formation in three patients with a gray platelet syndrome. We studied lyzed platelet suspensions, thrombin-activated washed platelet suspensions as well the kinetics of: plasma factor Va formation.

\section{MATERLALS AND METHODS}

\$2238 was purchased from AB Kabi Dlagnostica. Human serum albumin (fatty acld free) was from Sigma. ZK 36374, a stable carbacyclin derivative of prostacyclin was obtained from Schering (Berlin). Human proteins (prothrombin and factor $x_{a}$ ) were a kind gift from Dx. H. Soons. Purification procedures for human factor $X$ and prothrombin were essentially the same as described earlier (13). Protein concentration determinations and phospholipid preparation were performed as previously reported (4). Case history*. Three patients were investigated, two slbllags H.B. and M.S., and a third unrelated patient B.O. The detailed case historles of the two siblings have been reported prevlously (12). Both suffered from epistaxis episodes and presented one severe hemorrhagic complication secondary to obstetrical or surgical interventions. The third patient, a woman aged $26 \mathrm{yr}$, had experienced mild bleeding episodes, essentially epistaxis that on one occasion requited a blood transfuston. She had a miscarriage without any excessive bleeding. All patients had a thrombocycopenia at the time of the present study (circulating platelet counts $40,000 / \mu \perp$ (M.S.), $90,000 / \mu \perp($ H.B.) and $60,000 / \mu \perp(B .0$.$) .$

\footnotetext{
* This investigation was performed according to the Declaration of Hellinkt. and informed consent was obtained.
} 
Isolation of Human Platelets. Blood was drawn by venepuncture directiy into acld cltrate-dextrose $0.18 \mathrm{M}$ glucose-0.08 M sodium citrate-0.052 M citric acld), $\mathbb{1 n}$ the ratio of 5 volumes of whole blood to 1 volume of anticoagulant. PGE, was added $(7 \mathrm{gg} / \mathrm{ml})$. Norital platelet-rich plasma was obtalned by centrifugation at $220 \mathrm{xg}$ for $15 \mathrm{~min}$. Platelet-rich plasma from the patients was obtalned by allowing whole blood to sediment for 1 hour at room temperature in tubes tilted at an angle of 45 degrees.

Platelets were isolated from platelet-rich plasma by centrifugation at 600 xig for $20 \mathrm{~min}$ and the pellet was resuspended in $10 \mathrm{mM}$ Hepes, 136 m $\mathrm{NaCl}, 2.7 \mathrm{mM} \mathrm{KCl}, 2 \mathrm{mM} \mathrm{MgCl} 2,5 \mathrm{mM}$ glucose and $1 \mathrm{mg}$ human serum albumin (HSA)/mi, pH 6.7. The platelets were washed twice in this buffer by centrifugation at $350 \mathrm{xg}$ for $15 \mathrm{~min}$. Before centrifugation one volume of actd citrate-dextrose was added to 14 volumes of the platelet suspension. Findly, the platelets were resuspended in the aforementioned Hepes buffer, $1 \mathrm{mg} \mathrm{HSA} / \mathrm{mL}, \mathrm{pH} 7.5$. Platelet concentration was determined with a Coulter counter.

Measurement of Platelet Factor Va Formation. Washed platelets $\left(5 \times 10^{7} / \mathrm{m} 1\right)$ in Hepes buffer were incubated with thrombin at $37^{\circ} \mathrm{C}$. Factor $V_{\text {a formation was }}$ determined by a factor $v_{a}$ assay as previously described (4) with the modiflcation that Instead of bovine factors, human factor $x_{a}$ and human prothrombin were used. Estimations of the factor $V_{a}$ concentrations were obtalned as follows. Maximal rate of thrombin formation, $v_{\max }=48 \mathrm{nM} / \mathrm{min}$, 1 s obtained when all factor $x_{a}$ present, $16 \mathrm{pM}$, is saturated with factor $v_{a}$. At factor $v_{a}$ concentrations far from saturation, the rate of thrombin formation, w, is propottional to the factor $\mathrm{V}_{\mathrm{a}}$ concentration. Thus, the Factor $V_{a}$ concentration in the assay mixture can be calculated from $v / v_{\text {max }}$ multiplied by the factor $x_{a}$ concentration.

Measurement of plasma factor Va formation. Platelet-free plasma was obtalned by centrifugation of platelet-rich plasma at 2000xg. Serial Alutions $(1: 150,1: 300,1: 600)$ of platelet-free plasma were made in $10 \mathrm{~mm}$ Hepes, $136 \mathrm{mM} \mathrm{MaCl}, 2.7 \mathrm{mM} \mathrm{KCl}, 2 \mathrm{mM} \mathrm{MgCl}, 5 \mathrm{mM} g$ lucose, $5 \mathrm{mM} \mathrm{CaCl}, 1 \mathrm{mg}$ $H S A / m 1$, $\mathrm{pH} 7.5$. The plasma dilutions were incubated at $37{ }^{\circ} \mathrm{C}$ for $4 \mathrm{~min}$, followed by the addition of thrombin ( $1 \mathrm{nM}$ ). Aliquots were taken for factor $\mathrm{V}_{\mathrm{a}}$ determination. The inital rate of factor $\mathrm{V}_{\mathrm{a}}$ formation was determined during $2 \mathrm{~min}$ following the addition of thrombin. Final factor $v_{a}$ concentration in plasma was determined after 16 min incubation of the 
diluted plasma with thrombin, multiplied by the dilution factor. The factor $V_{a}$ concentration in control plasma was obtained by assaying dilutions of platelet-free pooled plasma obtained from 50 human volunteers.

Factor Va formation in lyzed platelets. Platelet suspensions $\left(2 \times 10^{7} / \mathrm{ml}\right)$ were incubated for 10 min with Triton $X-100(0.2 \%)$ in the presence of calcium $(5 \mathrm{mM})$. Factor $V_{a}$ formation was determined in Triton-treated platelet suspensions after the addition of thrombin ( $2 \mathrm{nM}$ ).

\section{RESULTS}

Plasma factor $V$ activation. Factor $V_{a}$ formation in several dilutions of platelet-free plasma of two patients was monitored after addition of 1 nM alpha-thrombin. Table I shows the final factor $V_{a}$ concentrations measured for each dilution at complete activation of factor $V$ by thrombin ( $16 \mathrm{~min}$ ) and multiplled by the dilution factor. The variation between the different dilutions was whin $10 \%$ and the results of 3 determinations were averaged. Factor $V$ concentration in normal pooled plasma was found to be 5 nM. This value is in agreement with previously reported values of human factor $V$ plasma concentration as determlned with a bovine assay system (4).

Table I

Plasma Factor Va formation

\begin{tabular}{|c|c|c|}
\hline \multirow[t]{2}{*}{ Plasma } & $\begin{array}{l}\text { Final Factor } V_{a} \\
\text { concentration }\end{array}$ & $\begin{array}{l}\text { Initial rate/Factor } V^{\prime} \\
\text { concentration }\end{array}$ \\
\hline & $(\mathrm{nM})$ & $\left(\mathrm{nM} \mathrm{EV}_{\mathrm{a}} / \mathrm{mIn} / \mathrm{nM} \mathbb{E V}\right)$ \\
\hline
\end{tabular}

\begin{tabular}{lll}
\hline Control & 4.8 & 0.41 \\
Patlent H.B. & 3.5 & 0.31 \\
Patient B.O. & 2.9 & 0.40 \\
\hline
\end{tabular}

Plasma dilutions were assayed for factor $v_{a}$ formation after activation by thrombin ( $1 \mathrm{nM}$ ). The initlal rate of factor $v_{a}$ formation and the factor $v_{a}$ concentration were determined as described in Material and Methods. 


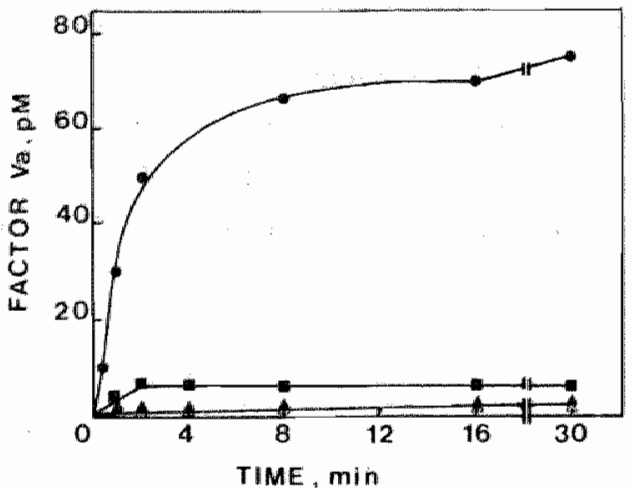

Figure 1: Time courge of thrombin induced platelet factor $V_{a}$ for mation. Washed platelete $\left(5 x \mathrm{x} 0^{\circ} / \mathrm{ml}\right)$ were incubrted at $37^{\circ} \mathrm{C}$ with throm bin (2 nM). Samples were Luken in time and assayed for factor $V_{a}$ activity. Control ( I: patient H.B. ( $)$; patient M.S. ( $\Delta$ ); patient $B . O$. ( $\Delta)$.

In the patlents H.B. and B.0. plasma factor $V$ concentrations were found to be $73 \%$ and $61 \%$ of control value, respectively. Furthermore, when the laitdid rate of factor $V$ incivation is normalized for the factor $V$ concentration, it is apparent that this rate is the same (patient B.0.) or slightly lower (patient H.B) than found in normal plasma (Table I). platelet factor Va formation. Washed platelet suspensions $\left(5 \times 10^{7} / \mathrm{ml}\right)$ were incubated with thrombin (2 nM). Figure 1 shows the time courses of factor $v_{a}$ forration in the patients' and control platelets. Whereas in control platelets, the inftial rate of factor $v_{a}$ formation was $30 \mathrm{pM} / \mathrm{m} i \mathrm{n}$ and the final factor $V_{\text {a }}$ concentration was $75 \mathrm{pM}$, both values were markediy reduced

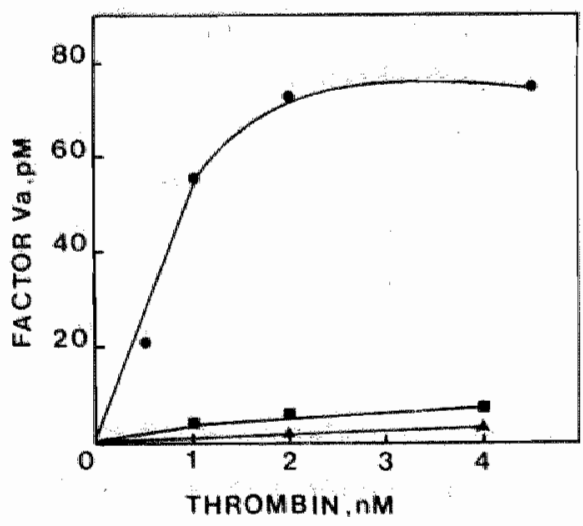

Furine 2: The dependency of factor $V_{a}$ formation from gray platelet on the thrombin concentration. Platelet wepenstions $\left(5 \times 10^{7} / \mathrm{ml}\right)$ were incubated with varying thrombin concentmations. platelet factor $V_{a}$ formation was determined after complete artivation by thrombin (usually $15 \mathrm{~min}$ ).

Control (-1); patient H.B. ( 1 ); patient M.S. ( $\mathbf{\Delta})$. 
in suspensions of gray platelets. It is shown that in patients M.S. and B.0. Factor $V_{\text {a }}$ formation is almost negligible ( $1 \mathrm{pM}$ in $30 \mathrm{~min}$ ), whereas in patient H.B. 5 PM factor $V_{\text {a }}$ was formed in 30 min.

Eifect of thrombin concentrations on platelet factor Va formation.

We determined platelet factor $V_{a}$ formation in control, patientsi. H. and M. S. as a function of the thrombin concentration. The results are shown in Figure 2. Whereas maximal factor $v_{a}$ formation was obtained in control platelets at 2 nM thrombln, we found that factor $v_{a}$ formation from gray platelets still increased at thrombin concentrations higher than 2 n. Furchermore, with varying thrombin concentrations, the final amount of generated factor $V_{a}$ was proportional to the intilal rate of factor $V_{a}$ formation in patlent H.B.'s platellets (Figure 3).

Effect of the prostacyclin analogue ZK 36374 on platelet factor Va forination. We have previously demonstrated that the prostacyclin analogue $7 \mathrm{~K}$ 36374 is a potent Inhibltor of the thrombin-induced release of platelet factor $V$, but has no effect on the thrombin-catalyzed activation of factor V. When control platelets are incubated with ZK 36374 ( 1 nM) 3 min prior to the addition of thrombin, platelet factor $\mathrm{V}_{\mathrm{a}}$ formation 1 s reduced to $2 \%$ of the activity reasured in the absence of $\mathrm{ZK} 36374$ (4). Because of the low factor $V_{a}$ activity that could be generated from the gray platelets, it can be questloned whether this anount is the result of the release reaction or

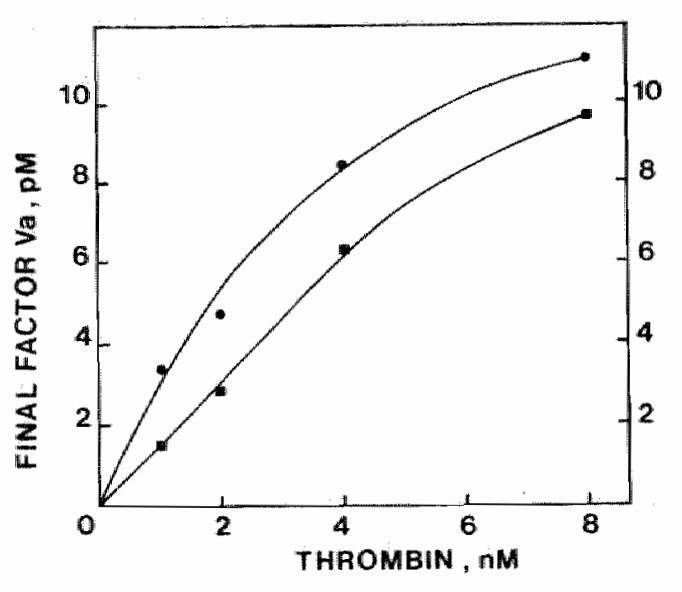

Figure 3: Initial mate of factor $V_{a}$ formation and total factor $V_{a}$ fomation ass a function of thrombin oncentration. ptatiolet subpensions $\left(5 \times 10^{7} / \mathrm{ml}\right)$ from patient H.B. weme tmoubated with inareasing thrombin concentrations.

The initial rate of faotor $V_{a}$ formation ( ) and the total factor $V_{a}$ fomation after $15 \mathrm{~min}(\mathrm{c})$ were determined as described in Material and Methodo. 
arose, for instance, from a contamination with plasma factor V. To this end, suspensions of gray platelets were incubated with $\mathrm{ZK} 36374$ (I nM) prior to the addition of thrombin $(2 \mathrm{nM})$. Compared to the value measured in the absence of ZK 36374, we found a reduced factor $V_{a}$ formation in the three pacients' platelets. Because of the low factor V activities in the thromblim-treated platelet suspensions of patients B.O. and M.S., no firm concluston can be drawn from those analyses. However, a 10-fold lower factor $V_{a}$ activity was found in the $2 K 36374$ treated platelets of patient H.B. This finding indicates that factor $V_{a}$ formation is the result of the thrombin-1ndeced release reaction and subsequent activation of factor $V$.

Factor Va formation in lyzed platelet suspenslons. Total platelet factor V content was determined in $0.2 \%$ Triton $x-100$ 1yzed platelet suspensions $\left(2 \times 10^{7} / \mathrm{ml}\right)$, after a further incubation with thrombin $(2 \mathrm{nM})$. Factor $\mathrm{V}$ concentration in control platelets was 52 pM. Less than $10 \%$ of this value was obtained in patients H.B. ( $8 \%$ ) and M.S (6\%). However, $20 \%$ of the control value was found in patient B.O.

\section{Drscusston}

Platelet factor $V_{a}$ formation was studied in suspensions of gray platelets In order to assess the amount of functional platelet factor $V$. It has been reported that most of the proteins normally present in alpha-granules are reduced 1 to $10 \%$ of the control walues in gray platelets (10). Our findings on three gray platelet pattents indtcate chat factor $V$ is also reduced to $6 \%-20 \%$ of normal values as determined in Triton-treated platelet suspensions. In addition, we have demonstrated that the factor $V_{\text {a }}$ formation can be induced by thrombln, but at least 4 -fold higher thrombin concentration are required than for optimal release and activation of factor $V$ from control platelets. Our observation that a prostacyclin analogue, a potent inhibitor of the platelet release reaction, was able to black the thrombin-induced gray platelet factor $V_{\text {a }}$ formation, strongly suggests the presence of a factor $V$ storage organelle rather than the locallzation of factor $V$ in the cytoplasma of the gray platelet. In view of the low content in the proteing normally stored in the alpha-granules and the impatred release reaction, it is interesting to note that a small population of gray 
platelets might contain inmature (precursors of) alpha-granules (12). Our data on platelet factor $V$ release are in good agreement with those of Levy-Toledano et al. (12) on the release of another alpha-granule proteln, beta-thrombogiobulin. As the same patients were described as in the present study, a direct comparison of the data is possible. In patients H. B. and M.S. respectively, $15 \%$ and $8 \%$ of the beta-thromboglobulin concentration of control platelets were obtained at a thrombin concentration of 1 NIH U/mI (10 nM) in patient H.B., and of $0.1 \mathrm{NIH} \mathrm{V} / \mathrm{ml}$ ( 1 nM) in patient M.S. Unfortunately, the dependency of beta-thromboglobulin release on the thrombin concentration which might account for the different beta-thromboglobulin values was not reported. In addition, these authors demonstrated. that platelet aggregation and serotonin release required higher concentrations of thrombin in the patients" than in control platelets (12). If one considers that the role of fibrinogen, and most probably of the platelet-fibrinogen, has been shown in thrombin-induced aggregation of nomal platelets (14), it is possible lo relate the platelet dystunctions of gray platelet patients to an impaired release of proteins normally present in alpha-granules.

Our findings on the factor $V$ content in gray platelets are in contrast with those reported by Tracy et all. (11). These authors claimed an almost nomal. concent of factor $V$ antigen. However, because the platelets were 1yophilised, they were unable to assess the factor $V$ content by a biossay. One should bear in mind that a slight contamination with plasma factor $V$ can account for this dlscrepancy.

Several studies have indicated that a severe bleeding disorder after trauma correlates wh the absence of functlonal platelet factor vather than with factor $V$ levels in plasma $(6,11)$. However, we believe that a stralght forward conclusion as to the important role of platelet factor $v$ over plasma factor $V$ cannot be drawn from these studies. Flrstly, a certain degree of dysfunctlonal plasma factor $V(11)$ or reduced plasma factor $V$ levels (6) was found concomittantly to the dysfunctional platelet factor $V$ or reduced platelet factor $v$ levels. Secondly, our results indicate that when platelet factor $V_{a}$ formation is almost absent, and plasma factor $V_{a}$ formation is nearly normal, the clinical symptoms can be characterized as a mild bleeding disorder. A particularly interesting observation is that when gray platelets are stimulated by thrombin and collagen, no abnormallty was 
found in thel prothrombin-converting activity determined in the presence of exogenous factor $V_{a}(15)$. That is, upon stimulation with thrombin and collagen, gray platelets appared to generate a normal procoagulant surface. Becanse plasma factor $V$ in these patients seens to account for an almost normal functional factor $V$ activity, it seems unilkely that a quantitative platelet factor $V$ disorder causes a severe impairment of hemostas 1s.

\section{REFERENCES}

1. Kane, W.H., Lindhout, T., Jackson, C.M., Majerus, P.W.: Factor Va-dependent binding of factor Xa to human platelets. J. Biol.Chem. $255,1170-1174,1980$

2. Kane, W.H., Mruk, J.S., Ma jerus, P.W.: Activation of coagulation factor $\mathrm{V}$ by platelet protease. J. C1in. Invest. 70, 1092-1100, 1982

3. Victc, W.J., Lages, B., Welss, H.J.: Release of human platelet factor $V$ activity $1 \mathrm{~s}$ induced by both collagen and ADP and is inhibited by asplrin. Blood, $56,448-455,1980$

4. Baruch, D., Hemker, H.C. "Lindhout, T.: Kinetics of thrombin-induced release and actlvation of platelet factor V. Eur. J. Blochen (in press).

5. Tracy, P.B., Eude, L.L., Bowle, E.J.W., Mann, K.G.: Radioimmunoassay of factor $V$ in human plasma and platelets. Blood $60,59-63,1982$

6. Miletich, J.P., Majerus, D.W., Majerus, P.W.: Patients with congenital factor $V$ deficlency have decreased factor $X a$ binding sites on their platelets. J. Clin. Invest. $62,824-831,1978$

7. Raccuglia, G.: Gray platelet syndrome. A variety of qualitative platelet disorder. Am.J.Med. 51, 818-828, 1971

8. Gerrard, J.M., Phlllips, D.R., Rao, G.H.R., Plow, E.F., Walz, D.A., Ross, R., Haxker, L.A., White, J.G.: Biochemical studies of two patients wh the Gray platelet syndrome. J.C1In. Invest. 66, 102-109, 1982

9. Breton-Gorlus, J., Valnchenker, W., Nurden, A., Levy-Toledano, S., Caen J.P.: Defective alpha-granule production in megakaryocytes from gray platelet syndrome. Ultrastructural studies of bone narrow cells and megakaryocytes growing in culture from blood precursors. Am.J.Pathol. $102,10-19,1981$

10. Nurdea, A.T., Kunicki, T.J., Dupuis, D., Soria, C., Caen, J.P.: Speciflc protein and glycoprotein deficiencles in platelets isolated from two patients with the gray platelet syndrome. Blood 59, 709-718, 1982

11. Tracy, P.B., Glles, A.R., Mann, K.G., Eide, L.L., Hoogendoorn, H., Rivard, B.G.: Factor V (Quebec): A bleeding diathesis associated with a qualitative platelet factor $V$ deficlency. J. Clin. Invest. 74 , $1221-1228,1984$

12. Levy-Toledano, S., Caen, J.P., Breton-Gorius, J., Rendu, F., CywinerGolenzer, C., Dupuy, E., Legrand, X., Maclouf, J.: Gray platelet syndrome: alpha-granule deficlency. J.Lab.CIin.Med. 98, 831-848, 1981 
13. Soons, H., Janssen-Claessen, T., Hemker, H.C., Tans, G.: The effect of platelets in the activation of human blood coagulation factor $\mathbb{I X}$ by factor XIa. Blood in press (1986)

14. Bennet, J.S., Hoxie, J.A., Leitman, S.F., Vilatre, G., Cimes, D.B.: Inhibition of fibrinogen binding to stimulated human platelets by a monoclonal antibody. Proc. Nat1. Acad. Sci. U.S.A. 80, 2417-2421 (1983)

15. Bevers, E.M., Comfurius, P., Nieuwenhuis, H.K., Levy-Toledano, S., Enouf, J., Belluci, S*, Caen, J.P., Zwall, R.F.A.: Platellet protronbin converting activity in hereditary disorders of platelet function. British $J$. Haematol., in press (1986) 
CHAPTER IV

INHIBITION OF THROMBIN CATALYZED REACTIONS IN BLOOD COAGULATION AND PLATELEI ACTIVATION. Effect of heparin and low molecular weight heparins in the absence of antithrombin III.

\section{SUMMARY}

The antithrombin III-independent effect of heparin was studled in the following thrombin-catalyzed reactions: activation of purifled plasma factor $V$ and partially purified plasma factor VIII:C, generation of factor $V$ from the platelets and, in the presence of collagen, generation of platelet procoagulant activity. Three heparin fractions and a heparinold were compared to crude heparin. The inhibitory effect of hepacin (fractions) was quantlated by the concentration required to cause $50 \%$ inhibition of the initial rate of the thrombin-catalyzed reactons $\left(\mathrm{rC}_{50}\right)$.

Crude heparin was a more potent inhlbltor of these reactions than the fractions or the hepartinoid. The inhlbitory atcion of the heparing was found to be the result of a direct effect on thrombin and not of an effect elther on platelet activation functions or on the assembly or functioning of the prothrombinase complex. Probably this heparin inhibition is due to the masking of secondary macromolecular substrate binding gites on the thrombln molecule. We found no correlation between $I_{50}$ values and the antithrombin III-dependent, ant-thrombin spectfic activites of the heparing. This supports the notion what besides lts affinity for antithrombin III, heparin possesses additional functional properties that may contribute to its action In blood coagulation, as shown in the present study by the inhtbition of che positive feedback rantions catalyzed by thrombin.

\section{INTRODUCTION}

Heparin is an effective antithrombotic agent, widely used in the treatment and prophylaxis of venous thrombosis and thromboembolism. However, its clinical use is limited by its najor side effect, bleeding. For many years, it was generally assumed that both the antithrombotic and hemorrhagic 
propertles of heparin were related to its ability to augment the reactions between activated coagulation factors and antichromin IIL. More recently, numerous comparat1ve studies on the hemorrhaglc, antithrombotic and anticoagulant affects of heparinotds and low molecular weight heparin fractLons, prepared from crude hepartin by a variety of methods, indicate that: 1) low molecular weight heparins with an anti-factor $x_{a}$ to anti-thrombin ratio larger than that of crude heparin, have simllar antithrombotic activities but produce less hemorrhage (1), 2) The anti-factor $x_{\text {a }}$ activity of hepartin is not related to its antithrombotic activity $(2,3)$, 3) The excess low affinity material present in heparin with a low affinity to antithrombln III Increases hemorrhage, without having either in vivo antithrombotic or ex vilvo antlcoagulant activity (4) and 4) Dematan sulfate, known to potentiate only the activity of heparin cofactor II on thrombin, has an antithrombotic activity equal to that of crude heparin but leaves hemostasis largely unaffected (5).

These studtes lllustrate the difficulty in attempting to correlate in vitro assays and in vivo blood changes. It can be questioned whether one has ta search for other, more specific markers of the anti-thrombin effect of heparln, that could be elther an antithrombin III-dependent or Independent: effect. In this context it is important to note that coagulation and platelet reactions are strongly coupled by a positive feedback mechanism - because thrombin-induced platelet activation generates procaagulant activities. This thrombin-dependent mechanism leads to an 1mportant amplification of thrombin generation and so of both hemostatic plug and thrombus formation.

The present study was undertaken to determine to what extent heparin (tractions) Inhlbit the thrombin-dependent feedback reactions in factor VIII and factor $V$ activation, as well as in the formation of platelet procoagulant activities and to investigate whether heparin (fractions) exert such an ant-thrombln activity through a mechanism that is independeat of antithrombin IIT.

MATERIAL AND METHODS

Materia1s. S 2238 (H-D-Phe-Pip-Arg-pNa) was purchased from AB Kabi Diagnostica, Stockholm, Sweden. Fatty acid free human serum albumin (HSA), Russell's Vlper Venom and Echis Carinatus venom were obtained from Sigma. 
Horse tendon collagen was obtalned from Hormon-Chemie Minchen, Germany. It was added in the non-fibrillar form dissolved in acldic dilution buffer obtained from Hormon-Chemie. Reaction tubes were 2 mi plastic flat-bottom tubes obtained from Sterilin Ltd (Teddington, England). Teflon-coated magnetic spinning bars $7 \times 2 \mathrm{~mm}$ were from Bel-Art Products, USA. Phosphatidylcholine (18:1 cis/18:1 clis phosphatidylcholine) was from Sigma, USA. All reagents used were of the highest grade commercially avallable.

Preparation of Phospholipids and Phosphollpid Vesicles. Phosphatidylserine $(18: 1$ cis/18:1 cis) was prepared from phosphatidylcholine by enzymatic synthesis according to the method of comfurlus and zwal (6). Single bilayer vesicle solutions were prepared as previously described (7). Phospholipid concentrations were determined by phosphate analysis according to Böttcher et al. (8).

Proteins. Purification of factor VIII:C was performed by differential. polyethyleneglycol precipitation. Bovine prothrombin, factor $x$, factor $X_{a}$, factor $V$ and factor $V_{a}$ were purified according to established procedures (9). Human and bovine a-thrombin were prepared as described by pletcher et a1. (10). The spectfic clotting activity was $2,800 \mathrm{NIH} \mathrm{U} /$ mg for human thrombin and $2,200 \mathrm{NIH} \mathrm{U/mg} \mathrm{for} \mathrm{bovine} \mathrm{thrombin.} \mathrm{The} \mathrm{protein} \mathrm{preparations}$ were stored at $-70{ }^{\circ} \mathrm{C}$ after dialysis against $50 \mathrm{mM} \mathrm{Tris} / \mathrm{HCI}, 175 \mathrm{mM} \mathrm{NaCl} a t$ pH 7.9 .

protein Concentrations. Concentrations of thrombin and factor $x_{a}$ were determined by active site titration with p-nitrophenyl-p-guanidinobenzoate hydrochloride (11). Prothrombin concentrations were deternited after complete activation with $\mathbb{E}$.cartnatus venom followed by active site ticra tion. Similarly, factor $x$ concentrations were obtalned by active site titration after complete activation with factor X - converting protein from Russell's viper venom (11). Factor $v_{a}$ concentrations were determined by kinetic analysis (9).

Heparin and Heparin Fractions. Crude porcine Intestinal mucosal heparin (MW $1,500-30,000$, mean MW 15,000, anti- $x_{a}$ and anti-thrombin activity $175 \mathrm{U} / \mathrm{mg}$ ) was obtained from organon Laboratorles (OBs, the Netherlands). The following low wolecular weight compounds were prepared from standard heparin by Choay Institute (Paris): CY 216 was obtained by ethanol extraction (mean MW 4,500, USP activity $50 \mathrm{u} / \mathrm{mg}$, anti-X activity $200 \mathrm{U} / \mathrm{mg}$, anti-thrombin activity 10-20 $\mathrm{U} / \mathrm{mg}$ ) and CY 222 was obtained by nitrous actd depolymerization (mean MW 2,500, USP activity $25 \mathrm{~J} / \mathrm{mg}$, anti-Xa activity 250 $\mathrm{U} / \mathrm{mg}$, anti-thrombin activity 5-15 $\mathrm{U} / \mathrm{mg}$ ). Org 10172 , a sulphated mucopoly- 
saccharide was 1 solated by organon laboratorles from porcine intestinal mucosa (mean M 6.400, USP activity $2.94 \mathrm{U} / \mathrm{mg}$, anti-Xactivity $8 \mathrm{U} / \mathrm{mg}$, anti-thrombin activity $0.32 \mathrm{U} /$ ing $)$. We also used the fragnent $\mathbb{P K} 10169$ (Pharmika laboratories) obtalned by controlled depolymerization (mean Mw

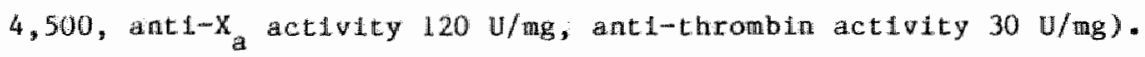

Isolation of Human Platelets. Blood was drawn by venepuncture from healthy volunteers who had not taken any medlcation for at least one week. As anticoagulant, one volume of acid citrate/dextrose $(0.18 \mathrm{M}$ glucose $/ 0.08 \mathrm{M}$ sodlum elitrate/0.052 citric acid) was added to 5 volumes of wholle blood. platelet-rich plasma was obtained after centrifuging at $220 \times \mathrm{xg}$ for 15 min. Platelets. were 1solated by centrifuglag at $600 \mathrm{xg}$ for $20 \mathrm{~min}$ and the pellet was resuspended in a Hepes buffer containing $136 \mathrm{mM} \mathrm{NaCl}, 2.68 \mathrm{mM} \mathrm{KCl}, 2 \mathrm{mM}$ $\mathrm{MgCl}_{2}, 10 \mathrm{mM}$ Hepes, $5 \mathrm{mM}$ glucose and $0.4 \% \mathrm{HSA}, \mathrm{pH} 6.7$. The platelets were washed. twice in this buffer by centrifuging at $350 \mathrm{xg}, 15 \mathrm{mln}$. Before centifuglng acid citrate/dextrose was added to the suspension ( 1 vol. to 14 vol.). Finally the platelecs were resuspended in the Hepes buffer, pH 7.5 containing $0.1 \%$ HSA. The entire procedure for platelet preparation took about $2 \mathrm{~h}$ and was carried out at room temperature $\left(22^{\circ} \mathrm{C}\right)$. Platelet concentration was determined with a Coulter counter. Platelets were kept at room temperature and no loss of platelet functions was found for at least. 15h. Partially purifled factor VIII:C activation. Partially purified factor VIII:C was activated by bovine thrombin in the following way: factor VIII:C $(20 \mu 1,27 \mathrm{u} / \mathrm{ml}$ ) was Incubated in $\mathbb{1} \mathrm{ml}$ Michaelis buffer containing $29 \mathrm{mM}$ sodiun barblturate, $29 \mathrm{mM}$ sodium acetate, $116 \mathrm{mM}$ Nacl $\mathrm{pH} 7.3$. The reaction was started with the addition of thrombin $(3 \mathrm{nM})$. Aliquots $(10 \mu 1)$ of factor VIII contalning aample were added to the clotting assay containing:

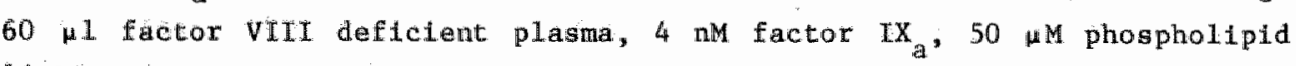
$[(25 \%$ phosphat1dylsertue (PS), $75 \%$ phosphatidylcholine (PC)] and 10 mM $\mathrm{CaCl}_{2}$. The clotting time was recorded on an automatic coagulometer. A calibration curve was constructed with normal pool plasma activated with 9 nM thrombin, in order to determine the amount of factor VIII present in the sample.

puxlfled plasma factor V activation. Bovine factor V (100 nM) was lncubated for $5 \mathrm{mln}$ at $37^{\circ} \mathrm{C}$ in the presence of $3 \mathrm{mM} \mathrm{CaCl} \mathrm{C}_{2}$. The reaction was started by the addition of thromblin (usually $0.5 \mathrm{nM}$ ). Aliquots were caken in time, diluted 1:1000 ti buffer containing $50 \mathrm{mM} \mathrm{Tris}, 175 \mathrm{mM} \mathrm{NaCl}$, $5 \mathrm{mM} \mathrm{CaCl} \mathrm{C}_{2}$, $0.5 \mathrm{mg} / \mathrm{ml}$ HSA, pH 7.9. Factor $\mathrm{V}_{\mathrm{a}}$ activity was measured by incubation of the allquots (usually 20 il) with factor $x_{a}\left(1.3 \times 10^{-11} \mathrm{M}\right.$ ), phospholipid 
containing $20 \%$ phosphatidylserine and $80 \%$ phosphatidylcholine $\left(1.0 \times 10^{-5} \mathrm{M}\right)$ and $\mathrm{CaCl}_{2}(10 \mathrm{mM})$ in a final volume of $0.225 \mathrm{ml}$ of the aforementaned buffer for $5 \mathrm{~min}$ at $37^{\circ} \mathrm{C}$ in a plastic cuvette. The reaction was initiated by the addition of $25 \mu \mathrm{l}$ of prothrombin $\left(2.0 \times 10^{-6} \mathrm{M}\right)$. After $2 \mathrm{~min}, 0.65 \mathrm{ml}$ of the same buffer containing 20 mM. EDTA and $0.24 \mu$ mol 52238 was added to the reaction mixture. The amount of thrombln formed was measured by the change in absorbance recorded on an Anlnco DW2 spectrophotomecer operating In the dual wave-length node $\left(\lambda_{s}=405 \mathrm{~nm}\right.$ and $\left.\lambda_{\mathrm{r}}=500 \mathrm{~mm}\right)$ thermostated at $37^{\circ} \mathrm{C}$. Standard curves were constructed by assaying diluclons of a bovine factor $V_{a}$ preparation whose concentration was decermined utilizing active site titrated factor $X_{a}(9)$. The assay had a functional range from $2 \times 10^{-14}$ $M$ to $1 \times 10^{-12} \mathrm{M}$ of factor $\mathrm{V}_{\mathrm{a}}$.

Determination of Platelet Factor V Release and Activation. $292 \mu 1$ of platelet suspension $\left(5.5 \times 10^{6} / \mathrm{ml}\right)$ were incubated with $13 \mu \mathrm{l}$ of $75 \mathrm{mM} \mathrm{CaCl} 2$ and stirred (350 revolutions/min) for $3 \mathrm{~min}$ at $37^{\circ} \mathrm{C}$ followed by the addithon of thrombin, resulting in a flual volume of 350 H. Subsequently, aliquots were taken and assayed for factor $v_{\text {a }}$ activity as described. Platelet Beta-Thromboglobulin Release. To a reaction tube contalndng $292 \mu 1$. of a platelet suspension $\left(5 \times 10^{7} / \mathrm{ml}\right), 13 \mu 1$ of $75 \mathrm{mM} \mathrm{CaCl}{ }_{2}$ was added. The tube content was stirred for $5 \mathrm{~min}$ at $37^{\circ} \mathrm{C}$ and platelet activation was started by addition of a platelet actiwator (thrombin or collagen) resulting in a final volume of $350 \mu 1$. After a variable time periode at $37{ }^{\circ} \mathrm{C}$, the release reaction was stopped by adding to the platelet suspension 56 il Hepes buffer contalning $135 \mathrm{mM}$ formaldehyde, $100 \mathrm{~m}$ EDTA, and bring $1 \mathrm{ng}$ it to a melting lce-bath (12). Platelets were centrlfuged for 1 min in an Eppendorf centrifuge $5412,200 \mu \mathrm{l}$ of the supernatant was carefully removed, to which $50 \mu 1$ of a $2 \mathrm{M}$ Tris solution was added to neutralize the excess oft formaldehyde. The sample was diluted $1: 3$ in Hepes buffer pH 7.5 contalning $20 \%$ of horse serum and the amount of $\beta$-thromboglobulin was measured ustng the radiolmmoassay kit from Amersham International Limited according to the instruction of the manufacturer.

Determination of Platelet Prothromin Converting Activity (PPCA) 292 시 of platelet suspenstion $\left(5 \times 10^{6} / \mathrm{ml}\right)$ ware incubated with 13 wl of $75 \mathrm{mM} \mathrm{CaCl}_{2}$ and stirred for 3 win at $37^{\circ} \mathrm{C}$. Platelet stimulation was started by adding thrombin or collagen plus thrombin resulteng in a final volume of 325 w and a $\mathrm{CaCl}_{2}$ concentration of $3 \mathrm{mM}$. After a variable time of stirring at 37 ${ }^{\circ} \mathrm{C}$ (i.e. platelet trigger time) the PPCA was deterinined as follows. 50 m factor $V_{a}(10 \mathrm{nM})$ and 50 sl factor $x_{a}(5 \mathrm{nM})$ were added to the triggered 
platelet suspension, to allow equilibration with the platelets. After 2 min period of preincubation, prothrombin activation was started with the addition of 751 of a prepared nixture contatning $6.6 \mu \mathrm{M}$ prothrombin and $27 \mathrm{mM}$

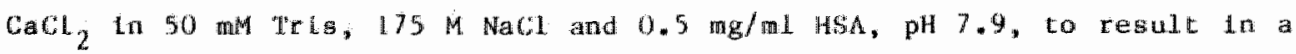
thal wolume of $0.5 \mathrm{~m}$. The final concentrations of the reactants were: 0.5 nM factor $x_{a}$, 1 aM factor $V_{a}$, $1 \mu M$ prothrombin and 6 mM CaC1 2 * After 30 and 60 allquots (usually 10 i) were taken from the reaction mixture to determitie the amount of thrombin formed.

Analysis of the Data. We assume that thrombin forms a complex with heparin and that such a complex has no enzymatic activity. The reversible association between heparin and thrombin 18 expressed as:

$[\mathrm{H}]+[\mathrm{ILa}] \stackrel{\mathrm{Ka}}{=}[\mathrm{H} . \mathrm{IIa}]$

$K_{\mathrm{d}}=[\mathrm{H}][\mathrm{ILa}] /[\mathrm{H} . \mathrm{LI} \mathrm{a}]$

where [H] is the free heparin concentration and [IIa] is the free thrombin concentration. Because heparin is present in excess over thrombin, [H] can be equaled to the total heparin concentration. Under conditions where the inftial rate of factor $V_{a}$ generation or PPCA generation $(v)$ are directly proportional to the free thrombin concentration:

$v=k[\mathrm{ILa}]=\mathrm{k}\left([\mathrm{ITa}]_{0}-[\mathrm{H} \cdot \mathrm{IIa}]\right)$

where [tIa] a the total thrombin concentration. From (2) and (3) we find:

$v /\left(v_{a}-v\right)=k_{d} /[H]$

where $v_{0}=k[I I a]_{0}$, is the intitial rate of factor $v_{a}$ or PPCA generation in the absence of heparin. A plot of $v /\left(v_{0}-v\right)$ versus the reciprocal heparin concentration gives a straight line with slope $\mathrm{K}_{\mathrm{d}}$. Since $\mathrm{K}_{\mathrm{d}}$ is the amount of heparin required to bind half the thrombin, the $\mathrm{k}_{\mathrm{d}}$ value can also be expressed as $\mathrm{IC}_{50}$, the amount of heparin causing $50 \% 1 \mathrm{inh}$ ittion. 
RESULTS

Effect of heparin on protein-phospholipid interaction. First of all we had to exclude any effect of heparin carried over into the assay mixtures. Because an effect of heparin on proteln-phosphollpid interaction has been reported (13) we had to assess whether or not this effect of heparin occurred under our experimental conditions. To this end we used protein1ipid equilibrium binding technique according to van de wart et all. (14). Factor $x_{a}(0.1 \mu M)$, factor $v_{a}(0.1 \mu M)$, or prothrombin $(0.05 \mu M)$ were incubated with large volume phospholipid vestcles (20\% PS - $80 \%$ PC, $25 \mu \mathrm{M}$ ) in $50 \mathrm{mM}$ Tris, $100 \mathrm{mM} \mathrm{NaCl}, \mathrm{pH} 7.5$ at $20^{\circ} \mathrm{C}$. After centrifugation for 30 min at $30,000 \mathrm{~g}$ at $20^{\circ} \mathrm{C}$ the concentrations of the bound protelns were estimated by determination of the remaining activity in the supernatant. Both crude heparin and PK 10169 at a final concentrations of $0.5 \mathrm{mg} / \mathrm{ml}$, could not displace factor $V_{a}$, factor $X_{a}$, or prothrombin from the phospholipid surface. The concentrations of bound protein in the presence and in the absence of heparin (fraction) were: $0.02 \mu \mathrm{M}, 0.10 \mu \mathrm{M}, 0.03 \mu \mathrm{M}$ for factor $\mathrm{X}_{\mathrm{a}}$, factor $\mathrm{V}_{\mathrm{a}}$ and prothrombin, respectively.

Effect of heparin on factor VIIIa assay. The effect of heparin on thrombin catalyzed factor VIrI activation was measured in a clotting assay ustng a factor VIII deficient plasma, therefore heparin was carried over and indeed influenced the clotting times. This problem was circumvented by making calibration curve for factor VIII formation in the presence of the same amounts of heparin as those that were carrled over. In that way heparin did not affect the relative changes occuring during the thrombln-catalyzed factor VIII activation.

Effect of heparin on prothrombinase activity. In all other studies we used a completely purifled system, in which no effect of heparin carried over into the assay was observed. This was demonstrated all follows: at a the the reaction of factor $V_{a}$ generation, or platelet prothrombln converting activicy generation reached completion, heparin was added inmediately before transferring a sample to the measuring system. No effect of heparin or heparin fractions at flnal concentrations of up to $0.5 \mathrm{mg} / \mathrm{m}$. was observed after a $10 \mathrm{~min}$ incubation, showing that the amount of factor $\mathrm{V}_{\mathrm{a}}$ activity or PPCA was Independent of the presence of heparin in the activation mixture (Table I). This demonstrates that heparin did not interfere with the assembly or the functioning of the prothrombinase complex. 
Table $I$ the effect of heparin on prothrombinase activity

Rate of thrombin formation

PPCA

Compound

(nM/min)

(

None

24.0

100

Heparin $\quad(0.64 \mathrm{mg} / \mathrm{ml})$

24.0

100

C) 216

( $1 \mathrm{mg} / \mathrm{ml}$ )

22.4

Cr 222

(1 $\mathrm{mg} / \mathrm{ml}$ )

23.4

96

Org 10172 ( $1 \mathrm{mg} / \mathrm{ml})$

26.3

108

Demonstration of the absence of antithrombin III in the platelet suspensions. In the reducions where platelets are involved, we had to rule out the presence of antithrombin III in the washed platelet preparations (15). This was done by incubation of washed platelet suspension $\left(10^{7} / \mathrm{m} 1\right)$ with $5 \mathrm{nM}$ thrombin in the presence of heparin (fractions) $(10 \mathrm{mg} / \mathrm{ml}$ ). After $20 \mathrm{~min}$, the amidolytic activity of thrombin appeared to be unaffected.

Effect of heparin (fractions) on thrombin-catalyzed plasma factor VIII activation. We used a semi-quantitative estimation of the effect of heparin on thrombin-catalyzed factor VIII activation. Activated factor VIII is the cofactor of factor $I X_{a}$ in the intrinsic factor $X$ activation reaction, whereas non-activated factor VIII has very little activity. In an assay where excess phospholipid is present, factor WIII activity is the rate limiting factor of the factor $x_{a}$ formation. Thus the inttial rate of factor VIII activation $2 s$ proportional to the rate of factor $x_{a}$ formation. In order to assess the effect of heparin on the thrombin-catalyzed factor VIII activation in a quantitative manner, it is fmportant to establish the dependency of the reaction on the thrombin concentration. This relationship ts shown in Figure 1. The rate of factor $x_{a}$ formation and thus the rate of factor VIII formation appeared to be linear wh the thrombin concentration up to 4 nM. From the data presented above we have chosen the following conditions to study the effect of heparin (fractions) on the thrombincatalyzed factor VICr activation reactlon. Thromblin ( $3 \mathrm{nM}$ ) was added to semi-purified factor VII preincubated with varying amounts of heparin. At timed intervals, samples were taken and assayed for factor VIII as described in Materials and Methods. 


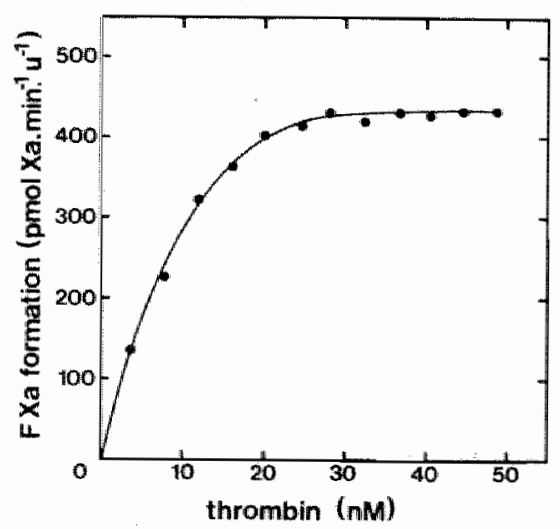

Eigura 1: Dependeney of Jactor Vin activation on thrombin consentration. Nornat plama to incubated at $37{ }^{\circ} \mathrm{C}$ with varying bovine thrombin conden trations for 15 sec. A sumple is brought to the factor $x$ activation miture containing phosphotiplda vesicles (25\% PS/75\% PC, $50 \mathrm{\mu M}$ ), $\mathrm{CaCl}_{2}(10 \mathrm{mM})$ and factom $\mathrm{Ix}_{\alpha}$ (4 $\mathrm{nM}$ ). The mate of factor $X$ activation is measured after 8 and $4 \mathrm{~min}$. Whe resutts are expressed as rate of Eactor $X_{a}$ formation per min, per whit

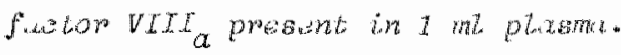

Figure 2 shows the time course of factor VIrI activation by thrombin ( 3 nM) in the absence and in the presence of varying amounts of unfractionated heparin. Heparin has an effect both on the initlal rate of factor VIII activation, and on the rate of inactivation of factor WIII. It was observed that the level of factor VIII after 4 min was 1 all cases lower in the absence than $\mathbb{1 n}$ the presence of heparin.

We estimated the effect on the initial rate of activation, af unfractionated heparin, PK 10169, and Org 10172 (Fig. 3). The $1 C_{50}$ walues were found to be $0.5 \mu \mathrm{g} / \mathrm{ml}, 1.75 \mu \mathrm{g} / \mathrm{ml}$ and $25 \mu \mathrm{g} / \mathrm{ml}$, respectively.

Effect of heparin (fractions) on thrombin-catalyzed plasma factor $V$ activation. Factor $v_{\text {a }}$ activity is determined by its potency to accelerate the rate of prothrombln activation. The non-activated factor $V$ has little effect on the rate of thrombin activation. However, the thrombin formed. during the assay is capable to activate factor $V$. We have to emphasize that even in the absence of factor $V$, prothrombin $\mathbb{H}$ s sowly converted to thrombin by the factor $x$-prothrombin complex. Figure 4 shows the activation of factor $W$ by thrombin formed during the assay. It 1 s apparent that all factor $V$ will be completely activated because the rate of thrombin formation becomes identical to the one observed in the presence of factor $\mathrm{V}_{\mathrm{a}}$. It also shows that the extent of factor $V$ activation increases 


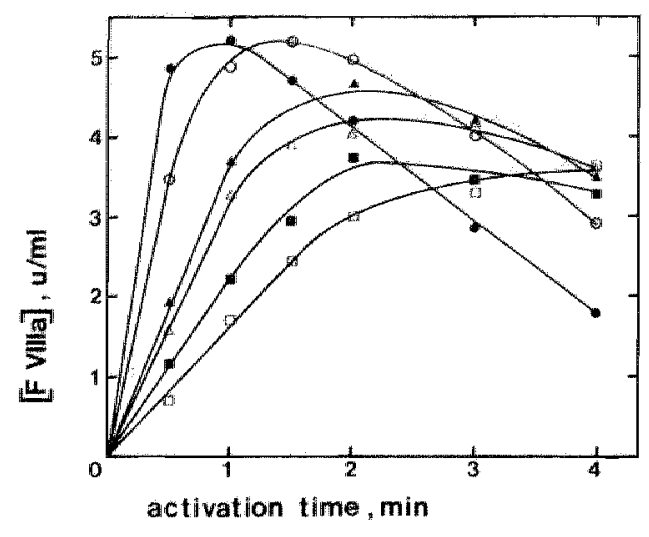

Eigure 2: Effect of unfrationated heparin on thrombin catalyzed factor VIII activation. Irolated factor WIII:C was incubated with thrombin ( 3 nM) and varying concentrations of heparin. ( $\bullet$ ), no heparin; (O) $0.14 \mu \mathrm{g} / \mathrm{ml} ;(\boldsymbol{\Lambda})$ $0.70 \mu \mathrm{g} / \mathrm{ml} ;(\Delta) 1.43 \mu \mathrm{g} / \mathrm{ml}$; (1) $2.8 \mu \mathrm{g} / \mathrm{ml} ;$ (口), $5.7 \mu \mathrm{\mu g} / \mathrm{mL}$. At timed intervals factor VIII containing bamples weme transferred to the assay. Factor VIII a was detemined by using a calibration curve eatablighed with nomat plasma as described in Experimentat Procedures.
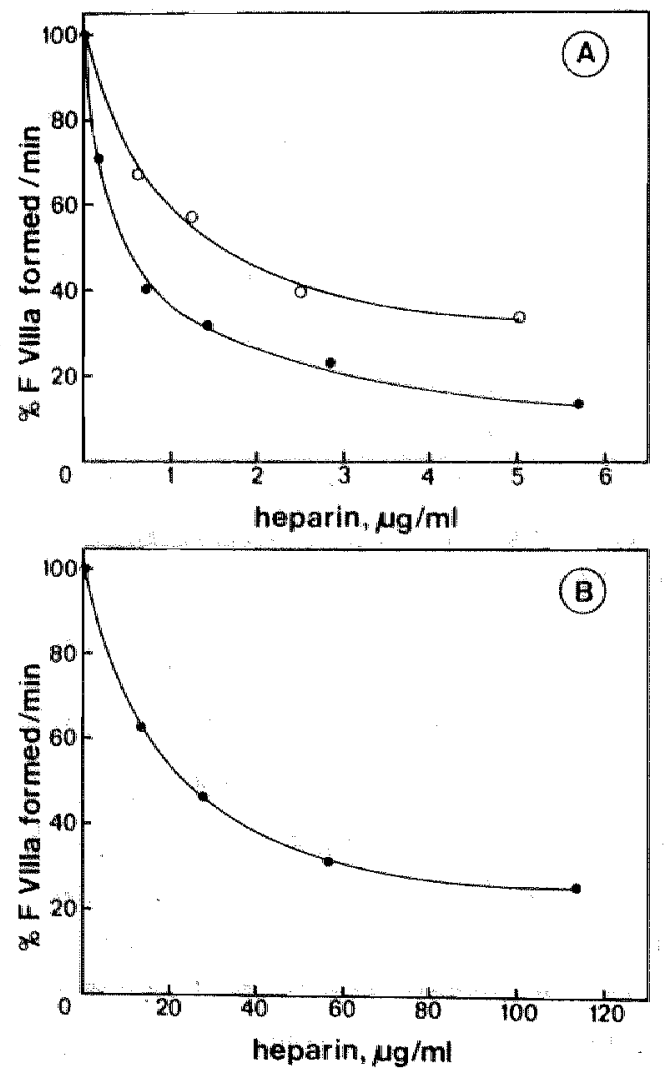

Figure 3: Effect of heparin (fractions) on the initiat rate of thrombin atalyzed factor VIII activation. Factor VIII:C was inaubated with thrombin, in the presence of varying amounts of heparin. The initial mate of factor VIII activation was measured at 30 sec as described in the legend to Fig 2. Panel $A$, (-) unfractionated heparin; (O) PK 10169; Panel $B$, Org 10172. 

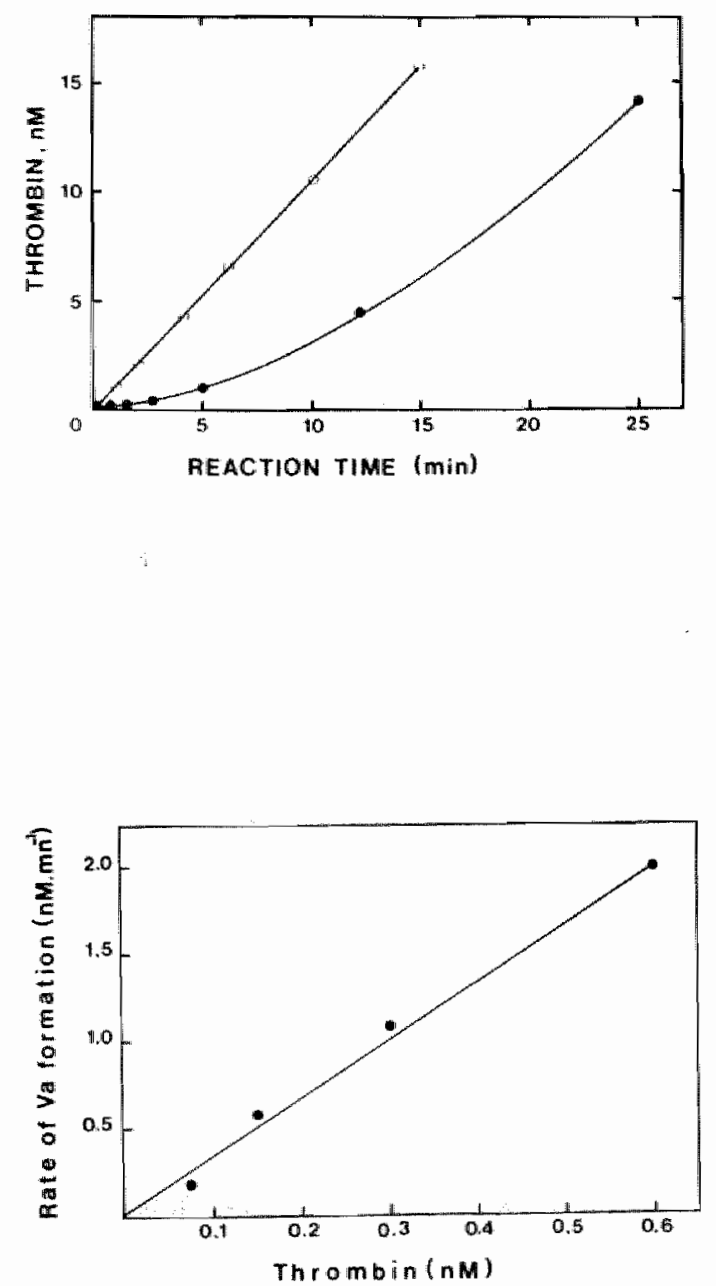

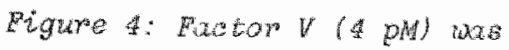
incubatad with factom $x_{a}$

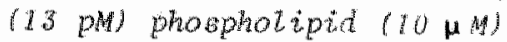
in 50 m Trats, 175 Mat, $10 \mathrm{mM} \mathrm{CuCL}_{2}, 0.5 \mathrm{mg}$ HSA/mi, pH 7.9 at $378^{0}$ for 5 min. Prothrombin lux added at $x$ funat concentration of 0.2 HM. The results are deptated by the closed circies. Open circles represent the time course during the reaction of prothrombin activation in the presence of $4 \mathrm{p}$ t $\mathrm{V}$.

Figure 5: Dependency of factor V activation on thrombin concentration. Purified bovine factor $V(100 \mathrm{nM})$ was incubated for 5 min at $37^{\circ} \mathrm{C}$ in a buffer containing $50 \mathrm{mM}$ Trie, 175 mM NaCt, $3 \mathrm{mM} \mathrm{CaCl} 2$ $0.5 \mathrm{mg}$ human exum albuthit/ml in the presence of varying thrombin concentrations. Pactor $v_{a}$ activity wa determ mined as desomibed in Experwmental procedures.

exponentially with the time. Under the conditions of prochrombin activation that we used in further experiments, the reaction was stopped after 2 in. It appeared that the factor $V$ activity is only $1.3 \%$ of factor $v_{\text {a }}$ activity. Before studying the effect of heparin, we had to find conditlons under which the rate of factor $V_{a}$ formation $1 \mathrm{~s}$ proportional to the thromblin concentration. Figure 5 shows that up to $0.6 \mathrm{aM}$ thrombin these conditions are met. We also studied the time course of factor $V$ formation and showed that up to 6 min the rate of factor $V_{a}$ formation was linear in time. 
Prom the data presented above se set the following experimental conditions to study the effect of heparin on the thrombin-catalyzed factor $V$ activation. Bovine factor $V(100 \mathrm{al})$ was incubated at $37^{\circ} \mathrm{C}$ with calcium ( 3 mM) and warying concentrations of heparin (fractions). The reaction was intitated by the addition of thrombin $(0.3 \mathrm{nM})$. After 6 min diluted samples were assayed for factor $V_{\text {al }}$ activity. The factor $V_{a}$ concentration, expressed as a percentage of the factor $V$ concentration found in the absence of heparin, was plotted as a function of heparin concentration (Fig. 6A). Determination of the $I_{50}$ values was performed by use of the double reciprocal plot as described in Material and Methods (Fig. 6B). It is clear that unfractionated heparin is a more effictent inhibitor ( $\mathrm{IC}_{50}=10 \mathrm{\mu g} / \mathrm{ml}$ ) than the fractions CY $216\left(\mathrm{IC}_{50}=25 \mu \mathrm{g} / \mathrm{ml}\right), \mathrm{CY} 222\left(\mathrm{IC}_{50}=25 \mu \mathrm{g} / \mathrm{ml}\right), \mathrm{PK}$ $10169(63 \mu \mathrm{g} / \mathrm{ml})$ or the heparinold org $10172\left(\mathrm{IC}_{50}=125 \mu \mathrm{g} / \mathrm{ml}\right)$. As strafght Ilnes were obtalned, golng through the origin, our assumption that the inhibition is caused by the formation of a heparin-thrombin complex, appears to be an acceptable minimal hypothesis.
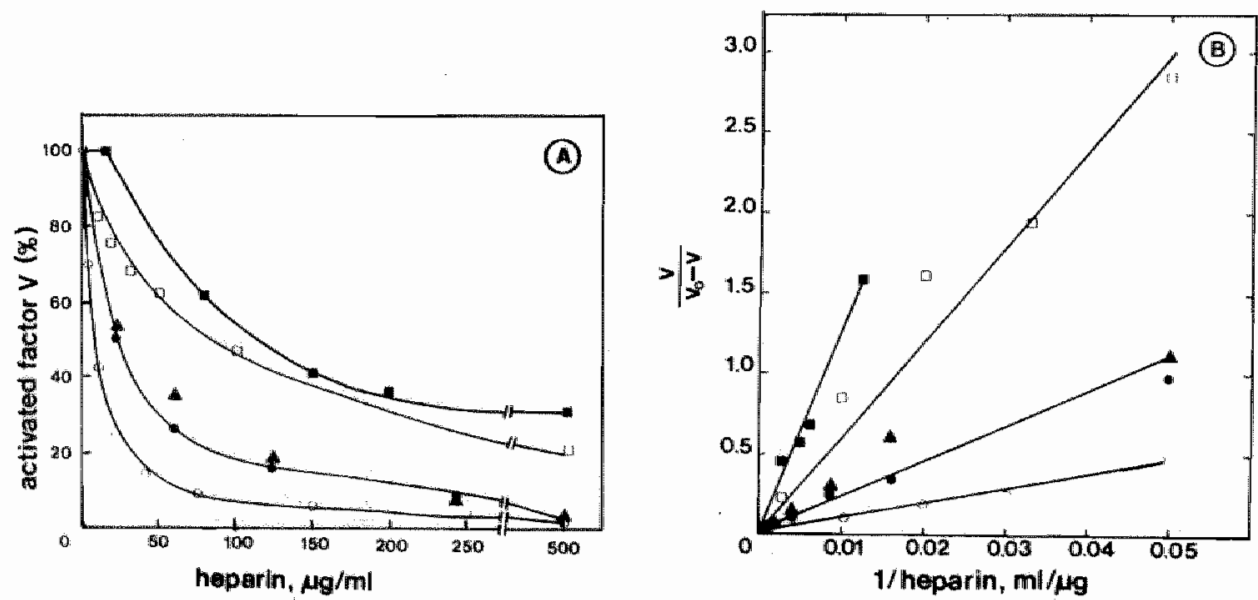

Fiture 6: Ejfeat of heparin on the initiat rute of thrombin-catalyzed factor $V$ activation: Factor $V(100 \mathrm{~m}$ ) was activated for 5 min by thrombin $(0.3 \mathrm{mM})$ in the presence of $\mathrm{CaCl}_{2}(3 \mathrm{mM})$ and varying concentrations of heparin. (O) crude heparin; ( ) CY 216; (4) CY 222; (D) PK 10169;

(D) Org 10172. A, percentage of residuat factor $V_{a}$ activity a a function of heparin concentrations. B, reptot of the data acoonding to equation (4) desamibed in the text. 

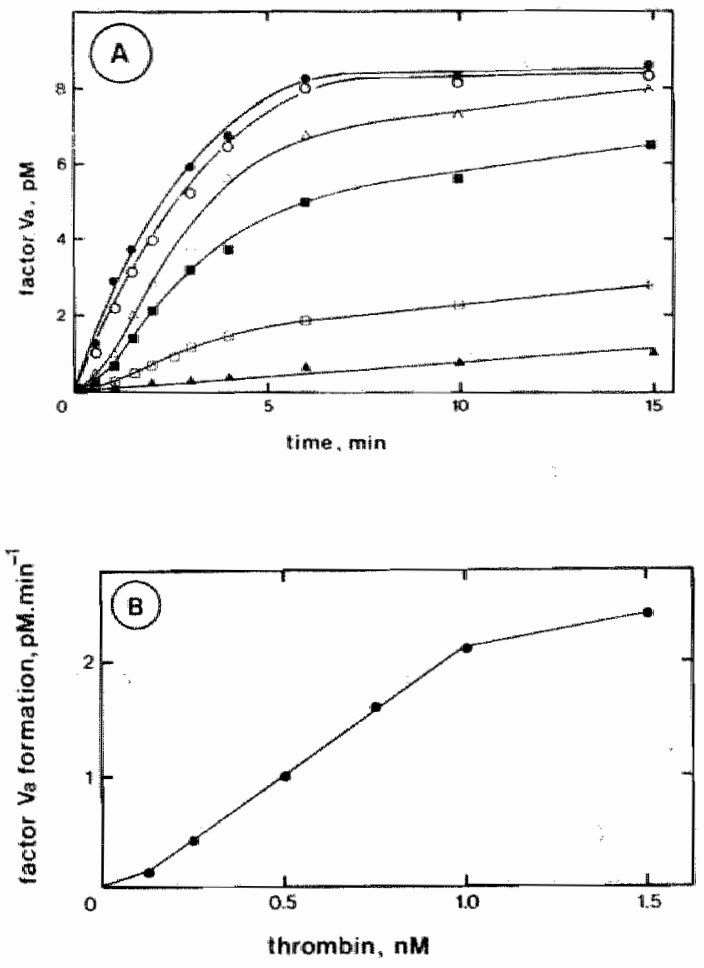

Eigure 7: Effect of varying thrombin conentrations on the time caurse of factor $V_{a}$ generation. A, platelets $\left(4.6 \times 10^{6} / \mathrm{ml}\right)$ were thoubated at $37{ }_{C}$ with varsing thrombin cancentrations:

(A) $0.125 \mathrm{~mW}$ (口) $0.25 \mathrm{~nm}$; (D) $0.5 \mathrm{~mm} ; \quad(\Delta) 0.75 \mathrm{~mm}$ (0) $1 \mathrm{~mm}$ : (०) $1.5 \mathrm{~m}$. $B$, reptot of the initiat rate of factor $v_{a}$ formation as a function of thrombin concentration.

In contrast with others (16), we found that heparin and heparin fractons up to $200 \mu \mathrm{g} / \mathrm{m} 1$ had no effect on the catalytic efflctency of thrombin on the chromogentc substrate $S 2238$ when the substrate concentration ls above or near the $k_{m}$ (data not shown). Thus, heparin alters the enzymatic activity of thrombin towards macromolecular substrates by interacting wh accessory binding sites, whereas it does not affect the active site for small synthetic peptide substrates.

Inhibition of platelet factor $V$ release and activation by heparin and heparin fractions. Factor $V$ is released from the a-granules as a profactor and activated after the release reaction when thrombin is presentt $(17,18)$. The initial rate of factor $V_{a}$ generation, after triggering the plateletg with thrombin, appeared to be proportional to the thrombin concentration up to $1.0 \mathrm{nM}$. The maximal amount of factor $V_{a}$ that could be generated was about $8.5 \mathrm{pM} / 4.6 \times 10^{6}$ platelets (Figure 7A). This is din accordance with the amount of platelet factor $V$ Tracy et a1. (19) reported by a bioassay in a suspension of Triton-lyzed platelets. 

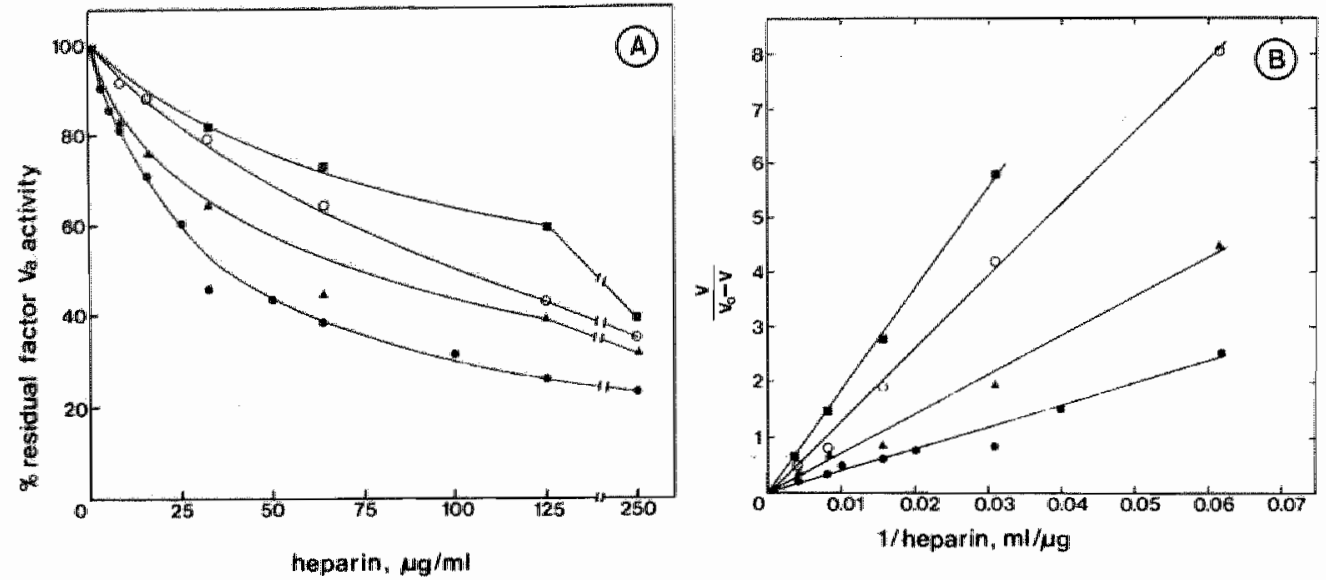

Figure 8: Effect of heparin (fractions) on thrombin inducud platelet fator $V_{a}$ genemation. platelete $\left(4.6^{6} \times 10^{6} / \mathrm{ml}\right)$ were stimed with 0.5 n human thrombin for $3 \mathrm{~min}$, in the presence of varying concentrations of heparin (1) $C Y 216$ (O), $C Y 222$ (4), or org 10172 (D). A, percentage of residual factor $V_{a}$ activity as a function of heparin concentrations. $B_{*}$ meplot of the data acconding to Equation 4 as described in Materials and Methods. $100 \%$ factor Va activity in the absence of heparin was 3 pM factor $V_{\alpha}(1 \mathrm{pM}$ $\left.V_{a} \cdot \min ^{-1}\right)$

To study the effects of heparin and heparin fractions on the initial rate of platelet factor $v_{a}$ generation, $4.6 \times 10^{6}$ platelets/ml were stimulated whth $0.5 \mathrm{nM}$ thrombin and the amount of factor $V_{\text {a }}$ formed was determined by assaylng samples taken 3 min after the addition of thrombin. It is important to note that under these conditions the rate of factor $V_{\text {a }}$ generation is proportional to the functional thrombin concentration (Figure 7B). The influence of varying amounts of crude heparin, $C Y 216, C Y 222$ and org 10172 on the initial rate of factor $v_{a}$ generation 1 s shown in Figure 8A. It is apparent that crude heparin is the most potent inhibitor. When the dita from Figure $8 \mathrm{~A}$ were replotted according to Equation 4 (see Materials and Methods) stralght lines were obtalned going through the origin (Figure 8B). The $I_{50}$ values, as estlmated from Figure $8 B$, are given in Table II.

If hum thrombin was replaced by bovine thrombin, the kinetics of bovine thrombin-1nduced platelet factor $V_{a}$ generation were found to be 1dentical to those reported herein for human thrombin (data not shown). However, the 
$I_{50}$ values for the different heparins are signiflcantly lower than those for human thrombin (Table III). This is in accordance with the higher affinity of heparin for bovine thrombin (20) and supports the idea that the heparins interact primarily with thrombin.

Effect of heparin on platelet beta-thromboglobulin release. In order to investigate if any interaction between platelets and heparin might result in an impaired release reaction, we studied the release of another pilatelet a-granule protein, B-thromboglobulin. Platelets(4.6 $\left.10^{7} / \mathrm{m} 1\right)$ were incubated with $10 \mu \mathrm{g}$ collagen/mil or with $0.5 \mathrm{~nm}$ thrombin elther in the absence or presence of crude heparin $(0.1 \mathrm{mg} / \mathrm{ml})$. When platelets were stimulated by collagen, heparin had no effect on the kinetics of $\beta$-thrombom globulin release, whereas heparin $(0.1 \mathrm{mg} / \mathrm{mi})$ diminished $\beta-t h r o m b o g l o b u l i n$ release to Less than $10 \%$ of the control value when thrombin was used to stimulate the platelets.

Effect of heparin and heparin fragments on the generation of platelet activity in prothrombin activation. Platelet prothrombin converting activity (PPCA) was measured under conditions where added factor $V_{a}$ exceeded greatly the amount of factor $V_{a}$ that is generated from platelets, so as to make the test independent of factor $V$ release. By omiting phospholipids from our assay, the rate of thrombin formation becomes proportional to the amount of procoagulant surface that was generated upon platelet stimulation. It has been shown that platelets activated by a combination of collagen plus thrombin form a more suitable catalytic surface for the prothrombinase complex than platelets wreated with thrombin alone $(21)$. Therefore, investigated the effect of heparins on human thrombin-pluscollagen-induced PPCA. Condftons had to be found where PPCA generation is

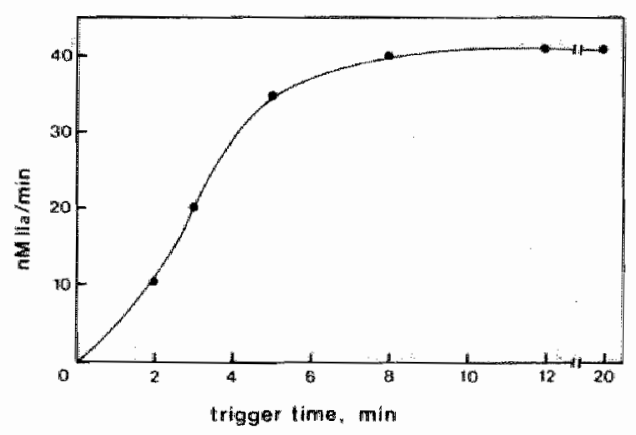

Figure 9: Time course of appearinos of PPCA. platelete (4.6) $\left.10^{6} / \mathrm{ml}\right)$ were incubated at $37^{\circ} \mathrm{C}$ with $0.3 \mathrm{rm}$ humoun thrombin and $5 \mu \mathrm{g} / \mathrm{ml}$ coltagen. At different trigger times, coagulation fartors $x_{\alpha}$, $v_{a}$ and prothrombin were added and thrombin formation was assayed as described in Materiat and Methods. 


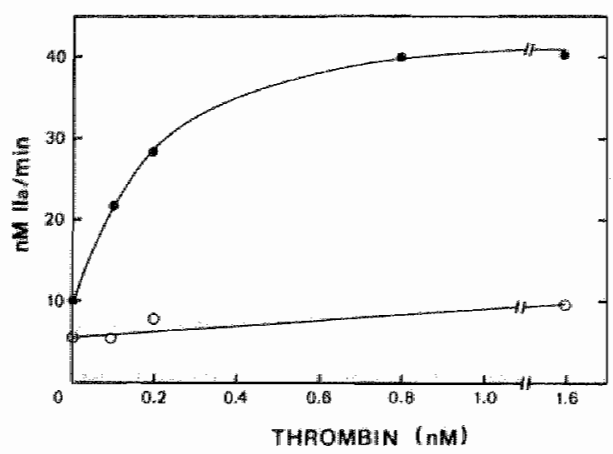

Pigure 10: PPCA generation as a function of human thrombin concentrations. Platelets $\left(4.6 \times 10^{6} / \mathrm{mL}\right)$ were triggered at $37^{\circ} \mathrm{C}$ for $5 \mathrm{~min}$ with vamying human thrombin concentrations in the abeence ( $\mathrm{O}$ ) or in the presence ( $)$ ) of $5 \mu \mathrm{g} / \mathrm{mL} \mathrm{col}$ Lagen. Thrombin formation was assayed ab desoribed in Matemial and Methode.

Table II The effect of heparin fractions on human thrombin-induced factor $V_{\text {a }}$ generation and human thrombin plus collagen-induced PPCA

Compound

Factor $V_{a}$ generation

$$
I_{50}(\mu \mathrm{g} / \mathrm{ml})
$$

PPCA

$\mathrm{IC}_{50}(\mu \mathrm{g} / \mathrm{ml})$
Heparin 40

CY 216

CY 222

org 10172
130
10

100

540

440

Inear in time and proportional to the thrombin concentration. The generation of a procoagulant surface was followed in time for platelets $\left(4.6 \times 10^{6} / \mathrm{ml}\right)$ stimulated with $0.3 \mathrm{nM}$ thrombin plus 5 Hg collagen/ml (Figure 9). The dependency of platelet activation on the thrombin concentration is shown In Figure 10, elther in the absence or presence of $5 \mu \mathrm{H}$ collagen/ml. As a standard procedure to study the effect of heparim, platelets were stimulated for $3 \mathrm{~min}$ with $0.3 \mathrm{nM}$ thrombin plus $5 \mu \mathrm{g}$ collagen/ml. Although collagen had to be added in order to potentiate the PPCA generating efficiency of low thrombin concentrations, it has to be mentioned that under these conditions the rate of PPCA generation is proportlonal to the thrombin concentration (Figure 10). 

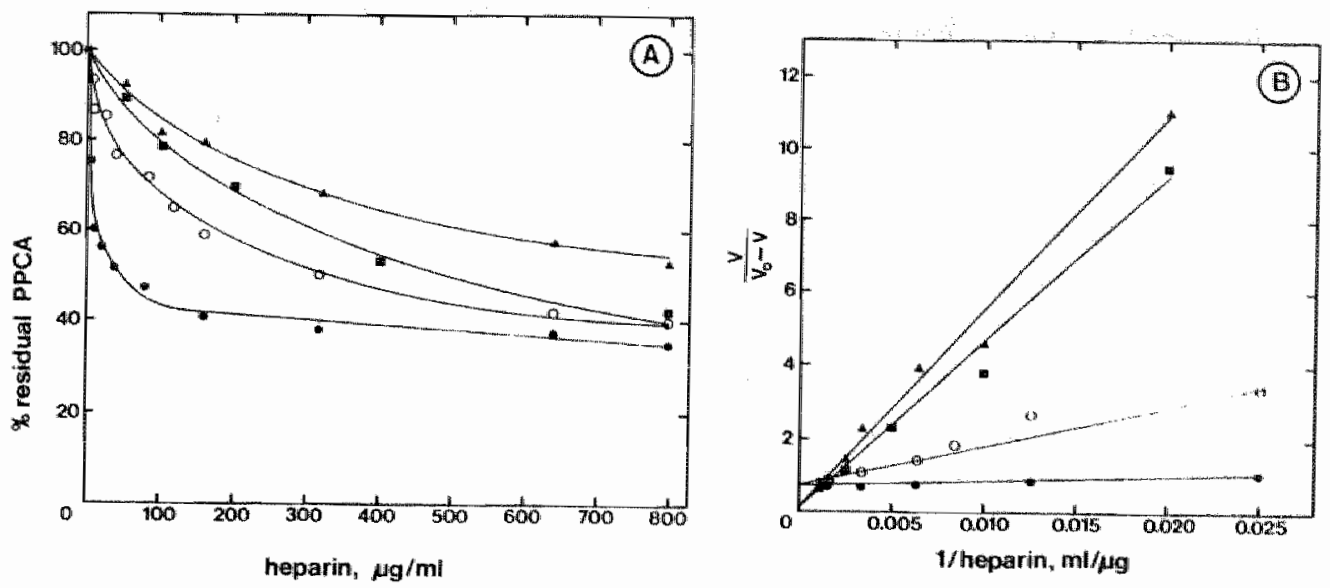

Figure 11: Effect of hepurinffrationsl on thrombin plis aotiogen-indued PPCA. PLatezets $\left(4.6 x 10^{6} \mathrm{mil}\right)$ were triggered $3 \mathrm{~min}$ with $0.3 \mathrm{~nm}$ humc thrombin and $5 \mu \mathrm{g}$ collagen/mL in the presence of varying concentrations of

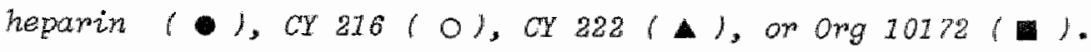
A. percentage of residul PPCA as a funation of heparin concentration. $B$, reptot of the data as deseribed in Matemans and Mothods. 100 " PPCA in the absence of heparin was $24 \mathrm{mM} I \mathrm{I}_{a} / \mathrm{min}$.

Figure 11 depicts the results of experiments where platelets $\left(4.6 \times 10^{6} / \mathrm{ml}\right)$ were lncubated for 3 min at $37^{\circ} \mathrm{C}$ with varying concentrations of crude heparin, $\mathrm{CY} 216, \mathrm{CY} 222$ or $0 \mathrm{rg} 10172$, followed by the stimulation of platelets during $3 \mathrm{~min}$ and measurement of platelet prothrombln converting activity. It is interesting to see that crude heparin is not able to block completely the generation of platelet prothrombin converting activity. Apparently, the remalning activity is equal to that generated by collagen in the absence of thrombin. Indeed, in a separate experiment we found that neither crude heparin nor heparin fragments were able to block the formation of collagen-induced PPCA. IC 50 values were deternined by allalyzing the data as described in Materials and Methods. The replot of the data from Figure $11 \mathrm{~A}$ according to Equation 4 is show in F1gure $11 \mathrm{~B}$. The incercept on the vertical axis represents the fraction of the PPCA activity generated by collagen alone. The $\mathbb{L C}_{50}$ values are $\mathbb{I i s t e d}$ in Table II. 
Human thrombin plus collagen acting on human platelets requires atore heparin or heparin fractions to attain 50\% inhibition of PPCA than bovine thrombtn does in the presence of collagen (Table III).

Table ill The effect of heparin fractions on bovine thrombin-induced platelet factor $V_{a}$ generation and bovine thrombin plus collageninduced PPCA

\begin{tabular}{lcc} 
Factor $v_{a}$ generation & PPCA \\
Compound & $\mathrm{LC}_{50}(\mu \mathrm{g} / \mathrm{mL})$ & $\mathrm{IC}_{50}(\mu \mathrm{g} / \mathrm{ml})$ \\
Heparin & 0.5 & 3.4 \\
CY 216 & 3.3 & 3.8 \\
CY 222 & 1.8 & 90.0 \\
Org 10172 & 15.0 & 125.0 \\
\hline
\end{tabular}

\section{DISCUSSION}

The heparin preparations that are in general use in antithrombotic therapy are extremely complex mixtures whth components that differ with respect to molecular weight, chemical composition, secondary structures as well as antithrombin. III affinity and other blological properties. It is not aurprising that, besides the well known antithrombin III-potentiating effect, many other inhibitory actions on the hemostatic system can be found. Crude heparin shows a marked anticoagulant and antithrombotic, but a1so a hemorrhage-Inducing effect. It was generally assumed that these three effects were intinately inked. More recently it has been shown that these three blological functions of crude heparin can to a large extent be dissoclated $(1-5)$. "This suggeats that different fractions of crude heparin might have different effects as to anticoagulation, antithrombotic action and increasing of hemorrhagle tendancies. This is extremely interesting and of great practical interest because, where antithrombotic action is pursued and hemorthage must be avolded, the therapeutic ratio between the two actions is always estimated on basis of anticoagulant action.

However, the relationshlp between in vitro kinetics as assessed by clotting assays and the antithrombotic action of heparin is far from beling 
understood. Although binding to antithrombin III plays an important role in the antithrombotic action of heparia, antithrombin low affinity heparin seems to contribute to the antithrombotic action of heparin (22).

A major question is therefore whether the favourable therapeutic ratio of low molecular weight heparins is related to their specific properties in antithrombin III-independent ant-thrombin activicy. The present study was undertaken to assess the effects of crude heparin, different heparin fractions and a heparinoid on the positive feedback reactions of thrombin, 1.t. plasida factor VII and factor V activation, and platelet activation, leading to the generation of platelet factor $v_{a}$ and, in the presence of collagen, to the platelet prothrombin converting activity.

The effect of heparin on the activation of factor VIIT results in lowering the initial rate of factor VIII formation as well as slowing down the rate of disappearance of factor VIIL. The Inactivation of factor VII a has been attributed either to a proteolytic action of chrombin (23) or a thrombinindependent inactivation (24). Therefore, the stabilizing effect of heparin on the factor VIII, could be due to an effect on thrombln and or factor $V i L L_{a}$.

It was recently shown in our laboratory that a highly sulphated polysaccharide, the pentosan polysulphate, exerts a strong inhibitory action on factor VILL formation by increasing the amount of residual non-activated factor VIII rather than by Inactivation of the formed factor VIII (25). The exact nature of the heparin action on either the activation of factor VILL or inactivation of factor VLII remalns to be determined. ofosu éc al. (26) Found that the inhibitory effect of heparin on factor $x$ activation by the phospholipld Eactor IX - factor VIIL(a) complexes, was markedly reduced when thrombin-activated factor VILl was used instead of non-activated factor VIII. Our findings, by a direct study of factor vill actuation, also suggest an effect of heparin on the chrombia-catalyzed activation of Eactor VILI.

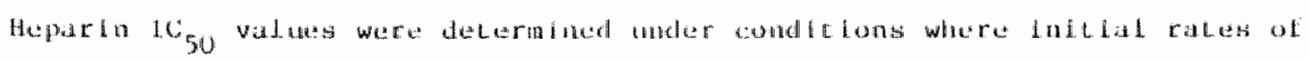
either plasma factor $v_{a}$, or platelet factor $v_{a}$, or PPCA generation, were proportional to the chrombin concentration. The assumpton was made that thrombin, when complexed with heparin, has no activily towards macromolecular substrates. Our experimental data appear co be consistent with that model (Figures $6 \mathrm{~B}, 8 \mathrm{~B}$ and $11 \mathrm{~B}$ ).

An interesting observation was the absence of effect of heparin (fractions) on the assembly and functioning of the prothrombinase complex at the outer 
membane of activated platelets (Table I). This seems to be in contrast with the findings of Walker et al. (13). They reported that heparin linhibled prothrombin activation by preventing the binding of activated clotting factors as well as prothrombin to phospholipid surface. When we performed equilibrlum binding studies according to Wan de Waart et a1. (14) we found that crude heparin $(0.5 \mathrm{mg} / \mathrm{ml})$ did not change the affinity of Eactor $V_{\text {a }}$ factor $x_{a}$ and prothrombin for phosphollpid as well as total phosphollpid-binding capacity.

Thrombin-1nduced platelet factor $v_{\text {a }}$ generation is the result of the release of non-activated factor $V$ followed by 1 ts activation by thrombin. Because our factor $V_{a}$ assay 19 virtually insenstelve for factor $v$, the tnhibitory action of hepartn on the release reaction could not be separated from its action on thrombin-catalyzed factor $V$ activation. However, we demonstrated that heparin did inhibit the thrombin-induced $\beta$-thromboglobulin release, whereas heparin did not inhiblt the collagen-induced $\beta$-thromboglobulin resecisi. "This supports the notion that heparin exerts its effect through a heparln-thrombin rather than through a heparin-platelet interaction.

As to the $I_{50}$ values measured for the different heparins in the reactions catalyzed by thrombin, it 15 obvious that for crude heparin relatively low $\mathrm{IC}_{50}$ values were found, compared to $\mathrm{CY} 216$, CY 222, PK 10169 and org 10172. Therefore, on a welght basis $(\mu \mathrm{g} / \mathrm{ml})$ crude heparin is a more potent inhlbitor of both factor $V_{a}$ and PPCA generation, and of factor $V$ and factor VIII activation. The inhibitory capacity of a heparin fraction on the thrombin-catyzed reactions is not always 1 accordance with its antithrombln III-dependent anti-thrombin speclfic activity (anti-II $\mathrm{U} / \mathrm{mg}$ ). Moreover when $\mathrm{IC}_{50}$ walues are glven in ant $1-\mathrm{II}_{\mathrm{a}} \mathrm{J} / \mathrm{ml}$, no correlation is found. This strongly suggests that, in studying the inhibitory action of heparin on thrombin, an antithrombin il-dependent effect can be distingulished from an Independent one.

As yat, we can only speculate about the occurrence in different heparin molecular spectes, of such differentlal anti-thrombin actions. It would be interesting to establish whether or not antithrombin III low affinity heparins have ant-thrombin activities in blood coagulation or platelet reactions as demonstrated in the present report. 


\section{REFEREMCES}

1. Carter, G.J., Kelton, J.G., Hirsh, J., Cerkus, A., Santos, A.V*, Gent, M." The relationship between the herarthagic and antithrombotic properties of low molecular weight heparin in rabbits. Blood 59, $1239-1245(1982)$

2. Thomas, D.P., Merton, R.E., Barrowcliffe, T.W., Thunberg, L., Lindahl, U.: Effects of heparin oligosaccharides with high afeinity for antithrombin III in experimental venous thrombosis. Thrombos. Hemostas. $47,244-248(1982)$

3. Holner, E., Mattson, C., NiIsson, S.: Anticoagulant and antithronbotic effects of heparin and low molecular weight heparin fragments in rabbits. Thromb.Res. 25, 475-485 (1982)

4. Ockelford, P., Carter, C.J., Cerskus, A., Smith, C.A., Hirsh, J.: Comparison of the in vivo hemorrhagic and antithrombotic effects of a low antithrombLn III affinity heparin fractions. Thromb.Res. 27 , $679-690(1982)$

5. Hirsh, J.: Heparin anduced bleeding. Nouv.Rev.Fr.Haemato1. 26, 261-266 (1984)

6. Comfurius, P., Zwaal, R.F.A.: The enzymatic synthesis of phophatidyl-serine and purification by CM-cellulose colum chromatography. BLochin. Blophys.Acta 483, 36-42 (1977)

7. Rosing, J., Tans, G., Govers-Riemslag, J.W.P., Zwaal, R.F.A., Hemker, H.C.: The role of phospholipids and factor Va in the prothrombinase complex. J.Biol. Chen. 255, 274-283 (1980)

8. Bötcher, C.J.F., van Gent, C.M., Prels, C.A.: Rapld and Sensitive sub-micro phosphorus determination. Anal. Chem.Acta 24, 203-207 (1961)

9. Lindhout, T., Covers-Riemslag, J.W.P., van de Waart, P., Rosing, J., Hemker H.C.: Factor Wa - factor Xa interaction. Effects of phospholipid vesicles of varying composition. Biochemistry $21,5494-5502$ (1982)

10. pletcher, G.H., Nelsestuen, G.L.: The rate determining step of the heparin-catalyzed antithrombin-thrombin reaction is independent of thrombin. J.Biol.Chem. 257, 5342-5345 (1982)

11. Wan Dieijen, G., Tans, G., Roslng, J., Henker, H.C.: The role of phospholipld and factor VIIIa in the activation of bovine factor X. J. BLol. Chem. $256,3433-3.442(1981)$

12. Akkerman, J.W.W., Gorter, G., Kloprogge, E.: Kinetic analysis of a-granule secretion by platelets; a methodological report. Thromb. Ras. $27,59-64(1982)$

13. Walker, F.J., Esmon, C.T.: Interactions between heparin and factor Xa. Inhibition of prothrombtr activation. Blochim. Blophys. Acta 585, 405-4.5 (1979)

14. Van de Waart, P., Bruls, H., Hemker, H.C., Lindhout, T.: Interaction of bovine blood clotting factor $V a$ and 1 tis suburits oth phospholipld vesicles. Biochemistry 22, $2427-2432$ (1983)

15. Kim, B.K., Steiner, M., Baldini, M.G.: Antthrombin III blnds to human platelets. Biochlm.Blophys.Res.Commun. 97, 1227-1232 (1980)

16. Griffith, M.S., Kingdon, H.S., Lundblad, R.L." The interaction of heparin with human alpha-thromin: effect on the hydrolysis of anfline tripeptide substrates. Arch.Bloch.Bioph. 195, 278-384 (1979)

17. Chesney, C.M., Pifer, D., Colman, R.W.: Subcellular localization and secretion of factor $V$ from human platelets. Proc. Nat.Acad.Scl. 78 , $5180-5184(1981)$

18. Kane, W.H., Lindhout, T., Jackson, C.M. "Majerus, P.W.: Factor Va dependent binding of factor Xa to human platelets. J.Blol. Chem. 255, $1170-1174$ (1980) 
19. Tracy, P.B., Giles, A.R., Mann, K.G., Elde, L.L., Hoogendoorn, H., Rivard, G.E.: Factor V (Quebec): A bleeding diathesis assoclated with a qualltative platelet factor $V$ deficiency. J.Clin. Invest. 74, 1221-1228 (1984)

20. Denson, K.W.E.: The sensitivity of human and bovine thrombin to heparin in plasma. Thromb. Res. $23,207-213$ (1981)

21. Bevers, E.M., Confurius, F., van Rijn, J.L.M., Hemker, H.C., Zwal, R.F.A.: Generation of prothrombln converting activity and the exposure of phosphatidylserine at the outer surface of platelets. Eur.J.Blochem. $122,429-436(1982)$

22. Merton, R.E., Thomas, D.P., Havercroft, S.J., Barroweliffe, T.W., Lindahl, 0.: High and low affinity heparin compared with unfractionated heparin as antithrombotic drugs. Thrombos. Hemostas. 51, 254-256 (1984)

23. Fulcher, C.A.* Roberts, J.R., ZImmerman, T.S.: Thrombin proteolysis of purified factor VII procoagulant protein: correlation of activation with generation of a specifle polypeptide. Blood 61, 807-811 (1983)

24. Hultin, M.B., Jesty, J.: The activation and inactivation of human factor VIII by thrombin. Effect of inhibitors of thrombin. Blood 54 , $476-482(1981)$

25. Wagenvoord, R., Hendrix, H., Sorla, C., Hemker, H.C.: Determination of the non-antithrombin ILI dependent inhibitor site of pentosan polysulphate in the blood coagulation. Thrombos. Haemostas. in press (1986)

26. Ofosu, F.A., Blajchman, M.A., Hirsch, J.: The inhibition by heparin of the Intrinsic pathway activation of factor $X$ in the absence af antithrombin ITI. Thromb. Res. 20, 391-403 (1980) 
CHAPTER $V$

THE ROLE OF HEPARIN CHARGE DENSITY IN THE ANTYTHROMBIN III-DEPENDENI AND ANTTTHROMBIN III-INDEPENDENT INACTIVATION OF THROMB IN

\section{SUMMARY}

We have previously demonstrated that, in the absence of antithrombin III, unfractionated heparin iahibits the activation of platelets and factor $V$ by thrombin. Two low molecular welght heparin fractions and a heparinoid were less effective [Baruch et al. (1985) Thromb. Res. 38, 447-458]. Lt appeared that this inhibitory effect of heparin is the result of the formation of a heparin-thrombin complex.

In the present study we evaluated, the thrombin-binding propertien of heparin fractions with different charge density, obtained by fon-exchange chronatography on DEAE-Sephacel and a heparin fraction with very low affinity for antithrombin III obtained by affinity chronatography on antithrombin III-Sepharose. We found that the later heparin fraction was not able to inhibit the thrombin-catalyzed platelet factor v formation. In addition, this fraction could not compete with unfactionated heparin for thrombin binding. The fractions with different charge density were able to bind to thrombin. This was shown by their inhibitory effect in the absence of antithrombin III on thrombin-catalyzed platelet factor $v$ formation and by the ability of active-site-blocked thrombin to prevent the hepariu (fraction)-dependent inhibition of thrombin by antithrombin IIT. The

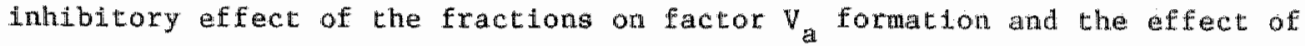
active-site-blocked thrombin Increased with the Increase in charge densty. However, these fractions not only differed in charge denglty but also in their content of antithromin III binding species. That is, the increase in clyarge density was found to go along with an increase in antithrombin ITt high affinity material.

In addition, we established that when the heparin fraction with the lowest charge density and very low in antithrombin III binding material was chemically modifled so as to achieve a higher charge densty, it obtained a 
higher affinity for thrombin but could not compete with the native fraction for binding to thrombin in the presence of antlthrombin LIL. It is apparent from our study that the int ithrombin IL-independent lahbition of thrombin by hepatin la the result of a heparin-thrombin interaction and depends on the charge denstiy of the polysaccharide. But this particular property of heparin 10 found cogether with the presence of a specific antithrombin III-binding domain. This indicates that unfractionated heparin does not contain a fraction that has an antithrombin IrI-independent inhibitory action on thrombin without having an antithrombin III-dependent one. Besides that, we demonstrated that when heparin is fractionated by charge density, the specific activities of the fractions in the thrombinantithrombin III reaction are the same when the concentration of antithrombin III bluding sites is taken into account.

\section{INTRODUCTION}

Heparin is a complex mixture of negatively charged glycosaminoglycans. Fractionation of heparin has led to the recognition of different functional binding domalins. A defined sequence of an actasaccharide has been lidentified to contaln the antithrombin III-binding domain $(1,2)$. The binding of thrombin to heparin has been shown to be an essential feature in the catalytic function of heparin on the inactivation of thrombin by antithrombin III. By using covalently bound heparin-antithrombin III complexes, Hoylaerts et a1. (3) demonstrated that the dissoclation constant of thrombin binding to these complexes decrased three orders of magnitude with Increasing the woleculat wetight of heparin from 3,200 to 15,000 . Theyr concluded that the binding of thrombin and heparin involved electrostatic interactions and that thrombin diffuses along the heparin chain to interact with antithrombin IIL bound to the same heparin chatn. As yet, no defined sequence has been found for a thrombla-bind limg domaln.

The wajor difficulty in studies on the structure-function relationship of heparin is to isolate by a fractionation technique one structural variable at time. Hurst et al. (4) showed that fractionation of heparin according to Its charge density followed by a further fractionation by affinity chromatography on antithrombin III-Sepharose offers a way to functionally 
Lsolate the effects of the protease-binding properties of heparin from the effects of the antithrombin III-binding properties. In addition, Hewck et a1. (5) could demonstrate that heparin acts on the antithrombin III-thrombin reaction through cooperative electrostatic binding to thrombin and nonelectrostatic interaction with antithrombin IIT.

We have previously investigated the antithrombin LII-ladependent effect of heparin on the thrombin-catalyzed reactions of platelet activation. Unfractionated heparin appeared to be a wore potent inhibitor of these reactions than two low molecular weight heparing fractions obtalned by ethanol extraction or depolymerization and a heparinoid (6). This effect was attributed to a direct action on thrombin resulting in the making of its secondary substrate binding sites by heparin.

The work presented here was initiated to establish whether and to what extent the antithrombin III-independent action of heparin on the Lnhibition of thrombin is a function of its charge denstty. Our second aim was to establish whether or not heparin species lacking the antiturombin III binding domain were able to inhibit the activity of thrombin towards nacromolecular substrates.

To this end we studied platelet activation by thrombin in the presence of heparin fractions obtained by Ion-exchange chromatography according to Sache et al. (7) and a heparin fraction with a very low affinity to antithrombin III obtained by affinity chromatography of unfractionated heparin on antithrombin ILI-Sepharose.

\section{MATERTAL AND METHODS}

Materials. HD Phenylanaly1-L-plpecoly1-L-arginine-p-nitroanilide hydrochloride (S 2238) was purchased from AB Kabi Diagnostica, Stockholm, Sweden. Fatcy acid free human serum albumin and dioleoyl phosphatidylcholine were obtalned from Sigma, USA. D-phenyl-alanyl-prolyl-arglnyl chloromethylketone (PPACK) was from Calblochem, La Jolla, USA. ALl reagents used were of the highest grade commercially avallable.

Preparation of phospholipids and phospholipid vesicles. Phosphatidylserine (18:1cis/18:Lcis) was prepared. from phosphatidylcholine by enzymatlc synthesis according to the method of Comfurius and zwal (8). Single bllayer 
vesicle solutions were prepared as previously described (9). Phospholipid concentrations were determined by phosphate analysis according to Bottcher et al (10).

protelins. Bovine prothrombin, factor $x_{a}$ and factor $v_{a}$ were purified according to established procedures (11). Bovine and human thrombin were prepared as previously reported (6). Bowine antithrombin III was prepared according to thalex and schmer (12).

Protein concentrations. Concentrations of thrombin, factor $x_{a}$ and prothrombin were determined as reported earller (13). Factor $V_{a}$ concentrations were decermined by kinetlc analysis (11). The molar concentration of bovine antithrombin III was calculated using $\mathrm{E}_{280}^{1 \%}=6.0$ and $\mathrm{M}_{\mathrm{r}}=56,600$ (14). Isolation of human platelets. Human platelets were isolated by differential centrifugation as described earifer (15). Platelets were kept at room temperature in a buffer containing $136 \mathrm{mM} \mathrm{NaCl}, 2.68 \mathrm{mM} \mathrm{KCl}, 2 \mathrm{mM} \mathrm{MgCl} 2,10$ miM Hepes, $5 \mathrm{mM}$ glucose and $0.1 \%$ fatty acid free human serum albumin, pH 7.5. No loss of placelet activity was found for int least 15 hours. platelet concentrations were determined with a coulter counter.

Heparinfractlons. Porcine mucosal sodiun heparin was fractionated by lon-exchange chromatography on DEAE-Sephacel with increasing salt molarities. The four fractions obtalied, corresponding to the fractions $A$, B, C, and D described by Sache et al. (7), as well as an extra-sulfated fraction A (fraction $A^{S}$ ) were a kind gltt from Choay Institute (Paris). High affinity and low affinity fractions were obtalned from crude hepartn by chromatography on an antithrombin III-Sepharose column. They were a kind glfe from Pharmuka Laboratorieb (Parls).

Fluorescence studies. Fluorescence measurements were made in the ratio mode using an SLM/Aminco SPF-500C spectrofluorometer. Titrations of antithronbin III with heparin were performed at $25^{\circ} \mathrm{C}$ using $\lambda_{\mathrm{ex}} 285 \mathrm{~nm}$ and $\lambda_{\text {en }} 345 \mathrm{~mm}$. The excltation and emission bandpasses were set at 2 and 4 nu respectively. We used a buffer containing $0.05 \mathrm{M}$, Tris $0.03 \mathrm{M}$ NaCl, pH 7.5. The ant thrombla $\mathrm{ITI}$ concentration used was $1 \mu \mathrm{M}$, a value far above the dissociaton constants of the heparin-antithrombin III complexes. The fluorescence increase resulting from the heparin-antithrombin interaction was calculated $a b\left(F-F_{0}\right) /\left(F_{\max }-F_{0}\right)$ where $F$ is the fluorescence intensity of the sample containing heparin, F $F_{\text {max }}$ that of the sample containing saturating heparin concentration, and $F_{0}$ that of the control solution without heparin (16). 
This ratio represents the fraction of antithrombin III-bound heparin over the maximal antichrombin III-bound hepardn and was plotted agatnst the heparin comcentration. It was used to determine the amount of antithrombin III high affinity material present in the heparin fractions as described by Nordenmann et al. (17).

Neutralization of chrombin activity by antithrombin III. Purified bovine thrombin $(10 \mathrm{nM})$ was added to ant 1 thrombin III $(100 \mathrm{n} / \mathrm{M})$ and varying amounts of heparin in $50 \mathrm{mM}$ Tris, $175 \mathrm{mM} \mathrm{NaCl}, 0.5 \mathrm{mg} / \mathrm{ml}$ human serura albumin, pH 7.9 at $37^{\circ}$ C. At intervals allquots were removed and brought 1 nto $1 \mathrm{ml}$ cuvette containing $\mathbb{I} \mathrm{mg} / \mathrm{ml}$ Pollybrene in the Tris-NaCl buffer and were assayed for residual thrombin activity by using the synthetic substrate S2238 ( $0.24 \mu$ mol). The amount of residual thrombin was measured by the change in absorbance recorded on an Aninco DW2 spectrophotoneter in the dual wavellength mode $\left(\lambda_{\mathrm{s}}=405 \mathrm{~mm}\right.$ and $\left.\lambda_{\mathrm{r}}=500 \mathrm{~nm}\right)$ thermostated at $37^{\circ} \mathrm{C}$. Pseudo-flrst order rate constants of inhibition of thrombin (k) were calculated from an exponential plot of residual thrombin concentrations versus time.

Inhibition by active site blocked thrombin. PPACK-thrombin was prepared by incubating purffied bovine thrombin $(8 \mu \mathrm{M})$ with PPACK ( $1 \mathrm{mM})$ in $50 \mathrm{mM}$ Tris-HC1, $175 \mathrm{mM} \mathrm{NaCI}, \mathrm{pH} 7.9$ at $37^{\circ} \mathrm{C}$ until no amidolytic activity was measurable. The solution was extensively dialyzed agalast the aforementioned buffer. Pseudo-first order rate constants of inhibition of thrombin were determined at fixed heparin concentration elther in the absence or in the presence of varying PPACK-thrombin concentrations. Determination of platelet factor Va generation. Washed platelet suspenstons were ineubated in the presence of varying heparin concentrations priot to activation with human thrombin $(0.5 \mathrm{nM})$. After 2 and 10 min aliquots were taken and assayed for factor $V_{a}$ activity and the amount of heparin causlng $50 \%$ inhibition of the reaction $\left(\mathrm{IC}_{50}\right.$ value) was calculated from double reciprocal plot as previously described (6).

\section{RESULTS AND DLSCUSSION}

Characterization of heparin fractions obtalned by 1on-exchange chromatography. The physico-chemical properties and the anticoagulant activities of the four heparin fractions $A, B, C$ and $D$, obtatned by fon-exchange 
Table I: Characteristics of heparin fractions obtained by fon-exchange chronatography on DEAE-Sephace ${ }^{\text {a }}$.

\begin{tabular}{|c|c|c|c|c|c|}
\hline \multirow[t]{2}{*}{ Properties } & \multirow[t]{2}{*}{$\mathbb{U R}^{\mathrm{b}}$} & \multicolumn{4}{|c|}{ Heparin fractions } \\
\hline & & $A$ & $\mathrm{~B}$ & $\mathrm{c}$ & $D$ \\
\hline Molecular welght & 17,300 & 7,300 & 13,200 & 17,300 & 20,300 \\
\hline Elurion position $(\mathrm{M} \mathrm{NaCl})$ & - & 0.55 & 0.65 & 0.75 & 0.85 \\
\hline Fraction weight (mg) & 1000 & 43 & 476 & 1174 & 158 \\
\hline TLEId ${ }^{c}$ & 1 & 0.10 & 0.62 & 0.17 & 0.13 \\
\hline Charge density $\left(z^{2}\right)$ & 10.96 & 6.81 & 9.67 & 10.56 & 11.02 \\
\hline \multicolumn{6}{|l|}{ Antithrombin activity } \\
\hline$(u / \operatorname{mg})$ & 304 & 4 & 133 & 396 & 538 \\
\hline$\%$ High affinity AP III & 52 & 23 & 43 & 86 & 100 \\
\hline \% High affindty AT CII & 50 & 7 & 40 & 88 & 182 \\
\hline
\end{tabular}

\footnotetext{
a Data taken from sache et al. (7)

b UFT, unfractionated heparin

c Moles of fraction/moles of heparin applied on the column

d

This study
}

chromatography eluted with increasing salt molaritles were taken from sache et al. (7) and 1isted in Table I. The fractions exhibited respectively negligible, intermediate, high and very high activities in the antithrombin III-dependent inactivation of factor $x_{a}$ and thrombin in plasma. Based on the data of sache et al. (7) on uronic acid content (UA) and sulfate content $\left(\mathrm{SO}_{4}\right)$ of the different fractions, we calculated the anionic density (z) from $z=1+\left(\mathrm{SO}_{4} / \mathrm{UA}\right)$ as described by Hurst et a 1 . (18). The $\mathrm{z}^{2}$ values are listed in Table $I$. It is worth noting that only the charge density of fraction A differs markedly from that of the other fractions and unfractonated heparin. When the amount of each fraction is calculated as the percentage of the total amount of heparin applied on the DEAE-Sephacel columa from the average molecular welght and the mass (mg) recovered in each fraction, it is clear that the heparin species with low anionic 
density only contributes to a small extent of the total amount of heparin (Table I). Moreover, it is evident that the low anionic density species are found in heparin fractions with rather low molecular weight (less than $13,000)$.

It has been assumed that the probability to find an anththromin IIIbinding sequence on the heparin chain increases with the chain length of the heparin molecule (19). Indeed, from the data of sache et al. (7) 1t can be concluded that the proportion of antithromin III high affinity material that was found to bind to immobilized antithrombin IIt increased with the Increase in average molecular weight of the heparin fraction. Bectuse the concentration of antithrombin III-binding sites on heparin can be more accurately determined by the heparin-dependent increase in the intrinsic fluorescence of antithrombIn $I I \mathbb{I}$ ( 17$)$, we performed such experiments in the presence of 1 MM antithrombin III. The arount of antithrombin III high affinity material present in each fraction as a percentage of the total heparin moliar concuntration is also listed in Table $I$. It is chenrly shown that with respect to fraction $A$ and $D$, our data differ markedly from the values reported by Sache et al. (7). Whereas fraction A contains one binding site for antithrombin III per 14 molecules of heparin, fraction $D$ contains almost two antithrombin IIJ-binding sites per molecule of heparin. Evidence that high molecular weight heparin may contain more than one antithrombin III-binding site per chain has already been reported (20). Thus, besides a marked difference in anlonic density between $A$ and the other fractions, the differences in antithrombin MI-binding sltes are even more pronounced. This ralses the question as to the ability of the Eractions $A, B, C$ and $D$ to catalyze the thrombin-antithrombin III reaction. To this end, thrombin (10 nM) was incubated with antithrombin till ( 100 nM) in the presence of warying amounts of the heparin fractions. The pseudo first order rate constants of inhibltion of thrombin were calculated from exponential plots of the residual thrombin concentration versus renction time and are listed in Table II. It is shown that in order to obtaln, for the heparin fractions, identical values of pseudo first order rate constants, the amount of each heparin fraction had to be varted whdely. It is of interest to compare our data ( $k$ values normallzed for the heparin concentration) with the antithrombin activities determined by an andolytic method in human plasma reported by Sache et al. (7). A comparlson based on 
Table II: Antlthromin activity of heparin fractions in the presence of antithxombin ILI.

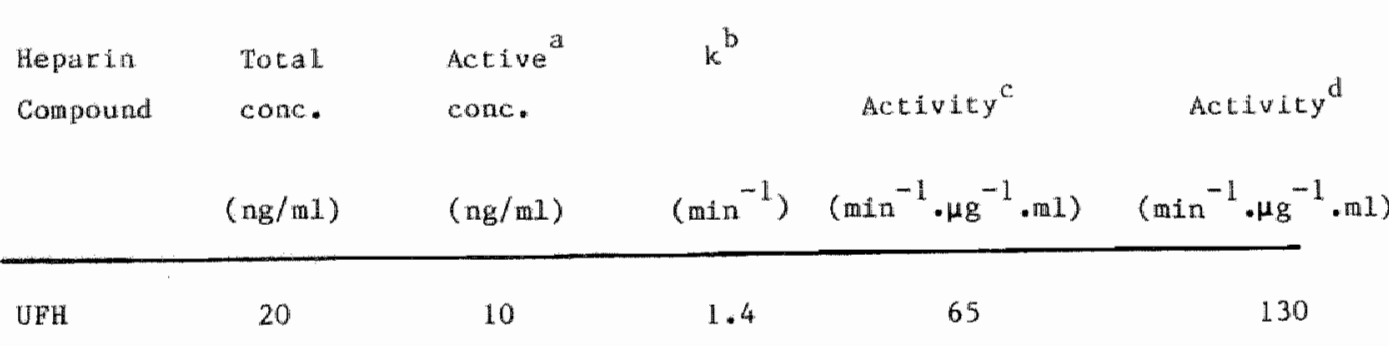

Fractons

\begin{tabular}{rrrrrr} 
A & 200 & 14 & 1.2 & 5 & 71 \\
B & 30 & 12 & 1.3 & 40 & 100 \\
C & 10 & 9 & 0.9 & 85 & 96 \\
D & 5 & 9 & 1.2 & 220 & 121 \\
\hline
\end{tabular}

a calculated for the percentage of heparin with high affinity for antithrombin III as determined by fluorescence titration.

b corrected for the heparia-independent reaction $\left(k=0.1 \mathrm{~min}^{-1}\right)$.

c calculated from the pseudo first order rate constant af inhibition of d thrombin by antithrombin III $(k)$ and the total heparin concentration. d calculated from the pseudo first order race constant (k) and the amount of antithrombin III affintty material in each fraction.

the respective activities reveals in our assay a 5 -fold and 2-fold higher speciflc activity for fraction $A$ and fraction $D$, respectively. When the molar concentration of antithrombin III-binding heparin is taken into account to calculate the specific activities of the fraction, then the differences between the fractions become much smaller.

Characterization of heparin fractions obtained by antithrombin III affinity chromatography. Pseudo first order rate constants of inhibition of thrombin (10 nM) and factor $x_{a}(10 \mathrm{nM})$ by antithrombin III (100 nM) were determined In the presence of unfractlonated heparin and low and high ant Lthrombin ILI affintey heparin at varying concentrations. The rate constants of inhibition of factor $x_{a}$, corrected for the heparin-independent reaction, were 
0.11 and $13.2 \mathrm{~min}^{-1} \cdot \mathrm{\mu g}^{-1}$. ml for low and high affinity heparin, respectively. The rate constants for thrombin were 0.9 and $137 \mathrm{~min}^{-1} \cdot \mu \mathrm{g}^{-1}$.m. for Low and high affinity heparin, respectively. We conclude that the antithrombin III low affinty heparin fraction contalned less than $1 \%$ of high affinity material.

Effect of heparin fractions on thrombin-lnduced platelet factor va fornation. The effect of heparin fractions with low and high affindty for antithrombin III, as well as the effect of heparin fractions with different charge density were studied on the thrombin-induced platelet factor $v_{a}$ formation. Washed platelets $\left(5 \times 10^{6} / \mathrm{ml}\right)$ were incubated with thrombin $(0.5$ nM) in the presence of varying anounts of the different heparin fractions.

Table TII: Binding of heparin fractions to thrombin.

$$
\mathrm{IC}_{50} \text { values }
$$

\begin{tabular}{lll} 
& Thrombin Induced & Heparin-dependent \\
Compound & Platelet Factor $v_{a}$ & Thrombin Inhibition \\
Generation & by Antithrombin III \\
& (heparin conc, $\mu \mathrm{g} / \mathrm{mI})$ & (PPACK-thrombin, $\mathrm{nM})$ \\
\hline
\end{tabular}

Unfractionated

\begin{tabular}{lrl} 
heparin & 31 & 200 \\
High Affinity & 27 & 200 \\
Low Affinity & 660 & $\mathrm{n} \cdot \mathrm{d}$. \\
Fraction A & 90 & 400 \\
Fraction B & 37 & 220 \\
Fraction C & 22 & 190 \\
Fraction D & 17 & 150 \\
\hline
\end{tabular}

n.d.: not determined 
Samples were caken at different time intervals and assayed for factor $V_{\text {a }}$ activity. We have prevlously shown that under our conditions the rate of platelet factor $V$ release and of platelet factor $V$ activation, as well as the maxtmal amount of platelet factor $V$ released are proportional to the thrombin concentration (6). Thus, when thrombin activity decreases as a result of inhibition by heparlin, the rate of factor $V$ formation and the maximal factor $v_{\text {a }}$ concentration decrease. The heparin concentrations at which half the rate of factor $V_{\text {a }}$ formation and half the maximal amount of factor $V_{a}$ formed were obtained ( $\mathrm{IC}_{50}$ values) are 11 sted in Table III. It is apparent that the $I_{50}$ values correlate with the charge density of the heparin fractions. That 18 , the highest $\mathbb{I C}_{50}$ value is found for the heparin fraction, fraction $A$, with the lowest charge density. Interestingly, the antithrombin III low affinity fraction showed a very high $\mathrm{IC}_{50}$ value, Indicating that this heparin fraction had hardly any affintty for thrombin. When compared with unfractlonated heparin, the antithrombin III high affinity fraction was found to have an identical $I C_{50}$ value. From this we concluded that the antithrombin Ill high affintty fraction contained most, 1 not all, of the thrombin-binding heparin species.

The effect of PPACK-thrombin on the heparin-dependent inhibition of thrombin by antithrombin III. The $I_{50}$ values reported above were obtained from a rather complicated reaction, i.e. the thrombin-catalyzed platelet factor $V_{a}$ formation. Because an active-site-blocked thrombin, like PPACKthrombin, has the same affinity for heparin when compared to thrombin, it can be used as a tool to compare the affinities of different heparin fractions for thrombin. That is, PPACK-thrombin is a competitive inhibitor of the heparin-dependent Inhibition of thrombin by antithrombin IIT. The amount of PPACK-thrombIn required to obtain haif the maximal rate constant of the beparin-dependent antithrombin ICt-thrombin reaction ( $1 \mathrm{C}_{50}$ valne) depends on the afflndty of PPACK-thrombin for heparln. The results of such an experiment are depicted in Figure 1. Pseudo first order rate constants were determined for the antithrombin III-thrombin reaction in the presence of fraction $\mathrm{D}(5$ or $10 \mathrm{ng} / \mathrm{ml})$ and varying amounts of PPACK-thrombin. It is shown that the $\mathrm{IC}_{50}$ values are independent of the heparin concentration. The $\mathrm{IC}_{50}$ values for the other heparin fractions were obtained in the same way and are listed in Table III. The results are comparable to the ones obtalned in the platelet experiments: the highest IC $_{50}$ value of 


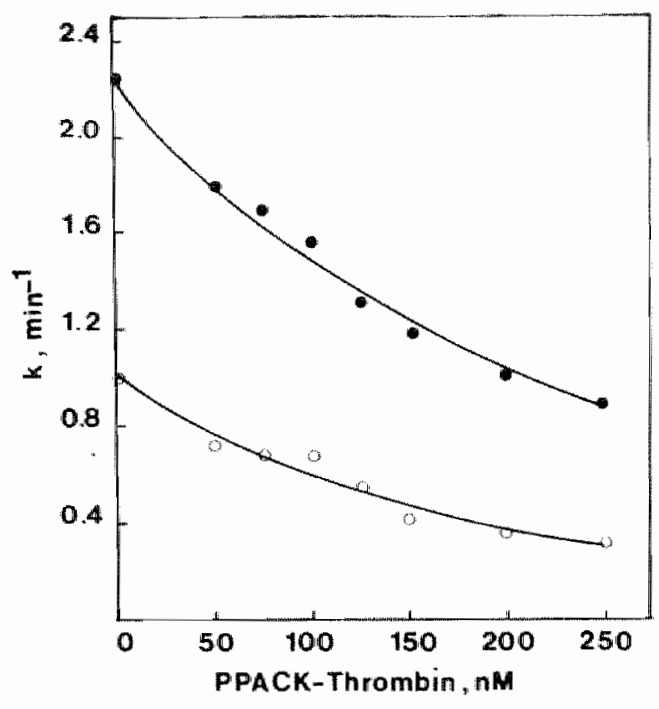

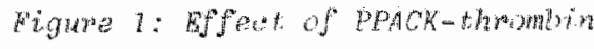
on the peaudo firet-onder wate constont of thrombin inatevetion by antithrombin III and hepamin fraction D. whombin $110 \mathrm{mH}$, antithrombin III (100 nN) were incubated with fraction $D$ in the presence of varying PPACK-thrombin concentration. Aliquots were taken in time and the pseudo first order rate constants were detemined at every PPACK-thrombin concentration. Heparin fraction $D, 5 \mathrm{ng} / \mathrm{ml}$ (0) $10 \mathrm{ng} / \mathrm{ml}$

PPACK-thrombin is found for the heparin fraction with the lowest charge density.

Studies with extra-sulfated fraction A (fraction $\left.A^{5}\right)$. Fraction A was chemically modified by the incorporation of sulfate groups. Upon this modification the sulfate/carboxyl ratio increased from 1.31 to 1.90 , thus the square of charge density increased from 5.3 to 8.41 . We questloned whether this increase was sufflelent to obtain a heparin fraction with a higher affinity for thromblin when compared with non-modified fraction. A. To this end, we estlmated the $\mathrm{LC}_{50}$ values of fraction $A^{\mathrm{s}}$ in the thrombincatalyzed platelet factor $V_{a}$ formation reaction and the $I_{50}$ walue of

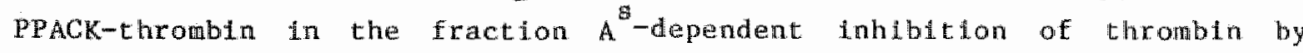
antithrombin III as described above. The $I_{50}$ values were in both cases lower for the extrasulfated fraction A than for fraction A. In the thrombin catalyzed platelet factor $V_{a}$ formation, the $I C_{50}$ value was $60 \mu \mathrm{g} / \mathrm{ml}$ for fraction $A^{S}$ compared to $90 \mu \mathrm{g} / \mathrm{ml}$ for fraction A. An $\mathrm{LC}_{50}$ value of $260 \mathrm{rM}$ was obtained in the competition experiment with PPACK-thrombin, compared to $400 \mathrm{nM}$ for fraction $A$. Desplte the increased affinity for thrombin we found that this fraction $A^{s}$ was less effective in the neutralization of thrombin 


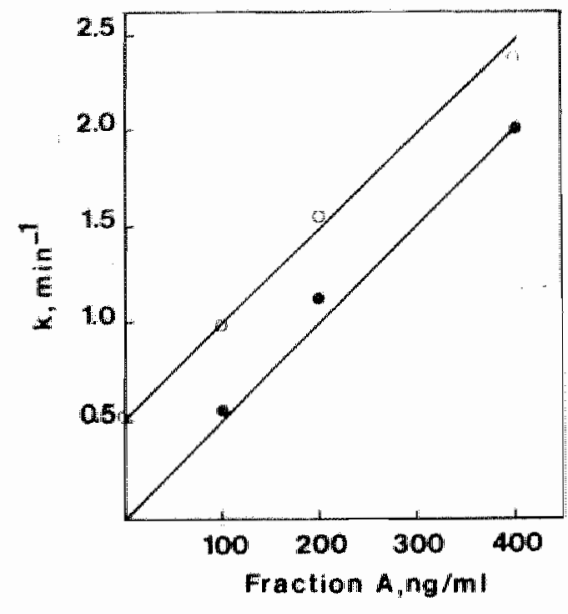

Eigure 2: Effect of extra-aufated fraction $A^{B}$ on the pseudo first oniter rate constant of inhibition of thrombin By antithrombin III and fraction A. Thrombin $(10 \mathrm{nM})$ and antithrombin TII (100 nM) were incubated with varying amounts of fraction $A$, in the absence (-) or in the presence (O) of fraction $A^{5}$ $(200 \mathrm{mo} / \mathrm{mL})$.

by antithrombln IIL. When normalized for the heparin concentration the pseudo first order rate constant of inhibition of thrombin by 100 nM antithrombin III was $2.9 \mathrm{~min}^{-1} \cdot \mu \mathrm{g}^{-1} \cdot \mathrm{ml}^{-1}$, which 1 s half the rate constant found with fraction A. Whatever caused the different rate constants, we were unable to demonstrate that the higher affinity for thrombin of fraction $A^{9}$ resulted in an inbibitory effect of the fraction $A$-dependent thrombin-antithrombin ILI reaction. Pseudo-first order rate constants were determined for the antithrombin II-thrombin reaction in the presence of varying anounts of fraction $A$, elther in the absence or in the presence of a Elxed amount of fraction $A^{s}$ (Flgure 2). It is shown that when fraction $A^{s}$ was added, the pseudo first onder rate constant of inhibition of thrombin 1ncreasid due the effect of fraction $A^{\text {salone. }}$

\section{CONCLUSION}

The results of the present study indicate that the inhibltory action of heparin in the thrombin-catalyzed release and activation of platelet factor $V$ depends on the affintty of heparin for thrombin and as such is a function of the charge density of the heparin molecule. A linear relationship was 


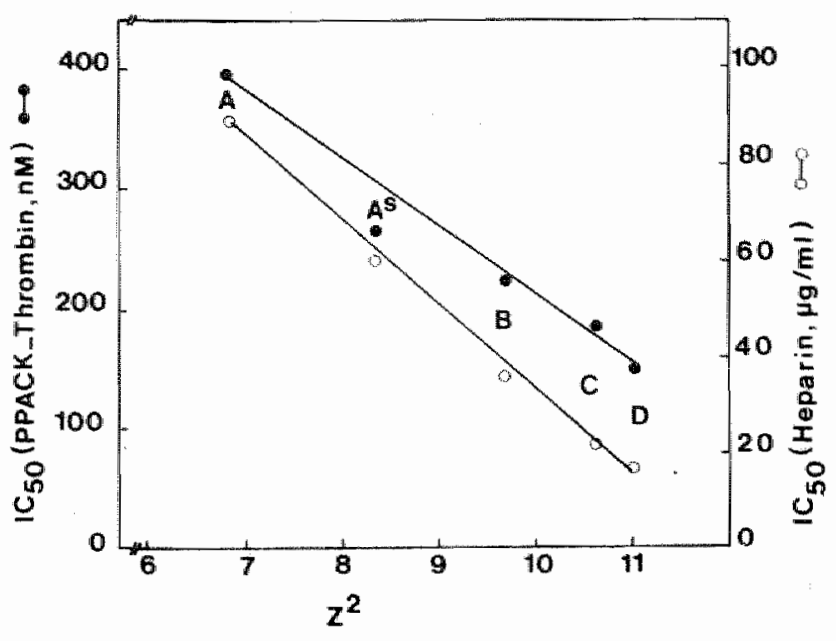

Figure 3: Relationship between thange denstty and heparin-thrombin interaction. Replot of IC 50 of heparin-thrombin interactions from Table III as a function of charge density $z^{8}$. Hepamin dependent thrombin inactivation by antithrombin YII in the presence of PPACK-thrombin; (-); thrombin indued platelet factor $V_{a}$ generation $(0)$.

found between the square of the charge density of heparin fractions obtained by ion-exchange chromatography and their IC 50 values in the thrombin-catalyzed platelet factor $V_{a}$ generation reaction (Figure 3 ), as well as in the effect of active-site-blocked thrombin on the hepartn-dependent inactivation of thrombin by antithrombin $I I I$.

In view of the rather high $\mathbb{I C}_{50}$ values, we have to assume that when these heparin fractions also catalyze the thrombin-antithrombin ILI reaction, the antithrombin III independent pathway of thrombin inactivation might not be of physiological importance.

In this respect it is interesting to see that when crude heparin is fractionated on lmobilized antithrombin IIT, the heparin fraction whth low antithrombin II affintly has a 20 -fold higher $I_{50}$ value in the above mentioned reaction when compared with crude hepartin and the antithrombin III high affintty heparin fraction. This indicates that in unfractionated heparin the heparin species with affinity for thrombin also possess the specific polysaccharide sequence required for antithrombin III bindlng. When crude heparin is fractionated on the basis of 1 ts charge density, thus indirectly of its affinity for thrombin, the same ls observed. The heparin fraction with the lowest charge density has the highest $I_{50}$ value and 
possesses almost no antithrombin lil-binding sites.

Moreover, our study indicates that when a heparin fraction (fraction A) is chembeilly wodifled lat such way that it acqulces a higher charge density, te does increase the ability to inactivate thrombin in the absence of antithrombin IIL, whereas such a modification reduces the catalytic efficlency of the heparin fraction in the thrombin-antithrombin III reaction.

\section{REFERENCES}

1. Jordan, R., Beeler, D., Rosenberg, R.D.: Fractionation of low molecular weight heparin specles and their interaction with antithrombin. J.Biol. Chem. 254, 2902-2913 (1979)

2. Choay, J., Petitou, M., Lormeau, J.C., Sinay, P., Casu, P., Gatti, G.: Structure activity relationships in heparin: a synthetic pentasaccharide with high affinity for antithrombin III and eliciting high anti-factor Xa activity. Biochem. Biophys.Res.Comm. 116: 492-499 (1983)

3. Hoylaerts, M., Owen, W.G., Collen, D.: Involvement of heparin chain length in the heparin-catalyzed inhibition of thrombin by antithrombin III. J. Biol.Chem. 259: 5670-5677 (1984)

4. Hurst, R.E., Poon, M.C.: Structure-activity relationships of heparin. Independence of heparin charge density and antithrombin-binding domains in thrombin inhibition by antithrombin and heparin cofactor $I$. J.Clin. Invest. $72,1042-1045$ (1983)

5. Heuck, C.C. , Schlele, U., Horn, D., Fronda, D., Ritz, E.: "The role of surface charge on the accelerating action of heparin on the antithrombin III-inhlbited activity of a-thrombin. J.Biol.Cher. 260, 4598-4603 (1985)

6. Baruch, D., Franssen, J., Herker, H.C., Lindhout, 'T': Effect of heparin and low molecular heparins on thrombin-induced blood platelet activatlon in the absence of antithrombin III. Thromb. Res. 38, 447-458 (1985)

7. Sache, E., Maillard, M., Bertrand, H. Mamen, M., Kunz, M. Choay, J., Fareed, J., Messmore, H.: Studies on a highly active anticoagulant fraction of high molecular welght 1 solated from porcine sodium heparin. Thromb. Res. $25,443-458$ (1982)

8. Confurtus, P., Zwal, R.F.A.: The enzymatic synthesis of phosphatidylserine and purification by CM-cellulose column chromatography. Biochim. Blophys.Acta. $483,36-42$ (1977)

9. Rosing, J., Tans, G., Govers-RLemslag, J.W.P., Zwaal, R.F.A., Hemker, H.C.: The role of phospholipids and factor va in the prothrombinase complex. J.B1ol. Chem. 255, 274-283 (1980)

10. Botceher, C.J.F., van Gent, C.M., Preis, C.A.: Rapid and sensitive sub-micro phosphorus determination. Ana1.Chem.Acta. 24, 203-207 (1961)

11. Lindhout, "T., Govers-Rlemslag, J.W.P., wan de Waart, P., Rosing, J., Hemer, H.C.: Factor Va-factor Xa interaction. Effects of phospholipid vestcles of varying composition. Biochemistry $21,5494-5502$ (1982)

12. Thaler, E.J, Schmer, G.: A simple two-step 1solation procedure for human and bovine antithrombin II/III (heparin cofactor): a comparison of two methods. Br.J.Haem. 31, 233-243 (1975) 
13. van Dieljen, G., Tang, G., Rosing, f., Henker, H.C.: The role of phospholipid and factor VIIIa in the activation of bovine factor $x$. J.B1o1. Chem. 256, 3433-3442 (1981)

14. Kurachi, K., Schmer, G., Hermodson, M.A., Teller, D.C., Davie, E. W.: Characterization of human, bowine and horse antithrombin III. Blachemistry 1.5, 368-372 (1976)

15. Rosing, J., van Rijn, J.L.M.L., Bevers, E.M., van Dieljen, G., Comfurius, P., Zwaal, R.F.A.: The role of activated human placelets in prothrombin atd factor X activation. Blood 65, 319-322 (1985)

16. Einarsson, R., Andersson, $L_{.0} 0$. : Binding of heparin to human antithrombin III as studied by measurements of tryptophan fluorescence. Biachim.Bioph. Acta 490, 104-111 (1977)

17. Nordenmann, B., Danielsson, A., Björk, I.: The binding of low-aftinity and high-affintty heparin to antithrombin. Fluorescence studles. Eur.J.Biochem. 90, 1-6 (1978)

18. Hurst, R.E., Menter, J.M., West, S.S., Settine, J.M., Coyne, E.H.: Structural basis for the anticoagulant activity of heparin. Relationship to the number of charged groups. Blochemistry 18, 4283-4287 (1979)

19. Holmer, E., Kurachi, K., Soderstrom, G.: The molecular weight dependence of the rate enhancing effect of heparin on the inhibition of thrombin, factor Xa, factor IXa, factor XIa, factor XI. Ia and kallikrein by antithrombin III. Biochem. I. 193, 395-400 (1981)

20. Rasenberg, R.D., Jordan, R.E., Favreau, L.V., Lam, L.H.: Highly active heparin species with multiple binding sites for antithrombin. Biochem. Blophys . Res. Comm. 86, 1319-1324 (1979) 
$-102-$ 
CHAPTER VI

THROMBIN GENERATION AND INAGT IVATION IN "THE PRESENCE OF ANTTTHROMBIN III AND HEPARIN

\section{SUMMARY}

We have determined the rate constants of lactivation of factor $x_{a}$ and thrombin by antithrombin IIl-heparin during the process of prothrombin activation. The second order rate constant of inhibition of factor $x_{a}$ alone by antithrombin III as determined by using the symthetic peptide substrate S-2337 was found to be $1.1 \times 10^{6} \mathrm{M}^{-1} \mathrm{~min}^{-1}$. Factor $\mathrm{x}_{\mathrm{a}}$ in prothrombin activation mixtures that contained prothrombin, and elther saturating amounts of factor $V_{a}$ or phospholipid ( 20 mol \% dioleoylphosphatidylserine/ 80 mol \% dloleoylphosphatidyleholine, $10 \mu \mathrm{M}$ ) was inhibited by antithrombin III with a second order rate constant that was essentially the same: $1.2 \mathrm{x}$ $10^{6} \mathrm{M}^{-1} \mathrm{~min}^{-1}$. When both factor $\mathrm{V}_{\mathrm{a}}$ and phosphollpid were present during prothrombin activation, factor $x$ inhibition by antithrombin III was reduced about 10-fold: second order rate constant of $1.3 \times 10^{5} M^{-1} \mathrm{~min}^{-1}$. Factor $x_{a}$ in the prothrombin activation mixture that contained both factor $V_{a}$ and phospholipid was even more protected from inhibition by the antithrombin II-heparin complex. The first order rate constants at 100 aM antelhrombin III and normalized for the heparin concentration were 0.11 $\mathrm{mLn}^{-1}(\mu \mathrm{g} \text { heparin/ml })^{-1}$ and $6.1 \mathrm{~min}^{-1}(\mu \mathrm{g} \text { heparin/ml })^{-1}$ in the presence and the absence of factor $V_{a}$ and phospholipid. When the prothrombin was varled widely around the $K_{m}$ for prothrombin, this had no effect on the first order rate constants of inhlbition. It is our conclusion that factor $x_{a}$ when acting in prothrombinase on prothrombin is profoundly protected from inhlbition by antithrombin III In the absence as well as lin the presence of therapeutic concentrations of heparta. The second order rate constant $\left(4.5 \times 10^{5} \mathrm{M}^{-1} \mathrm{~min}^{-1}\right.$ ) of Inhibltion of thrombin activity generated during prothrombin activation was found to be: 1) Constant during the time course of prothrombin activation, 2) Independent of the composition of the prom thrombin-converting complex and 3) About 4-Fold lower than the second order 
rate constant of inibition of purifled alpha-thrombin $\left(1.9 \times 10^{6} \mathrm{M}^{-1}\right.$ min

-1). Surpeisingly, heparin did not enhance the antithromin III-dependent rate of indibition of thrombin actuity formed during the intelal phase of the prothrombin activation. This is possibly caused by the fact that meizothrombin (des fragment 1 ) is the major product during the initial phase of prothrombin activation. A mathematical model is given which provides a relationship between the thrombin concentration and the pseudo first order rate constant of inhibition of factor $x_{a}$ as well as that of thrombin when prothrombin $1 \mathrm{~s}$ actiwat in the presence of antithrombin III-heparin.

\section{INTRODUCTION}

The plasma protein antithrombin II is an inhibitor of serine proteases involved in the process of blood coagulation. Its action is dramatically enhanced by heparin. The matn targets of antithrombin III are activated blood coagulation factor $I x$ (factor $I X_{a}$ ), factor $x_{a}$ and thrombin ( 1 ). The activation of prothrombin to thrombin ls a membrane-mediated process requiring the binding of both factor $x_{a}$ and prothrombin to a negatively charged membrane surface (phospholipid vesicles). In addition, activated blood coagulation factor $V$ (factor $V_{a}$ ) that interacts with the membrane, with factor $\mathrm{x}_{\mathrm{a}}$ and with prothrombin, greatly increases the $\mathrm{V}_{\max }$ of prochrombin activation and lowers the $\mathrm{K}_{\mathrm{tal}}$ for prothrombin when the membrane contalng a low negative charge density (2). Because in vivo both factor $v_{\text {a }}$ and phospholiplds are present during factor $\mathrm{x}_{\mathrm{a}}$-catalyzed activation of prothrombin, a number of studies were undertaken to reveal the effects of these so-called accessory components on factor $x_{a}$ inhibition by antithrombin III. It has been shown that the Imhibition of Eactor $X_{a}$ is reduced by phospholiplds alone $(3,4)$ and by phospholipids when factor $v_{a} \mathbb{H}$ also present $(5)$.

Bldis et al. (4) used the rate of prothrombin activation as a measure for residual factor $x_{a}$ activity. Quite unexpectedly, the antithrombin LII carried-over in the prothrombin activation assay, as far as we understand, did not affect the thrombin activity, nor factor $x_{a}$. Walker \& Esmon (6) reported that fragment 2 was found to slow down the rate of inhibition of alpha-thrombin about 3-fold. These observations incite to the investigation 
of the kinetics of the antithromin ITI-dependent neutraligation of both factor $X_{a}$ and thrombin activity under nore physiological conditions. Therefore, our purpose was to assess the kinetics of the antithrombin III-dependent inhibition of factor $x_{\text {ats }}$ part of the prothromblnase complex while acting on prothrombin, as well as the kinetics of the antithrombin III-dependent inhibition of thrombin activity as a product of the prothrombinase reaction. The basic assumption underlying the data analysis of the experiments presented here was that, at any time during the prothrombin activation reaction in the presence of antithrombin III, the observed rate of thrombin formation equals the actual rate of thrombin formation (proportional to the residual factor $x_{a}$ activity) minus the rate of inhibition of the thrombin activity. The same experiments were also performed in the presence of unfractionated heparin.

Our results lead us to question the validity of a number of basic assumptions underlying the current ideas about the effects of factor $v_{a}$ and phospholipid on the factor $x_{a}$-antithrombin III reaction. Furthermore, a dramatic discrepancy was found between the kinetics of the heparindependent inhibition of thrombin generated directly from prothrombln activation and the kinetics of the heparin-dependent inhibition of alphathrombin by antithrombin III.

\section{MATERIALS AND METHODS}

Materials. Phosphatidylcholine (dioleoyl), soybean trypsin inhibltor and fatty acid free human serum albumin were purchased from $S 1$ gna. $H-D-p h e n y l-$ allany 1-L-pipecoly L-L-arginine-p-nitroanilide dihydrochloride $(\mathrm{S}-2238)$ and Bz-L-isoleucy 1-L-glutamy1 (piperidyl)-L-glycyl-L-arginine-paranitroan 11 de hydrochloride (S-2337) were obtained from Kabi AB, Sweden. Crude heparin (165 USP units/mg) was generous1y prowided by Pharmuka Laboratoires, France. All reagents used were of the highest grade commercially obtainable.

Proteins. Bovine antithrombin III was prepared by the method of Thaler \& Schmer (7). All other bovine clotting factors were prepared and quantitated as previlously described (8). 
Phospholipid Vesicle Preparation. 1,2-Dioleoy1-sn-glycero-3-phosphoserine (DOPS) was prepared from 1,2-dioleoyl-sn-glycero-3-phosphocholine (DOPC) as described by confurius \& zwal (9). Sonicated vesicle solutions were prepared from mixtures of DOPS ( 20 mol \%) and DOPC ( 80 mol $\%$ ) in a buffer that contained 50 mM Tris-HCL, $175 \mathrm{mM}$ NaCl, $\mathrm{pH} 7.9$ as described by de Kruljfif et al. (10).

Determination of Inhibition Rate of Purified Proteases. The neutralization of factor $X_{a}$ and thrombin by antithrombin LII was investigated under pseudo first order conditions. Factor $x_{a}(5 \mathrm{nM})$ or thrombin $(5 \mathrm{nM})$ was tncubated at $37^{\circ} \mathrm{C}$ dn $50 \mathrm{mM}$ Tris-HCl, 175 mM NaCl and $0.5 \mathrm{mg}$ human serum albumin/mi, pH 7.9 with antithrombin III (50 to $300 \mathrm{nM}$ ). At timed intervals after the addition of the protense, $10 \mu 1$ aliquots were removed into $590 \mu 1$ of substrate solution (contalning $50 \mathrm{mM}$ Tris-HCl, $175 \mathrm{mM}$ NaCl, $20 \mathrm{mM}$ EDTA, 0.5 Ing human serum albumin/mil, and $0.22 \mathrm{mM} \mathrm{S}-2238$ or $5-2237, \mathrm{pH} 7.9$ ) at $37{ }^{\circ} \mathrm{C}$. After $4 \mathrm{~min}, 300 \mu \mathrm{l}$ of $50 \%$ acetlc acid $(\mathrm{v} / \mathrm{v})$ was added and the absorbance of the mixture was measured at 405 mu against a blank by using an Aminco DW-2 spectrophotometer. The rates of thrombin and factor $x_{a}$ inhibition by antithrombin III after sampling into the substrate solution wete found to be suffictentiy slow so as to not result in measurable enzyme inhibition. The residual enzyme activity was calculated from a standard curve constructed under the same conditions from known amounts of thrombin or factor $x_{a}$ and exponentially plotted versus reaction time.

Neutralization of Factor Xa and Thrombin by Antithrombin III in Prothrombin Actlvation Mixtures. Prothrombin was incubated with antithrombin III in the presence of elther factor $V_{a}$ " phospholipid vesicles or heparin or a conbination of these in $50 \mathrm{mM}$ Tris-HCl, $175 \mathrm{mM} \mathrm{NaCl}, 5$ or $10 \mathrm{mM} \mathrm{CaCl} 2$ and $0.5 \mathrm{mg}$ human serun albumin/mi, pH 7.9 at $37{ }^{\circ} \mathrm{C}$ for $4 \mathrm{~min}$. Prothrombin activacion was actared by the addition of factor $X_{a}$. The final concentrathons of the reaction components are listed in Table. I. At timed intervals after the addition of factor $x_{a}, 40 \mu l$ allquots were removed into $560 \mu 1$ of the aforementioned solutions of $5-2338$. Thrombin concentrations were deterintined as descrtbed befire. In separate experinents, soybean trypsin Inhibitor $(20 \mu \mathrm{g} / \mathrm{mL})$ was added to prothrombin activation mixtures at known intervals after the addition of factor $x_{a}$, resulting in an instantaneous 
Table I: Conditions of Prothrombin Activation.

Composition of the

prothrombinase complex
Prothrombin kate of thrombin

concentration formation

$F_{a} \quad F_{a} \quad \begin{aligned} & \text { Phospho- } \mathrm{Ca}^{++} \\ & \text {Ilpid }\end{aligned}$

\begin{tabular}{|c|c|c|c|c|c|c|}
\hline & $(\mathfrak{n M})$ & $(\mathrm{nM})$ & $(\mu \mathrm{M})$ & $(\mathrm{mM})$ & $(\mu \mathrm{M})$ & $\left(M I I_{a} \min ^{-1} M_{x^{-1}}^{-1}\right)$ \\
\hline 1. & 0.003 & 0.1 & 10 & 5 & 1.0 & 2000 \\
\hline 2. & 1.5 & 20.0 & - & 5 & 6.0 & 2 \\
\hline 3. & 4.0 & - & 5 & 10 & 0.5 & 0.6 \\
\hline
\end{tabular}

The reactions were performed in a buffer containing $0.05 \mathrm{M}$ Tris-0.175 M $\mathrm{NaCl}-0.5 \mathrm{mg}$ human serum albumin/ml, pH 7.9 at $37^{\circ} \mathrm{C}$.

and complete Inhibition of thrombin formation. After the addition of soybean trypsin inhibitor, $40 \mu \mathrm{H}$ aliquots were removed at regular intervals and assayed for thrombin activity. Control experiments established that soybean trypsin inhibitor had no effect on the antithrombin III-thrombin reaction nor on the amidolytic activity of thrombin.

Kinetic Analysis of Antithrombin III-Factor Xa and Antithrombin III-Thrombin Reaction in Prothrombin Activation Mlxtures. When thrombin is generated by prothrombiase-catalyzed activation of prothrombin in the presence of antithrombin. III, the appearance rate of amidolytic active thrombin', $v_{r}$, will vary as a function of time $t$ during prothrombin activation according to:

\footnotetext{
"Amidolytic active thrombin" or "thrombin activity" is used throughout this paper to indicate that this activity 1 s not necessarily identical with the formation of alpha-thrombin
} 
$\left(v_{r}\right)_{t}=\left(v_{a}\right)_{t}-\left(v_{i}\right)_{t}$

where $\left(v_{t}\right)_{t}$ is the welocity of thrombin generation at time $t$ and $\left(v_{\mathbb{L}}\right)_{t}$ is the velocity of the antithrombin III-thrombin reaction at time $t$. In all experiments, the intial antithrombln IIL concentration was signiflcantly greater than the protease concentrations, so that the protease-antithrombin III reaction followed pseudo first order kinetics ower the time course studfed. Thus, when at any tine interval prothrombin activation is blocked, $\left(v_{1}\right)_{t}$ can be calculated by mulciplying the observed pseudo first order rate constant of the antithrombin III-thrombin reaction by the thrombin concentration.

It is worth noting that the antithrombin III-protease reaction is a two atep reaction. The reversible interaction between antithrombin III and thrombin $\left(K_{d}=1.4 \times 10^{-3} M\right.$ in the absence of heparin and $K_{d}=4 \times 10^{-6} \mathrm{M}$ in 1 ts presence) is followed by a conversion into a stable antithrombin IIIthrombin complex, resulting in the inactivation of thrombin with a pseudo first order rate constant, $k=10.4 \mathrm{~s}^{-1}$ (11). Thus, the reaction can be analyzed by pseudo first order kinetics only when both the antithrombin III and protease concentrations are far below the $k_{d}$ value. This condition holds for our experiments.

The pseudo first order rate constant of the antithrombin III-factor $X_{\text {a }}$ reaction can be obtalned when $\left(v_{a}\right)_{t}$ is plotted exponentially versus $t$. The veloctty of thrombin generation, $v_{a}$, at time $t$ was calculated from Equation 1. The appearance rate of amidolytic active thrombin, $v_{r}$, at time $t$ was detertined from the slope of the thrombin generation curve at time $t$. Electrophoret1c Blotting Procedure. proteins were subjected to slab gel lectrophorests in the presence of sodium dodecyl sulfate as described by Laemm11 (12). The protelns were then transferred to nitrocellulose sheets according to the procedure described by Towbin et al. (13). The electrophoretic blots were soaked $1 \mathrm{t} 0.1 \%$ bovine serum a 1 bumin and $0.05 \%$ Tween in phosphate-buffered suline. In essence, the immunological detection of antithrombin III and antithrombin LIT-protease complexes were performed as deacribed by Towbin et al. (13). The first antiserum was rabbit anti-human antithrombin III (Sigma). We used horseradish peroxidase-conjugated swine anti-rabbit IgG (Dakopatts, Denmark) as an indicator. For the color reaction, the blots were soaked in a solution of $0.5 \mathrm{mg}$ diaminebenzidine 
tetrahydrochloride/mL (Fluka) and $0.01 \% \mathrm{H}_{2} \mathrm{O}_{2}$ in $0.05 \mathrm{M}$ Tris-HCl, pH 7.5. This solution was freshy prepared and filtered before use.

\section{RESULTS}

The Activation of Prothrombin to Thrombin in the Presence of Antithrombin III. The experimental conditions of prothrombin activation that were used to study the inhibitory action of antithrombin III are sumartzed in Table I. The reactions were initiated by the addition of factor $x_{a}$. Under all conditions the rate of thrombin formation was proportional to the factor $x_{a}$ concentration and when performed in the absence of antithrombin III linear during the time of the experiment. In the presence of antithrombin II the rate of appearance of thrombin activity decreased in time. We assumed that this was due to the inactivacion of factor $x_{a}$ and the inhibition of thrombin activity. A typical curve is shown in Figure 1. .

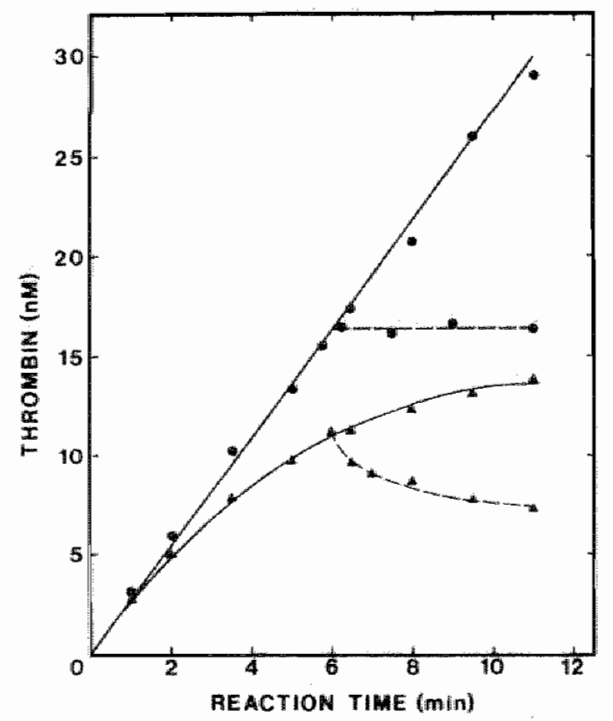

Figure 1: Inhibition of thrombin formation and thrombin activity in prothrombin activation mixtures by antithrombin IIT. Prothrombin 10.5 M) was xatinated by ffactor $X_{a}$ (4.0 nM) - phosphotipid (5 M) $\mathrm{CaCl}_{2}(10 \mathrm{mM}) \mathrm{J}$ either in the absence ( ) or prosence ( ) of $100 \mathrm{nM}$ antithrombin III. At timed intervale samples were taken and assayed for thrombin activity. Th sepurate experiments boybern trapsin inhibitor $(20 \mathrm{\mu g} / \mathrm{ml})$ was added 6 min after atarting the reaction with factor $x_{a}$. Whe time counses of thrombin activity are indicated by the dashed lines. 


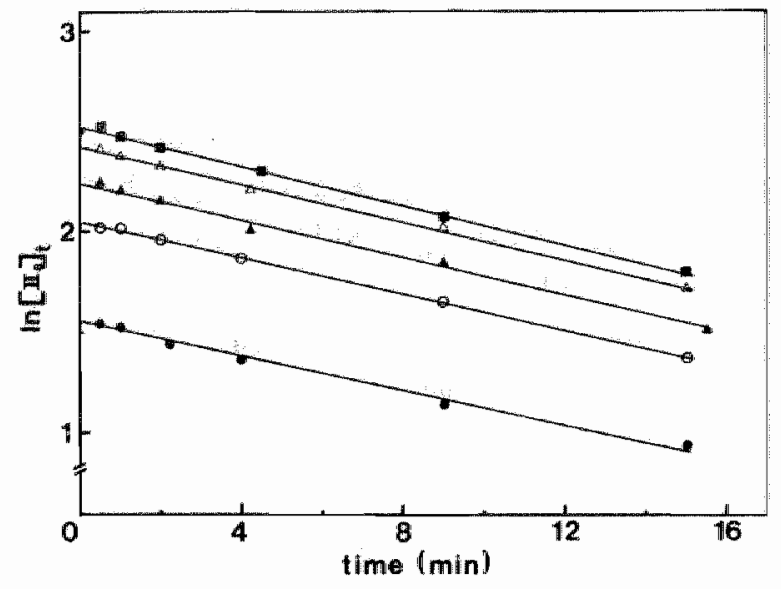

Figume 2: paudo fimet order plots of inhibition of thmombin activity in prothrombin activation mixtures by antithrombin III. Conditions of prothrombin activation in the presence of antithrombin III were as given in Figure 1. After the addition of soybean trypsin inhibiton samples were taken and assayed for residuat thrombin activity.

The expresetions are various time intremals of addition of soybean trypsin inhibiton: (O), $2 \min ;(0), 4 \mathrm{~min} ;(\Delta), 6 \mathrm{~min} ;(\Delta), 8 \mathrm{~min} ;(\mathbf{B}), 10 \mathrm{~min}$

To distinguish between the antithrombin III action on thrombin and that on factor $x_{a}$ we inactivated factor $x_{a}$ by soybean trypsin inhibitor. Thus by preventing further thrombin formation the inhibition of thrombin activity can be studied separately. As shown ln figure 1, soybean trypsin inhibitor instantaneously and completely inhibits factor $x_{a}$ inactivation, whereas it had no effect on the thrombin activity.

Soybean trypsin inhibitor was then added at timed intervals after the start of prothrombin activation and residual thrombln activity was exponentionalIy plotted versus time. We found that the pseudo first order rate constants of Intibition of thrombin activity were the same at different time intervals of prochrombin activation (Figure 2 ).

Knowing the rate constant of inhibition of chrombin activity, the rate of inhibition of thrombin can be calculated at any known concentration of thrombin, i.e. at any point of the curve of thrombin activity versus time. From the same curve the rate of appearance of thromin activity can be determined from the slope at time $t$. The sum of this rate and the rate of 


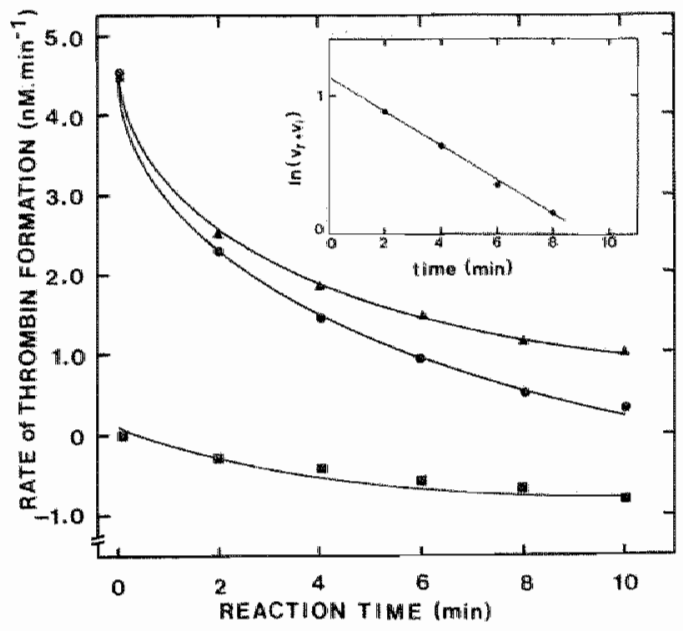

Figure 3 : Whe rate of thrombin fomption in the prosence of antithrombin HrT. Prothrombin activation in the presence of $100 \mathrm{mM}$ antithrombin III wha armated out as described in winge 1. The rate of thrombin fomation (1) $v_{m}$ ) was calculated from the sope of the thrombin generation cume at the times indicated on the homisontal axts. The note of thrombint formation, wy correated for the rate of thrombin inat

vation $\left(v_{i}\right.$ ) is depicted by the closed triangles ( $v_{a}$ ). The inset to the figure shows the exponentional plot of " a vensus the prothrombin activation time.

disappearance gives the actual rate of prothrombin activation. The lacter then $1 \mathrm{~s}$ a true measure for the residual factor $\mathrm{x}_{\mathrm{a}}$ activity at time $t$ (Figure 3). From an exponentional plot of rate of prothrombin activation (prothrombinase activity) versus time, the pseudo first order rate constant of inhibition of factor $x_{a}$ by antithrombin IIT can be estimated (Figure 3 , inget).

The Inhibition of Factor Xa in Prothrombin Activation Mtxtures. Following the aforementioned procedure, inhibition of factor $x_{a}$ by antithrombin iri was studied in prothrombin actlvation mixtures of different compostion. In addition, the antithrombin III concentration was varied between 50 and 300 nM in order to obtain the second order rate constant of inhibition of factor $\mathrm{X}_{\mathrm{a}}$ under these circumstances.

The dependency of the pseudo furst order rate constant of inhibition of factor $\mathrm{X}_{\mathrm{a}}$ under the different conditions of prothrombin activation on the antithrombin III concentration is shown in Figure 4. "The validity of our measuring system is indicated by the observed Inear relationships. In 


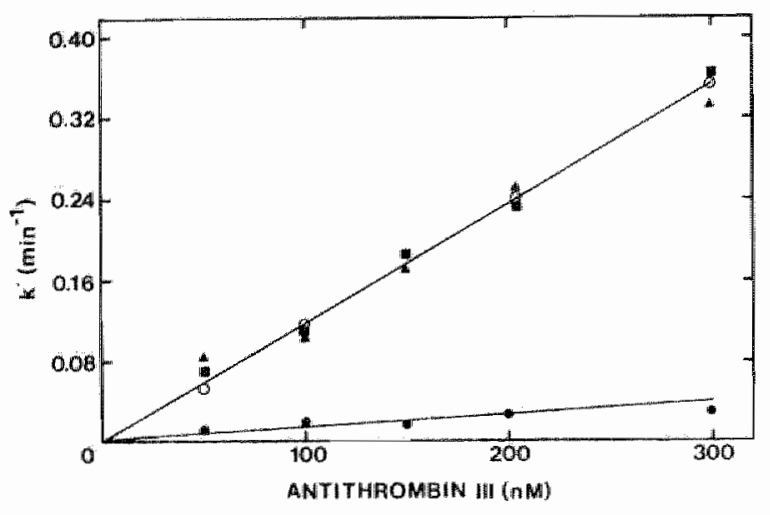

Figure 4: The pseudo first onder rate canstant of inhibition of factor $X_{a}$ as a function of the antithrombin III concentmation. Prothrombin was activated by: ( ) , factor $X_{a}$-factor $V_{a}$-phospholipid-Ca ${ }^{++} ;(\mathrm{O})$, factor $x_{a}$-factor $V_{a}-C o^{H+} ;(\Lambda)$, factor $X_{a}$-phospholipid-Ca ${ }^{++}$. The concentrations of the various reaction componente are liated in Table I, entries 1,2 and 3 , respectuvely. The prevdo first order rate constant of inhibition of factor $X_{a}$ was determined as described in pigure 3. The preudo first order rate constants of inhibition of free factor $x_{a}(\mathbf{)}$ ) were determined as described in Materials and Methods.

adidition, the first order plots extrapolated to within $10 \%$ of the rate of thrombin formation in the absence of antithrombin III. The second order rate constants are listed in Table II. When compared with the second order rate constant of inhibition of factor $x_{a}$ alone, as assayed with the synthetic peptide substrate $\mathrm{S}-2337$, it is clearly shown that the inhibition of factor $x_{a}$ is reduced only when both factor $v_{a}$ and phospholipid were present. No reduction of factor $x_{a}$ inhibition was found when prothrombin activation was performed in the presence of phospholipid and at a prothrombir concentration of $0.5 \mu \mathrm{M}$, $1 . e$. about $25-$ fold the $K_{n a}$ value (2). It 18 apparent that under these condittons, prothrombin is not a competitive Inhibitor of the factor $x_{a}$-antithrombin III reaction. Also when factor $v_{a}$ and phospholipid were present the second order rate constant of inhibition of factor $\mathrm{x}_{\mathrm{a}}$ was found to be independent of the prothrombin concentration when varied between below and above the $\mathrm{K}_{\mathrm{m}}$ (data not shown). 
Table II: The Second order Rate constants of Inhibition of factor $x_{a}$ and Thrombin by Antithrombin ILT.

Condition

Second order rate constant ${ }^{a}$

$\left(\mathrm{M}^{-1} \min ^{-1}\right)$

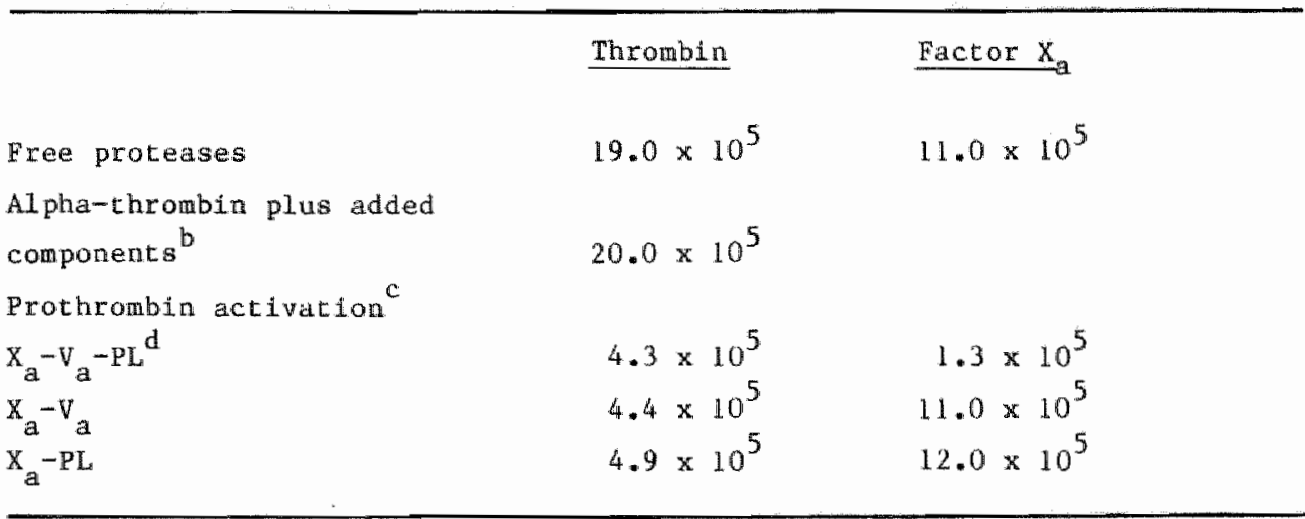

a The second order rate constants were determined as described in Materials and Methods.

b Inhibition of alpha-thrombin in the presence of prothrombin activation reactants.

c The conditions of prothrombin activation were as listed in Table I. The rate constants are given for the inhibition of the thrombin activity formed during prothrombin activation and for factor $x_{a}$ as part of the prothrombinase complex.

d PL, phospholipid.

Heparin (30 ng/ml) increased the pseudo flrst order rate constant of lnhibition of free factor $x_{a}(5 \mathrm{nM})$ by antithrombin III (100 nM) from 0.096 $\mathrm{min}^{-1}$ to $0.28 \mathrm{~min}^{-1}$. The synthetic peptide substrate $\$-2337$ was used to measure residual factor $x_{a}$ activity. When compared to the inhibition of Eree factor $X_{a}$, 10-fold higher heparin concentration was required to obtain a measurable effect of heparin on factor $x_{a}$ inactivation in the prothrombin activation mixture that contalned $3 \mathrm{pM}$ factor $\mathrm{X}_{\mathrm{a}}, 1.0$ HM pro thrombin, $0.1 \mathrm{nM}$ factor $V_{g}$ and $10 \mu \mathrm{M}$ phospholipid. The pseudo first order 
Table III: Pseudo First Order Rate Constants (k) of the Heparin-Dependent Antithrombin III-Protease Reaction.

\begin{tabular}{|c|c|c|c|}
\hline Protease & $\begin{array}{l}\text { Heparin conc. } \\
\qquad(\mathrm{ng} / \mathrm{ml})\end{array}$ & $\left.\operatorname{kin}^{-1}\right)$ & $\begin{array}{l}\left(k-k_{o}\right) /[\text { heparin }]^{b} \\
\left(\min { }^{-1} \mu g^{-1} n\right)\end{array}$ \\
\hline Free factor Xa & $\begin{array}{r}0 \\
30\end{array}$ & $\begin{array}{l}0.096 \\
0.28\end{array}$ & 6.13 \\
\hline Al pha-thrombin & $\begin{array}{r}0 \\
30 \\
100 \\
200 \\
300\end{array}$ & $\begin{array}{r}0.18 \\
1.34 \\
3.86 \\
7.41 \\
11.58\end{array}$ & $\begin{array}{l}38.7 \\
36.8 \\
36.2 \\
38.0\end{array}$ \\
\hline $\begin{array}{l}\text { Alpha-thrombin plue } \\
\text { added components }\end{array}$ & $\begin{array}{r}0 \\
30 \\
100 \\
200 \\
300\end{array}$ & $\begin{array}{l}0.18 \\
0.49 \\
2.73 \\
5.92 \\
8.48\end{array}$ & $\begin{array}{l}10.3 \\
25.5 \\
28.7 \\
27.7\end{array}$ \\
\hline $\begin{array}{l}\text { Prothrombin activat } \\
\text { FX }_{\mathrm{a}}-\mathrm{FV}_{\mathrm{a}}-\mathrm{PL}\end{array}$ & $\begin{array}{r}0 \\
300\end{array}$ & $\begin{array}{l}0.024 \\
0.056\end{array}$ & 0.11 \\
\hline Thrombin activity & $\begin{array}{r}0 \\
300\end{array}$ & $\begin{array}{l}0.040 \\
0.039\end{array}$ & 0 \\
\hline
\end{tabular}

a The pseudo first order constants were determined as described in Materials and Methods. "The antithrombln IIl concentration was $100 \mathrm{nM}$. b. $k_{o}$ pseudo first order rate constant of the heparin-independenc reaction. c Added components: prothrombin ( $1 \mu M)$, factor $V_{a}(0.1$ nM), phospholipid $(10 \mu \mathrm{M})$ and $\mathrm{Ca}^{++}(5 \mathrm{mM})$.

d The conditions of prothrombin activation were as 11sted in Table $I$, entry 1. The rate constants are given for factor $x_{a}$ as part of the prothrombinase complex and for the thrombin activity formed during prothrombin activation. 
The econd order rate constancs of Antbition tre listed in Table II. Under the different conditions of prothrombin activation we measured identical rate constants of inhibition $\left(4.5 \times 10^{5} \mathrm{M}^{-1} \mathrm{~min} \mathrm{n}^{-1}\right)$. Howewer, the rate constants were markedly reduced when compared with the inhibition of al pha-thrombin $\left(1.9 \times 10^{6} \mathrm{M}^{-1} \mathrm{~min}^{-1}\right)$.

It might be questioned whether the prothrombin activation reactants (e.g., factor $V_{a}$, phospholipld, $\mathrm{Ca}^{+}$and prothrombin) caused the reduced rate of inhtbition of the thrombin activity. To this end, pure alpha-thrombin (10 $\mathrm{nM}$ ) was added to a mixture containing factor $\mathrm{X}_{\mathrm{a}}(3 \mathrm{pM})$, factor $\mathrm{v}_{\mathrm{a}}(0.1 \mathrm{nM})$, phospholipid $(10 \mu \mathrm{M}), \mathrm{Ca}^{++}(5 \mathrm{mM})$, prothrombin $(\mathrm{l} \mu \mathrm{M})$ and soybean trypsin Inhibitor $(20 \mu \mathrm{g} / \mathrm{mL})$. Because of the presence of soybean trypsin inhibitor no thrombin formation occured. After an incubation of $5 \mathrm{~min}$ at $37{ }^{\circ} \mathrm{C}$, antithrombin III was added and samples were taken at different time Incervals to determine residual alphathromba artivity. The antithrombin 11L concentration varied between 50 and 300 nM. The second order rate constant of inhibition of alpha-thrombin under these conditions was found to be $2.0 \times 10^{6} \mathrm{M}^{-1} \mathrm{~min}-1$, Indicating that the prothrombin activation components had no effect on the rate constant of inhibition (Table II). To our surprise, heparin concentrations that caused a dramatic increase in the rate constant of Inhibition of alpha-thrombln had virtually no effect on the rate constant of inhibition of thromin activity formed from prothrombin by the prothrombinase complex. The pseudo first order rate constant of Inhibition of alpha-thrombin ( $5 \mathrm{nM}$ ) by antithrombin III ( 100 nM) in the presence of heparin $(30 \mathrm{ng} / \mathrm{ml})$ was $1.3 \mathrm{~min}^{-1}$, whereas the rates of dnhibition of thrombin activity in the prothrombin activation mixtures, $0.04 \mathrm{~min}^{-1}$ * remalned the same whether or not heparin $(300 \mathrm{ng} / \mathrm{ml})$ was present.

One explanation that might account for the absence of a heparin effect is that some of the prothrombin activation components remove heparin from the thrombin-antithrombin III reaction. Therefore, we performed the antithrombin til-dependent inhibition of alpha-thrombin in a mfxture containing $1.0 \mu \mathrm{M}$ prothrombla, $0.1 \mathrm{nM}$ factor $V_{a}, 10 \mu \mathrm{M}$ phospholipid, $5 \mathrm{mM} \mathrm{Ca}$ and varying anounts of unfractionated heparin. The pseudo first order rate constants are given in Table III. It is shown that in the presence of the added components the rate constants are lower, but proportional to the heparin concentration. It appeared that prothrombin competed with throm- 
bin-antithrombin II for heparin. However, it is clear that because of the absolute absence of a heparin-stimulating effect on the inhibition of the formed thrombin activity, a different cause has to be found.

Identiflcation of the Molecular Species with Thrombin Actidity During Prothrombin Activation. It has been reported that prothrombin fragment 2 reduced the rate of Inhibition of thrombin by antithrombin III about 3-fold. The second order rate constants for antithrombin III-mediated inhibition of thrombin in the presence of saturating amounts of fragment 2 and antithrombin III-mediated lahibition of meizothrombin (des fragment I) appeared to be identical (6). Therefore, our results showing a reduced rate of tuhibition of thrombin activity could be explained by the presence of prothrombin activation products fragment 1.2 and/or fragment 2. Another interesting possibility might be the formation of meizothrombin as an intermediate in prothrombin activation (14). In order to establish the presence of different molecular species with thrombin activity at nanomolar concentrations we used the following procedure. At timed intervals samples were removed from prothrombin activation mixtures containing prothrombin $(1.0 \mu M)$, factor $X_{a}(3 \mathrm{pM})$, factor $\mathrm{V}_{\mathrm{a}}(0.1 \mathrm{nM})$ and phospholipid $(10 \mu \mathrm{M})$. The samples were incubated with antithrombla III ( $1 \mu M)$ and heparin ( $1 \mathrm{Hg} / \mathrm{ml}$ ) at $37{ }^{\circ} \mathrm{C}$ for $10 \mathrm{~min}$, $1 . e$. sufficlently to abtain complete inhibition of thrombin activity. Subsequently, the samples were analysed by polyacrylamide gel electrophoresis in the presence of sodium dodecyl. sulfite, followed by a blotting procedure and detection of antithronbln III by antibodies conjugated with peroxidase, as described in the Matertals and Methods section. The results are shown in Figure 6. In addition to a heavily stalned band, comlgrating with the large excess of free antithrombin III, two antithrombIn III containing complexes are visulitzed: a ma jor band comigrating. with the melzothrombin (des fragment 1)-antiturombin II complex $\left(M_{r}=110,000\right)$ and a minor band comigrating with alphathrombin-antithrombin III complex $\left(M_{r}=91,000\right)$. Upon reduction the two antithrombin III-containing complexes were found at a position which corresponds to that of the thrombin B chatn-ant thrombin $\mathrm{C} L \mathrm{C}$ complex $\left(M_{r}=75,000\right)$. We concluded that the major product of prothroubln activation under initial rate condtions was meizothrombin (des fragment 1). 


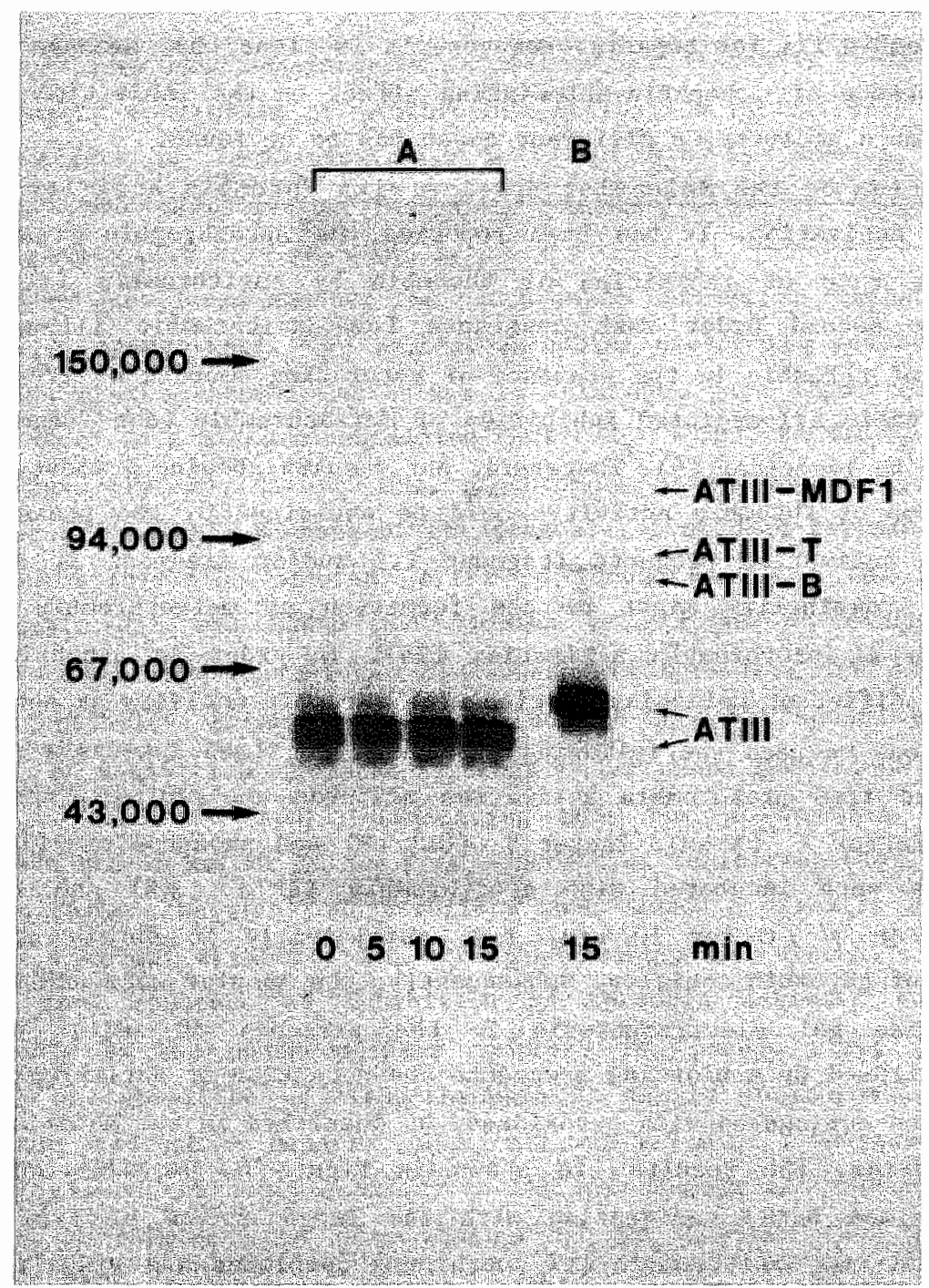

Figure 6. Identifiaation of molecular species with thrombin aetivity in prothrombin activation mixture. Prothrombin $(1.0 \mathrm{M})$ was activated by $[3 \mathrm{pM}$ factor $X_{\alpha}-0.1 \mathrm{mM}$ factor $V_{\alpha}-10 \mu \mathrm{M}$ phospholipid - $5 \mathrm{mM} \mathrm{CaCl_{2 }}$. Samples were removed at the times indicated, irubated with antithrombin III (I $\mu M$ ) and heparin (1 $\mathrm{\mu g} / \mathrm{mL})$ and subjected to SDS-gel electrophoresis. A, unreduced samples; $B$, diaulfide reduced sample. Abbreviations used: AT III, antithrombin III; MDF 1, meizothrombin (des fragment 1); T, atpha-thrombin; B, B-chain of alpha-thrombin. Experimental details are given in Materiale and Methods. 


\section{DISGUSSION}

In the present communication we report the results of a study on the inhibition of factor $x_{a}$ and thrombin by antithrombln III-heparin. Whereas other studles have used a synthetic peptide substrace on prothrombin to measure residual factor $x_{a}$ activity, our approach was to study factor $x_{a}$ inactivation under its actual working conditions, i.e. durling prothrombin activation. An inceresting advantage of this approach is that the effects of the reaction constituants like factor $v_{a}$, phospholipid and prothrombin (activation products) can be studied simultaneously on both the inactiwation of factor $\mathrm{x}_{\mathrm{a}}$ and the inhibition of thrombin activity.

In order to obtain a relationship between the thrombin activity at any time of the reaction and the pseudo first order rate constants of inhibition of factor $X_{a}$ and thrombin, Equation 1 can be expressed as:

$d / d t(T)=v_{0} \exp \left(-k_{1} t\right)-k_{2} T$

where $T$ is the thrombin concentration, $w_{0}$ is the rate of thrombin formation in the absence of antithrombin III, $k_{1}$ is the pseudo fitst order rate constant of inhibition of factor $x a$ and $k_{2}$ is the pseudo first order rate constant of inhibition of thrombin.

Integration of Equation 2 leads to:

$T_{t}=\left[v_{0} /\left(k_{2}-k_{1}\right)\right]\left[\exp \left(-k_{1} t\right)-\exp \left(-k_{2} t\right)\right]$

where $T_{t}$ is the thrombin concentration at time $t$.

Equation 3 was titilized to calculate the thrombln concenteacion at different time intervals of the prothrombin activation reaction under the conditions of the experinent given in Figure 1 . We have set $k_{1} 0.11 \mathrm{~min}^{-1}$, $k_{2}=0.047 \mathrm{~min}^{-1}$ and $v_{0}=2.8 \mathrm{nM} \mathrm{min}^{-1}$. The calculated thrombin activities are in excellent accord with those decermined experimentally (igure 7 ). Inhibition of Factor Xa. The experiments premented here show that when prothrombin activation occurs at a phospholipid surface in the absence of factor $V_{a}$, factor $x_{a}$ is not protected from inactivation by antithrombin IIr. Under this condition the second order rate constant of inhibition of factor $x_{a}$ was found to be $1.2 \times 10^{6} \mathrm{M}^{-1} \mathrm{~min}-1$ which is identical to the cate 


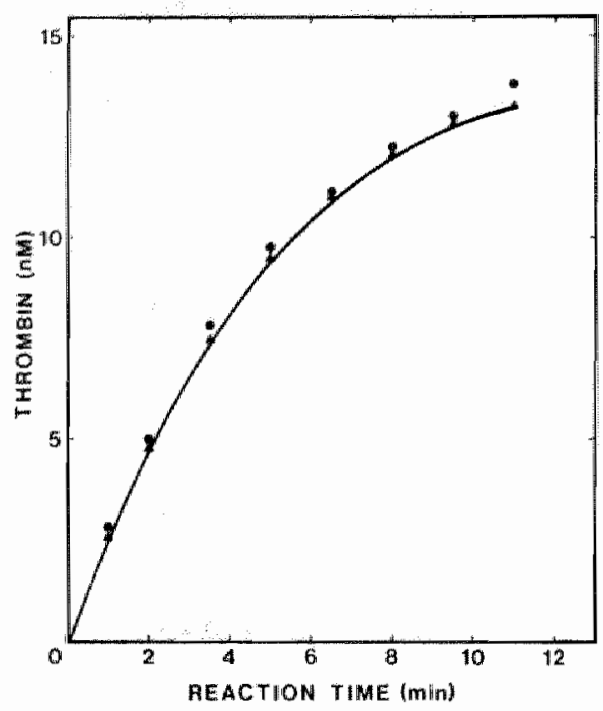

Figure 7 : Thrombin fornation duming prothrombin activation in the presence of antithrombin TIT. The conditions were as givan in Eigure 1. The experimental data (-) were taken from Figure 1. The data, alaulated as decomibed in the Discuseion seation, are preaented by the closed triangles.

constant of Inhibition of factor $x_{a}$ alone as measured with a synthetic peptide substrate (Table II). Because in the absence of phospholipid, factor $v_{a}$ did not protect factor $x_{a}$ from inactivation either, it is evident that protection must arise from the formation of the phospholipid-bound Factor $x_{a}$ - factor $V_{a}$ complex.

Ellis et al. (4) concluded that "the protective effect is probablly due to the factor $V_{a}$ that altered the binding of factor $x_{a}$ on the phospholipid surface in such a way that the steric hindrance to antithrombin III-binding is increased, with the large bulk of the factor $V_{a}$ molecule perhaps contributing to this effect". Walker \& Esmon (3) came to the same conclusion. Ellis et al. (4) reasoned that since their assay only determined phospholipid-bound factor $x_{a}$ and not free factor $x_{a}$, they have determined the kineties of inhibition of phospholipid-bound factor $x_{a}$. obviously, thls can only be true if during the time of the axperiment phospholipid-bound factor $X_{a}$ did not exchange with free factor $X_{a}$. We note that this assumption is probably irreconcilable or incompatible with the current knowledge of both the equilibrium and dymamic properties of factor $x_{a}$-phospholipid interaction $(15,16)$. The kinetics of the factor 
$x_{a}$-phospholipid interaction can be indicated by the second order rate constant of association and the first order rate constant of dissociation: $10^{-7} \mathrm{M}^{-1} \mathrm{~s}^{-1}$ and $2 \mathrm{~s}^{-1}$, respectively. Therefore, it is highly unlikely that ELLis at al. (4) have solely monitored the inhibition of phospholipid-bound factor $x_{a}$.

Our data support that notion. Using previously reported factor $x_{a}^{-}$ phospholipid binding parameters $(17,18)$ it can be calculated that under our conditions of prothrombin activation in the presence of phospholipid the amount of factor $x_{a}$ bound to phospholipid was at least $50 \%$ of the cotal amount of factor $x_{a}$ present. In addition, the $k_{m}$ walues for prothrombin in the presence or absence of phospholipid being $0.02 \mu \mathrm{M}$ and $100 \mu \mathrm{M}$, respectively (2), we can calculate that because prothrombin was present at a concentration of $0.5 \mu \mathrm{M}$, al1 phospholipid-bound factor $x_{a}$ is saturated with substrate, whereas in solution the amount of factor $x_{a}$-prothrombin complexes is neglegible. Therefore, our assay virtually measures the thrombin formation by the factor $x_{a}$ bound to the phosphollpid surface only. It is worth noting that synthetic preptide substrates at concentrations above thelr $x_{m}$ value have been reported to compete with antithrombin III for factor $x_{a}(19)$. Thus, when factor $x_{a}$ is saturated with prothrombin, we might expect to find such a competilive action of prothrombin in the factor $x_{a}$-antithrombin $t 4 l$ reaction. However, the second order rate constant of factor $x_{a}$ inactivation by antithrombin II during prothrombln activation in the presence of phospholipid was the same as that determined for free factor $x_{a}$ (Table $\left.I I\right)$. This observation, together with the known data on the kinetics of factor Xa-phospholipid interaction, strongly indicate that the hypotheses and conclusions of Ellis et al. (4) are untenable. That 1s, the effect of phospholipid on the kinetics of inhlbition of factor $x_{a}$ by antithrombin III cannot be explained by assuming that the enzymatic properties towards antithrombin III are altered when factor $X_{a}$ is bound to the phospholipld surface. Moreover, because of the rapid kinetics of the factor $x_{a}$-phospholipid interaction, the inhibition of free factor $x_{a}$ has to be considered as well. In this respect it is important to note the followlng.

Firstly, Pusey et al. $(16,20)$ demonstrated that factor $x_{a}$ has a very riarked effect on the rate of dissociation of factor $V_{a}$ frota a phospholipid surface. The most likely explanation for this effect is that because of the 
Light association between the two phospholipid-bound proteins a complex is produced wh tho membrane association sites (8). The overall result is a markedly reduced rate of dissociation of both factor $V_{a}$ and factor $x_{a}$ from the phospholipid surface. Therefore, the protection of factor $x_{a}$ from Inhibition by antithronbin IIL when both factor $v_{a}$ and phosphollpid are present might be caused by the reduced rate of dissociation of factor $x_{a}$ from the phospholipid surface.

Secondly, we demontrated that when prothromin is activated by the complete prothrombinase complex, factor $x_{a}$ is even more protected from inactivation by the heparin-dependent inactivation reaction than from the heparin-independent one. When compared with free factor $x_{a}$ a 55-fold and 4-fold lower pseudo first order rate constants were found in the presence and absence of heparin, respectively.

Thirdly, antithrombin III has no affinity for the phospholipid vesicles that were used throughout our studies (Lindhout, unpublished result).

In conclusion, our results argue strongly for a competition for factor $x_{a}$ between a phospholipid surface and antithrombin II in solution. It is feasible that protection of factor $x_{a}$ from inhibition by antithrombin $\mathrm{Ir}$ depends on both the rate of inhibition of factor $x_{a}$ in solution and the rate of dissociation of factor $x_{a}$ from the phospholipid surface.

Inhibition of thrombin. The second ald of this study was to reveal whether or not the kinetics of inhibition of alpha-thrombin differ from those of inhibition of thrombin activity formed during the initial phase of prothrombin activation. There has been a report on the effect of prothrombin fragiment 2 on the intibition of alpha-thrombin by antithrombin III $(6)$. In addition, recent work from our laboratory has indlcated that during the intelal phase of prothrombin activation by factor $x_{a}$ prothrombin is mainty cleaved between $\operatorname{Arg}_{323}$ and $L_{12} \mathrm{H}_{24}$, resulting in amidolytic active nelzothrombin (14). We found that the second order rate constant of inhibition of alpha-thrombin by antehrombin III was about 4 times the rate constant of thrombin activity in the prothrombin activation mixtures and independent of the composition of the prothrombinase complex. Walker \& Esmon (6) reported that fragment 2 was found to slow down the rate of inhlibition of alpha-thrombin about 3-fold. Therefore, the presence of fragment 2 and/or fragment 1.2 in our activation mixtures might be a plausible explanation for our findings. An alternative explanation is the 
formation of meizothrombin, because covalenty and non-covalently linking of Eragment 2 to thrombin gave the same second order rate constants of inhibition (6). Therefore, we analysed our activation mixtures for the presence of teizothrombin. As shown, a considerable amount of meizothromin (des fragment 1) was detected (Figure 6). Because meizothrombin appeared to be the main product under the conditions used, it can be questioned whether pure alpha-thrombin can be used as a standard to measure the reaction product of prothrombin activation. However, on basis of the functional molar concentrations as assessed by active site titration of meizothrombin preparations obtained by the activation of prothrombin by Rchis carinatus venom and alpha-thrombin preparations, we found no differences between the reactivity of alpha-thrombin and melzothrombin towards the synthetic peptide substrate $5-2238$.

Eigure 6 demonstrates that alpha-thrombin is present as a minor reacton product. Because the pseudo first order plots of inhibtulon of thrombin activity extrapolated to within $5 \%$ of the amount of thrombin activity origlnally present and assuming that alpha-thrombin is neutralized at a much faster rate than meizothrombin (Table II), it indicates that alphathrombin contributes to less than $5 \%$ of the total thrombin activity. In addition, our experimental data could be fitted according to Equation 3 with the experimentally determined pseudo first order rate constants of inhibition of both thrombin and factor Xa (Figure 7).

An effect of phospholipid, as described for the inhibition of factor $x_{a}$, on thrombin which might be bound to the surface via a covalantly or noncovalently linking wia fragment $\mathbb{1} .2$ could be ruled out. When soybean trypsin inhibitor was replaced by EDA, the rate of inhbition of thrombin did not increase.

Intriguing is the observation that when heparin is studied in prothrombin activation, mixtures, it had no effect on the Inhibition of thrombln activity by antithrombin III. We ruled out that this phenomenon was caused by the heparin-binding propertles of prothrombin. As yet, it rematng to be established to what extent and tn which mode fragment 2 and/or fragment 1.2 eicher covalently or non-covalently bound to alpha-thromin affects the interaction between heparin and thrombin. Recently, we indtiatced a study on the interaction between aeizothrombin and heparin. Our preliminary results 
Andtcate that in contrast to alpha-chrombin, meizothrombin is unable to bind hepartin.

Our work indicates that the mode of action of heparin and its derivatives on the process of blood coagulation can never be deduced from its actions. on the puriffed free serine proteases.

\section{REFERENCES}

1. Rosenberg, R.D.: Heparin-antithrombin system in "Hemostasis and Thrombosis: Baslic Principles and Clinical Practice" . [Ed] R.W. Colman, J. Hirsh, V.J. Marder, G.E.W. Salzman, J.B. Lipplncott, Philadelphia Pp. 962-985 (1982)

2. Van Rijn J.L.M.L., Govers-Riemslag J.W.P., Zwaal R.F.A., Rosing J.: Kinetic studies of prothrombin actlvation; the effect of factor va and phospholipids on the formation of the enzyme-substrate complex. Biochemistry $23,4557-4564(1984)$

3. Walker F.J., Esmon, C.L.: The effects of phospholipid and factor Va on the inhibition of factor Xa by antithrombin IIT. Biochem. Biophys. Res. Commun. 90, 641-647 (1979)

4. Eduis W., Sculdy M.F., Kakkar V.V.: Inhibition of prothrombiaase complex by plasma proteinasae inhibitors. Biachemistry 23, 5882-5887 $(1984)$

5. Marciniak E.: Factor Xa inactivation by antithrombin III. Evidence for biological stabilization of Factor Xa by factor V-phospholipid complex. Br.J.Haematol. 24, 391-400 (1973)

6. Walker F.J., Esmon C.T.: The effect of prothrombin fragment 2 on the Inthibition of thrombin by antithrombin III. J.BLol.Chem.254, 5618-5622 (1979)

7. Thaler E., Schmer G.: A simple two-step isolation procedure for human and bovine antithrombin II/III (heparin cofactor): a comparison of two methods. Br.J.Haematol. 31, 233-243 (1975)

8. Lindhout T., Govers-RIenslag J.W.P., van de Waart P., Henker H.C., Rosing J.: Factor Va-Factor Xa interaction. Effects of phospholipid vestcles of: varying composition. BLochemistry $21,5494-5502$ (1982)

9. Comfurtug P., Zwal R.F.A.: The enzymatic synthesis of phosphatidy1serine and purification by cm-cellulose column chronatography. Biochim. Blophys. Acta $488,36-42$ (1977)

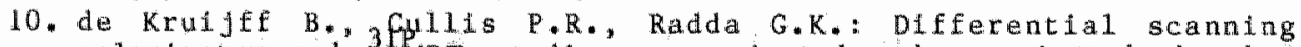
calorimetry and 3 NMR studies on sonicated and unsonicated phosphatidyleholine liposomes. Blochim. Biophys.Acta 406, 6-20 (1975)

11. Olson S. I. , Shore J.D." Demonstration of a two-step reaction mechanism for 1 nhibition of alpha-thrombin by antithrombin TII and identification of the step affected by heparin. J.Biol.Chen. 257, 14891-14895 (1982)

12. Laemill U.K.: Cleavage of structural protelns during the assembly of the head of bacteriophage T4. Nature 222, 680-685 (1970)

13. Towbin H., Staehelin T,, Gordon J.: Electrophoretic transfer of protetas from polyacrylamide gels to nitrocellulose sheets: Procedure and some applications. Proc. Nat..Acad.Sci. USA 76, $4350-4354$ (1979) 
14. Rosing J., Zwaal R.F.A., Tans G." Formation of meizothrombin as intermediate in factor Xa-catalyzed prothrombin activation. J.Biol. Chem, in press (1986)

15. Wei G.J., Bloomfield V.A., Resnick R.M., Nelsestuen G.L.: Kinetic and mechanistic analysis of prothrombin membrane binding by stopped-flow light scattering. Biochemistry $21,1949-1959$ (1.981)

16. Pusey M.L., Nelsestuen G.L.: Membrane binding properties of blood coagulation factor $V$ and derived peptides. Bilochemistry $23,6202-6210$ (1984)

17. Nelsestuen G.L., Broderlus M.: Interaction of prothrombin and blood-cloteing factor $x$ with membranes of varying compositlon. Biochemistry 16,4172-4177 (1977)

18. van de Waart P., Bruls H., Hemker H.C., Lindhout T.: Interaction of bovine blood clotting factor $\mathrm{Va}$ and its suburits with phosholipid vesicles. Blochemistry 22, 2427-2432 (1983)

19. Ceustermans R., Hoylaerts M., de Mol M., Collen D.: Preparation, characterization and turn-over properties of heparin-antithrombin IJJ. complexes stabilized by covalent bonds. J.Blol. Chem. 257, 340l-3408 (1982)

20. Pusey M.L., Mayer L.D., Wel G.J., Bloomfleld V.A., Nelsestuen G.L.: Kinetic and Hydrodynamic analysis of blood clotting factor V-membrane binding. Blochemistry $21,5262-5268$ (1981)

\section{ACKNOWLEUGEMENT}

We are grateful to Dr. George Willems for useful assistance with the data analysis, Dr. Hans Soons for assistance with the ellectrophoretic blotting. procedure and to Dr. Jan Rosing for reading and criticizing the manuscript. 


$$
-126-
$$


CHAPTER VLI

GENERAL, DISCUSSION

The work presented here concerns in vitro studies on the influence of heparin and heparin derivatives on the generation of thrombin. our aim was to identify some important reactions of blood coagulation and platelet activation that are sensitive to the action of heparin. Thrombla is generated from 1 ts presursor prothrombin by the proteolytic action of the prothrombinase complex. The maxtmal rate of thrombin formation 1 s increased 2000-fold in the presence of the non-enzymatic cofactor, factor $V_{a}(1)$. Factor $\mathrm{V}_{\mathrm{a}}$ is formed by the limited proteolytic action of thrombin on plasm factor V. Furthemore, thrombin catalyzes platelet activation reactlons inducing the release of factor $V$ and its activation. This illustrates how a trace anount of thrombin causes a considerable amplification of its awn formation and that regulatory mechanisns axe required in order to prevent the development of thrombosis as a result of such an explosive process of thrombin formation. It is important to note that heparin can inhlbit thrombin by two different mechanisms, either antithrombin III-dependent or antithrombin II-independent. Whereas the cole of heparin in catalyzing the antithrombin 111 -dependent lnactiveton of thrombin has been well documented, much less information is avallable on the signifleance of the antthrombin II-independent tnactivation of thrombin by hepartin (Chapteit I).

\section{Studies on thrombin-laduced platelet factor Va format lon}

In chapter II we describe a kinetic study on thrombtn-induced factor $W_{a}$ formation in suspensions of human platelets. The effect of thrombin trit stimulating the release ceaction could be separated from its affact on factor $V$ activation by use of a stable prostacyclin aralogue that blocked Instantaneously and completely the release reaction without interfering with the activation reaction. The rate-limiting gtep in thronbin-induced platelet factor $v_{a}$ formation was found to be the thrombinacatalyzed activation of the released non-activated factor $v$. The rate of platelet 
factor $V$ releage was 10 thes faster than the rate of factor $V$ activation and as fast as that of B-thromboglobulin release, a specific platelet a-granule protein (2). Thus our results differ from previously reported rates of factor $V$ release, that actually measured the rate of factor $V$ activation (3). The rates of factor $V$ release and factor $V$ activation appeared to be proportional to the thrombin concentration whereas the maximal amount of relessed factor was obtained at a thrombin concentration of $1 \mathrm{nM}$ and was identical to the amount measured in Triton $x-100$ lyzed platelets $\left(0.3 \mathrm{nM}\right.$ factor $\mathrm{W} / 10^{8}$ platelets/ml). This amount represents half of the value as determined by a radioimunoassay (4). However, it is Ldentical to the value reported by the same group in a more recent report (5). That all factor $\mathrm{W}$ present in platelets can be released by thrombin is in agreement with previous reports $(3,6)$. Whether other agents like collagen are able to completely release platelet factor $V$ is not yet established, because thrombin had to be used to convert the released factor $V$ in its biologlcal active form $(7,8)$. Our method, which offers a way to separate the release step from the activation step, infght be used to solve that problem.

An important question that needs to be addressed, is the contribution of platelet factor $V_{a}$ generation over plasma factor $V_{a}$ generation in the regulation of thrombin formation. Factor $x_{a}$ and factor $V_{a}$ interact stoichlometrically at the platelet surface $(9,10)$. Locally high platelet. factor $V_{a}$ concentrations wight be provided upon platelet stimulation. It has been reported that the presence of platelet factor $v$, rather than plasma factor $V$ activity, correlates with the severity of bleedling $(5,11)$. However, we found that the rate of activation of platelet factor $V$, once it is released by thrombin, is identical to the rate of plasma factor $V$ activation, and that platelet factor V concentration is only $10 \%$ of plasma factor $V$ concentration. Furthermore, in this respect, our study on the thrombin-induced platelet and plasma factor $V_{\text {a }}$ formation in patients with a Gray platelet syndrome, characterized by an absence of a-granules in the platelets, revealed some interesting information (chapter III). These patients have a moderate bleeding disorder that we found on the one hand, to go along with an almost normal plasma $V$ concentration and rate of plasma factor $V$ activation, and on the other hand revealed a decreased amount of platelet factor $V$ (less than $20 \%$ of normal), that required 4-fold higher 
thrombin concentrations in order to be released than what is observed in normal placelets. Thus, our results suggest that a significant reduction of platelet factor $V_{a}$ activity does not result in a severe bleeding disorder as long as the factor $V_{a}$ formacion is provided by plasma factor $V$.

The effect of heparin on thrombin-catalyzed reactions in the absence of antithrombin IIL. We have demonstrated that in the absence of antithrombin III, unfractionated heparin could inhibit four chrombin-catalyzed reactions: plasma factor $V$ and plasma factor VIILC activation, platelet factor Va formation and generation of platelet prothrombin converting activity. The generation of the latter requires the combined action of thrombin plus collagen (chapter IV). The concentrations of unfractonated heparin required to reduce the rates of the previously mentioned reactions to $50 \%$ of those in the absence of heparin are in the same range as the therapeutic heparin concentration in plasma ( 1 USP unit/ml). However, Low molecular welght fractions and fragments as well as a heparinoid were much less inhibitory in these thrombin-catalyzed reactions. Our results indicate that this effect of heparin 1 s caused by the formation of a $1: 1$ molar complex with thrombin. In this complex the activity of thrombin towards small synthetic peptide substrates remained Intact but was lmpared on macronolecular substrates.

It has been reported that heparin is able to displace the blood coagulation protelns involved in the prothrombin or Factor $X$ activating complex, from the phospholipid surface $(12-14)$. By equllibriun binding studles we have found that heparin did not alter the affinity nor the binding capaclty of the proteins for phospholipid vesicles. Furthermore, we showed that, in the absence of antithrombin $I \mathbb{L}$, heparin did not imbibit prothrombin activation. Thus, heparin did not interfere with the assembly not the functioning of the prothromblnase complex.

It might be questioned whether the inhibitory action of heparin in thrombin-catalyzed platelet activation 1 s caused by a heparin-platelet rather than by a heparin-thrombin interaction. Salzman et al. (15) reported that high molecular weight heparin fractions irrespective of thelr antithrombin III affintty induced signtficanty more platelet aggregation than low molecular weight, antithrombin III high affinity fractions. However, Hirsh (16) showed that antithrombin III low affinity fractions 
were unable to bind to platelets, whereas antithrombin II figh affinity fractions did.

We found that the release of $\beta$-thromboglobulin could be inhibited by unfractonated heparn when thrombin was used as the platelet activator but not In the case of collagen-induced $\beta$-thronboglobulin release. Unless heparth binds to the very same platelet site as thrombin does, this result supportg the notion that the thrombin-heparin interaction is the event that causes the inhibltory action of heparin on thrombin-catalyzed platelet actlvation reactions.

We further trivestigated the structural properties of heparin that are involwed in the mechanism of inhibition of the thrombin-catalyzed reactions in the absence of antithrombin IIL (Chapter $v$ ). We studied the influence of heparin fractions obtained from unfractionated heparin by lon-exchange chromatography, on thrombin-catalyzed platelet factor $V_{a}$ formation and on thromin Inactivation by antithrombin III in the presence of active-siteblocked thrombin. We observed a linear relationship between the $I_{50}$ values of hepartn fractions and their charge density, indicating that their affintly for thrombln increased with their charge density. This finding is in accordance with those of Hoylaerts et all. (17) as to the electrostatic nature of the interaction between heparin and thrombin. However, we found that hepardn fractions with increasing charge density also had an increasing percentage of antithrombin III-binding spectes. Furthermore, we found that an antithrombin III low affinity fraction hardly had any effect on thrombin-induced platelet factor $W_{\text {a }}$ formation whereas the antithrombin III high aftinlty fraction had a simllar effect as unfractionated heparin. We concluded that antithrombin III high affinity heparin contained most, 11 not all, of the thrombin-binding heparin species.

It is likely that the antithrombin III-independent mechanism of action of heparin is comparable to the anticoagulant properties of some sulphated hepartnolds like the pentosan polysulphate, and related to their thrombin affinity (18). The effect of pentosan polysulphate on some thrombincatalyzed reactions has been demonstrated in our laboratory (19). An important question is whether or not this antithrombin III-Independent effect of heparin on thrombin-catalyzed reactions of platelet activation and plasma factor $V$ and factor VIII:C activation is of importance in the regulation of the hemostatic mechanisms. As yet, this question cannot be 
answered. However, several studies have indicated that upon fractionation of crude heparin the in vitro antithronbin IIT-dependent activity of heparin can be dissociated from its in vivo antithrombotic and/ow hemorrhagic effects. For instance, an antithrombin III low atenity fractlon significantly increased bleeding without having any antithrombotic effect in vivo, as well as any antithrombin III-dependent anti-factor $x_{a}$ or anti-thrombin effect in vitro (20). It has also been reported that when an antithrombin III low affinity fraction was added to an antithrombin II high affinity decasaccharide devoid of in vitro anti-thrombin activity as well as in vivo antithrombotic activity, the mixture significanty prevented thrombosis in an animal experimental model (21). Buchanan et al. (22) have suggested that whereas the antithrombotic properties of heparin are related to the antithrombin III-mediated tactivation of serine prom teases, the hemorragic effects are due to an antithromblu MI-independent inhibition of platelet aggregation and of thrombin formation at the platelet surface. We believe that such an interpretation of the antithrombin Lli-independent effect of hepartu cannot be drawn from our studies which were limited to in vitro assays. However, our results clearly demonstrate that in studying the in vitro anti-thrombin activity of heparin(fractions), the antithrombin III-tindependent action should also be taken into account.

The antithrombin III-dependent action of heparin during factor $x$-catalyzed prothrombin activation.

The major question about the antithrombln III-dependent actions of hepartin on thrombin, generated by the prothrombinase complex and on the prothrom binase complex itself, is whether the actions of antithrombin III-heparin can be Inferced from studies on the inactivation of purtfled a-thrombin and factor $x_{a}$. It has been reported that when factor $x_{a}$ was bound to phospholipid elther in the absence or presence of factor $V_{\text {, }}$ its rate of inactivation by ant thrombin III was much slower than that of free factor Xa (23-25). In addition, prothrombin fragnent 2 , an activation fragment generated during prothrombin conversion was found to slow down about 2-fold the rate of inhibition of a-thrombin by antithrombin ri (26). No data are available on the effect of fragment 2 on the inactivation of a-thrombin by antithrombin III in the presence of heparin. In view of the physlological 
1mportance of the aforementioned modulating effects on both factor $X_{\text {a }}$ and a-thrombin tractivation by antehromin ILI-heparin, a study on the efficlency of antithrombin MI-heparin during the process of prothrombin activation 1 s highly relevant. To this end, we developped a method which allowed us to study separately the rate of factor $x_{a}$ inactivation by antithrombin III from the rate of thrombin inactivation during the conversion of prothrombin by the prothrombinase complex. We have found that both factor $V_{a}$ and phospholipid are required to obtain a protection of factor $x_{a}$ from the inactivation by antithrombin III. In the presence of hepartin, an enhanced protection was observed compared to the one in the absence of heparin. Kinetic studies on the interaction of factor $x_{a}$ with factor $V_{\text {a }}$ in the presence of phospholipid have shown that factor $V_{a}$ facilitates the bindling of factor $X_{a}$ to the phospholipid surface, by decreasing the dissociation constant about 200 -fold (26). Thus, the rate of Inactivation of factor $x_{a}$ by antithrombin III strongly depends on the way In which the equillbrium between free factor $x_{a}$ and bound factor $x_{a}$ is modifled in the presence of factor $V_{a}$. It is likely that a protection of factor $x_{a}$ from inhibition by anththrombin III depends on both the rate of inhibition of factor $x_{a}$ in solution and the rate of dissociation of factor $x_{a}$ from the phospholipid surface. This is in contrast with other studies where it has been suggested that the binding of factor $x_{a}$ to phospholipid altered its enzymatic properties $(24,25)$. Our study on the inactivation by antichrombin III of the thrombin activity generated during prothrombin activation revealed an important difference with the inactivation of the purffled enzyme, a-thrombln. This difference resulted in a 4-fold lower aecond order rate constant of inactivation of the formed thrombin than the one for the inactivation of a-thrombin. Analysis of the molecular species whitch are formed during prochrombin activation showed that considerable amounts of melzothrombin (des fragment 1) were formed during the early stage of prothrombin activation. This is in accordance with the findings of Rosing al. (28). Under our conditions we found that the amount of a-thrombin represented about $5 \%$ of the total thrombin activity. Because the rate of Inactivation of melzothrombin is slower than that of a-thrombin, this finding thus explains why the rate of lnhibition of the thrombin activty generated during prothrombin actiwation is lower than the race of inhibition of purified a-thrombin. 
Furthermore, we found that in contrast with its effect on the inactivation of $a-t h r o m b i n$ by antithrombin III, heparin could not entance the rate of inactivation of the thrombin activicy formed by the prothomblatise complex. Preldmary results from our laboratory indicate that the affintey af heparin for melzothrombin ls at least one order of magnitude lower chan its affinity for a-thrombin.

Thus, the analysis of the inhibition by antithrombin IIL of thrombin formed by the prothrombinase complex, not only shows that this inhibitory effect differs from the one on the purified enzymes, but ralses new questions an the mechanism of thrombin formation.

\section{REFERENCES}

1. Rosing, J., Tans, G., Govers-Rlemslag, J.H.P., Zwad, R.F*A., Hemker, H.C.: The rolle of phospholipids and factor Va in the prothromblnase complex.J. Biol. Chen. 255, 274-283 (1980)

2. Akkerman, J.W.N., Gorter, G., Kloprogge, E.: KInetic analysts of a-granule secretion by platelets; a methodological report. Thromb. kes. $27,59-64(1982)$

3. Kane, W.H., Lindhout, T., Jackson, C.M., Majerus, P.W.: Factor Va dependent binding of factor Xa to human platellets. J. Blol, Chem. 255, 1170-1174 (1980)

4. Tracy, P.B., Eide, L.L., Bowle, E.J.W., Mann, K.G.: Radiolmmunoassay of factor V in human plasma and platelets. Blood 60, 59-63 (1982)

5. Tracy, P.B., Giles, A.R., Mamn, K.G., Elde, L.L. Hoogendoorn, H., Rivard, G.E.: Factor $V$ (Quebec): A bleeding diatheslis associated with a qualitative platelet factor W deficiency. J. Gin. Invest.74, 1221-1228 (1984)

6. Usterud, B. Rapaport, S.L., Lavine, K.L.: Factor V activity of platelets. Evidence for an activated factor $V$ molecule and for a platelet activator. Blood 49, 819-834 (1977)

7. Vicic, W.J., Lages, B., Weiss, H.J.: Release of human platelet factor activity is induced by both collagen and ADP and is luhibited by aspirin. Blood $56,448-455$ (1980)

8. Chesney, C.M., Pifer, D., Colman, R.W.: Subcellular locallzation and secretion of factor $V$ from human platelets. Proc. Nath. Acad. Sci. 78, $5180-5184$ (1981)

9. Tracy, P.B., Mesheim, M.E., Mann, K.G.: Coordinate binding of factor Va and factor Xa to unstimulated platelets. J. Blol. Chem. 256, 743-751 (1981)

10. Lindhout, T., Govers-Riemslag, J.W.P., wan de Wart, P*, Hemker, H.C., Rosing, J.: Factor Va-factor Ka lnteraction. Efects of phospholipid vesicles of varying composition. Blochemlstry 21 , 5494-5502 (1982)

11. Miletich, J.P., Majerus, D.W., Majerus P.W.: Patients with congenital factor $V$ deficiency have decreased factor $X a$ binding sites on thetr platelets. J. Clin. Invest. 62, 824-831 (1978) 
12. Walker, F.I., Rsmon, C.T.: Interactions between heparlin and factor Xat. Inhibltion of prothrombin activation. Blochin. Blophys. Acta 585 , $405-415(1979)$

13. Brown, J.E., Baugh, R. Hougle, C.: The inhibition of the inteinsic generation of accivated factor $X$ by heparin and hirudin. Thromb. Res. 17. $267-272(1980)$

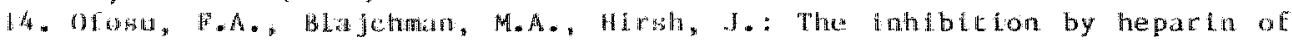
the incrinstc pathway activation of factor $X$ in the absence af antithrombin III. Thromb. Res. 20, $391-403$ (1980)

15. Salzman, E. W., Robenberg, R.D., Smith, M.H., Lindon, J.N., Favreau, L.: Effect of heparin and heparin fractions on platelet aggregation. J. C1in. Invest. $65,64-73$ (1980)

16. Hirsh, J.: Heparin induced bleeding. Nouw. Rev. Franc. Henato1. 26, $261-266 \cdot(1984)$

17. Hoylaerts, M., Owen, W.G., Collen, D.: Involvment of heparin chain length in the heparin-catalyzed inhibition of thrombin by antithrombin III. J. Blol. Chem. 259, 5670-5677 (1984)

18. Scully, M.F., Kakkar, V.V.: Effect of a pentosan polysulphate upon thrombln and factor Ka inactivation by antithrombin III. Biochen.. J. $222,571-578(1984)$

19. Wagenwoord, R., Hendrix, H., Soria, C., Hemker, H.C. Determination of the non-antithrombin LII dependent inhtbitor site of pentosan Polysulphate in the blood coagulation. Thrombos. Haemostas. In press (1986)

20. Ockelford, B., Carter, C.J., Cerskus, A., Smith, C.A., Hirsh, J.: Comparison of the in vivo haemorrhagic and antithrowbotic effects of a low heparin fraction. Thromb. Res. 27, 679-690 (1982)

2L. Barrowcliffe, T.W., Merton, R.E., Havercroft, S.J., Thunberg, U., Thomas, D.P.: Low affinity heparin potentiates the action of high affinity heparin oligosaccharides. Thromb. Res. 34, 125-133 (1984)

22. Buchanan, M.R., Boneu, B., Ofosu, E*, Hirsh, J: The relative importance of thrombin inhibition and factor Xa intubition to the anththrombotic effects of heparin. Blood 65, 198-201 (1985)

23. Marclniak, E.: Factor Xa inactivation by antithrombin III. Evidence for biological stabilization of factor Xa by factor V-phospholipid complex. Brit. J. Haem. 24, 391-400 (1973)

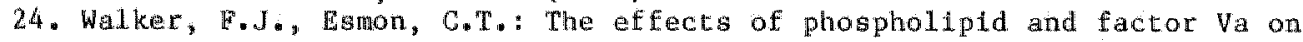
the Inhibition of factor Xa by antithrombin ITI. Biochem. Biophys. Res. Cominun. 90, 641-647 (1979)

25. Ellis, V., Scully, M.F., Kakkar, V.V.: Inhibition of prothrombinase complex by plasma proteinase inhlbitors. Biochenistry $23,5882-5887$ (1984)

26. Walker, F.J., Esmon, C.T.: The effect of prothrombin fragment 2 on the Inkibltion of thrombin by antithrombin III. J.Blol.Chem. 254, 5618-5622 (1979)

27. van de Wart, P., Bruls, H., Hemker, H.C., Lindhout, T.: Interaction of bovine blood clotting factor $\mathrm{Va}$ and its subunits with phospholipid vesicles. Biochemistry 22, 2427-2432 (1983)

28. Rosing, J., Zwaal, R.F.A., Tans, G.: Formation of meizothrombin as tnternediate in factor Xa-catalyzed prothrombin actiwation. J. Biol. Chom. In Press (1986) 
SUMMARY

Heparia, a heterogeneous mucopolysaceharide existing in different molecular forms is widely used in antithrombotic therapy. The relationship between its in wivo antithrombotic and in vitro anticoagulant action is far from being understood. The aim of our work is to identify sone reactions of blood coagulation that contribute to thrombus formation and that are sensitive to the action of heparin. In this respect chrombin has central role in the blood coagulation process as it governs several positiwe feedback reactions. Heparin linhibits thrombin through two different mechanisms that are either dependent or independent of a plasma inhtbitor, antithrombin I.I. . Whereas the antithrombin III-medlated mechandsen of heparin action has beeu extensiwely studied, the artithrombln ILLindependent one has been the subject of a very few lavestigatlons. These studies are reviewed in Chapter 1.

The prothrombinase complex, which converts prothrombin into thrombin, consists of the enzyme factor $X_{a}$ bound to the protelin cofactor factor $V_{a}$ " assemblied on a phospholipid surface. Factor $V_{\text {a }}$ is formed by the proteolytic action of thrombin on a blologlcally inactive procofactor, factor $V$, which is present in plasma and in the alpha-granules of platelets. Moreover, thrombin induces the release of platelet factor $V$. We were able to determine the kinetios of platelet factor $V$ release and activation in thrombin-activated platelet suspensions by using a specific inhibicor of the release reaction, a semi-synthetic prostacyclin analogue (Chapter LD). We found that the initial rate of factor V releage 1 s lo-fold Faster than the rate of factor $v$ activation which is the rate-limiting step of platelet factor $V_{a}$ formatlon. The platelet factor $V$ concentration is onliy $10 \%$ of the one in plasma. In this respect it can be quegtloned whether platelet factor $v_{\text {a }}$ activity contributes to thrombin formation conpared to plasma factor $V_{a}$ activity. Alchough it may be important for the humostasts and coagulation processes to obtain high factor $V$ concentrations at the site of platelet activation, two arguments point to this contribution rot being essential. First, factor W from plasma or platelets are functonally identical. Second, studies on platelets from patients with a heredtary alpha-granule deficiency revealed a factor $V$ content which was about $1 \%$ of 
their plasma factor $V$ concentration. (Chapter III). Despite this platelet factor $v$ deficlency these patients have a moderate bleeding disorder. In this case, plasma factor $V$ which was found to be quantitatively and functonally normal, might account for a not severely impaired thrombin Eormation.

The inhibition of thrombin-catalyzed reactions such as plasma factor $v$ activation and platelet factor $V_{\text {a }}$ formation is a potential regulatory mechanism against thrombosis, as it results in an interruption of the amplification of thrombin formation. As a first step to study these complex reactions we showed that in the absence of antithrombin III, an inhibitory effect of heparin could be demonstrated on four thrombin-catalyzed reactions (Chapter IV). Besldes the two previously mentioned reactions, plasma factor $V$ activation and platelet factor $V_{a}$ formation, thrombin converts plasma factor VIII:C to factor VIII and, in the presence of collagen, induces the platelet prothrombin converting activity by providing a procoagulant phospholipid surface. This inhibitory action of heparin is due to the formation of a complex wth thrombin, where the activity of thrombla towards tts macromolecular substrates is impalred, but its enzymatic activity towards small synthetic peptide substrates is unaffected. We found that unfractonated heparin has a higher affinity for thrombin than the low nolecular weight heparin fractions that we studied. The inhibitory action of heparin on platelet activation by thrombin was not due to an effect of heparin on platelet functions.

To better characterlae the properties of heparin fractions involved in the inhibition of thrombin-catalyzed reactions in the absence of antithrombin III, we studled the effect of heparin fractions obtained by fon-exchange chromatography (chapter $V$ ). We found that the affinity for thrombin increased with the charge denstey of heparin fractions, indicating an electrostatic type of interaction with thrombin. However, in parallel with the vartation in charge density, the heparin fractions were found to differ in their percentage of antithrombin III-binding species. Furthermore, an antititrombin ILI low affinity fraction had no inhibitory effect on the thrombin-catalyzed platelet factor $\mathrm{V}_{\mathrm{a}}$ formation. Our results suggest that in a heterogeneous heparin preparation no polysaccharide chalns can be found which have exclusively an antithrombin III-independent action on thrombin. 
It has been reported that the antithrombin III-dependent action of heparin on the Inactivation of thrombin and factor $x_{a}$ is modified by the presence of the components of the hemostatic system. However, the inhibitory mode of action of antithrombin III-heparin on factor $x_{a}$ and thrombin during thrombin formation by the prothromblnase complex remained uncertain, "Therefore we have developped a method in order to assess the effect of antithrombin III-heparin on the inactivation of factor $x_{a}$ and thrombin during prothrombin activation by the prothrombinase complex. This inhlbitory action was compared to the inactivation of each of the purifled, free enzymes (Chapter VI). In the presence of phospholipid and factor $v_{a}$, factor $x_{a}$ was protected from the inactivation by antithrombin III alone and in the presence of heparin. Moreover, independent of the composition of the prothrombinase complexes, the rate of disappearance of the amidolytic activity of the formed thrombin was considerably slower than the one of purified thrombin (alpha-thrombin). This was explained by the fact that, during prothrombin activation, the chrombin activity resulted mainly from the formation of meizothrombin and to a minor extent of alpha-thrombin. In contrast to thrombin, meizothrombin is virtually insensitive to the action of antithrombin III-heparin. Our conclusion is that the action of heparin on the antithrombin III-mediated inactivation of purifled thrombin and factor $x_{a}$ cannot be extrapolated to its effect in conditions that are more likely to reflect the in vivo situation. 
RESUME

L"hêparine, melange de mucopolysaccharides sulfatés, est un agent antithrombotlque largement ut1Lige en clinique humaine sous diverses formes moleculatres. Les relations existant entre son action antithrombotique in vivo et son action anticoagulante in vitro sont loln d'etre entièrement Elucldês. L"abjectif de notre travail est de reconnaitre, parmi les reactions de la coaguiation qui sont importantes dans le developpement de la thrombose, celles qui sont sensibles à l'action de l'héparine. A cet égard, on peut considerer que la thrombine occupe une position centrale dans la coagulation car elle contrôle plusieurs réactions conduisant a une amplification de sa propre formation. L'héparine peut inhiber la thrombine par deux mécantsmes dlfferents selon que son action est dépendante ou indépendante d'un Inhibiteur plasmatique, L'antithrombine ILI. Alors que le mécanisme d'action de L'héparine medié par 1'antithronbine III est le mieux

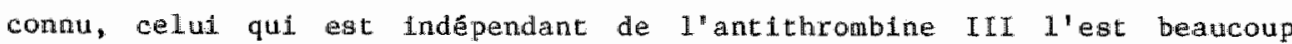

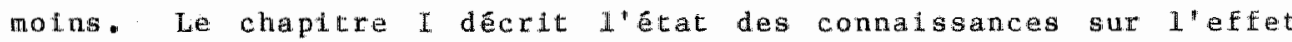
inhibiteur de 1'héparine sur la thrombine dans chacune de ces deux voies. Le complexe de la prothrombinase, quil permet la conversion de prothrombine en thrombine, est formé par un enzyme, le facteur $X_{\mathbb{Q}}$, associé à un cofacteur proteique, le facteur $V_{a}$, qui sont assemblés sur une surface phospholipidique. Le facteur $V_{a}$ provient de $L^{\prime a c t i o n ~ p r o t e ́ o l y t i q u e ~ d e ~ l a ~}$ thrombine sur un procofacteur blologiquement lnactif, le facteur $V$, présent dans le plasola et dans les gramules alpha des plaquettes. De plus la thrombine Induit la secretion du facteur $W$ plaquetalre. Alnsi apras gtimulation des plaquettes par la thrombine, deux réactions (secretion du facteur $V$, activation en facteur $V_{a}$ ) ont lieu simulanement. Nous avons pu déteminer sêparément les clnetiques des deux rétactions en ajoutant au cours du temps un lnhibiteur spéclifique de la réaction de sécrétion, un analogue semi-synthétique de la prostacycline (Chapltre II). Nous avons montre que la vitesse thitlale de secrtton du facteur $V$ est 10 fais plus rapide que celle de son activation. Celle-ci represente donc l'étape limitante de la formation d"activite facteur $v_{a}$ plaquettaire. De plus nous avons trouve que la concentration du facteur $v$ plaquetcalre ne représente que $10 \%$ de celle du plasma. Cela pose le probleme de la contributín de l'activite facteur $V_{a}$ plaquettaire par rapport a l'activité facteur $V_{a}$ 
plasmatique dans la focmacton de chromblne. Bien que l"obention de concentrations elevtes de facteur $V$ a a ste meme d"activaton des plaquettes pulsse avoir une Importance dans les processus d'henostase de coagulation, deux arguments soulignent que cetce contribution n'est pas essentielle. D'une part, sur le plan fonctionnel les facteurs plasmatque et plaquettaire sont identiques. D'autre part, l'etude des plaquettes de patients présentant une absence congénitale en granules alpha a révểé qu'ejles ne contiennent pas plus de $1 \%$ du facteur $V$ présent dans leur plasma (Chapitre III). Malgré cette anomalie du facteur V plaquetcaire, ces patients ne présentent qu"un syndrome hémorragique modéré. Ceci peut être attribué a la présence d'un facteur V plasmatique fonctionnellement et quantitativement normal.

L'inhibition des réctions catalyses par la thrombine, telles que 1"activation du facteur $V$ plasmatique et la formation du facteur $V_{a}$ plaquettaire, représente un mécanisme régulateur potentiel de protection contre la thrombose car elle intercompt l'auto-amplification de la formation de thromblne. Notre première apprache à letude de ces interactions complexes a ete de dénontrer qu'en absence d'antithrombine III, quatre rẻactions catalysées par la thrombine pewvent etre inhibés par l'heparine (Chapitre IV). Outre les deux rëactions decrites ci-dessus, 1 'activation du facteur $V$ plasmatique et la formation d'activité facteur $V_{\text {a }}$ plaquettaire, la thrombine active le facteur VIII:C plasmatique en facteur VIIT et, en présence de collagène, indult la formation d"une activlté procoagulante de nature phospholipidique a la surface des plaquettes. L'action lnhibitrice de l'heparine est dô a la formation d"un complexe avec lat thrombine, dans lequel 1'activite de la whrombine vig-rists de ses substrats macromoleculaties est inhibee sans que son activfte enzynatique sur des petits substrats peptidiques synthetiques solt modifié. Nous avong

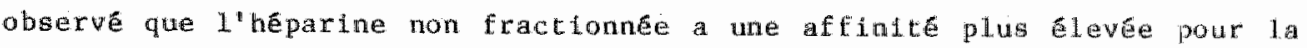

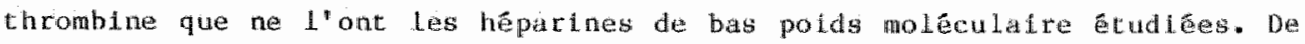
plus I."action Inhibitrice de l'heparine sur les reactions d'activaton des plaquettes par la thrombine $n^{\prime}$ est pas dôe $1^{\prime}$ inhibition des fonctions plaquettalres par l'heparine.

Pour prêtser les caracteristiques de l'hêparine et de ses dérivés

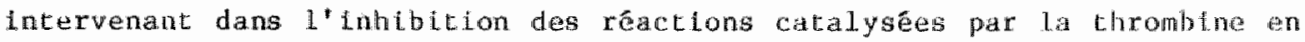
absence d'antithrombine III, nous avons etude lé leffect de fractons 
d"hepartne obtenues par chromatographle sur colonne Echangeuse d'ions (Chaptire $W$ ). L'afflnite de fractions d'heparine pour la thrombine augmente avec leur densite de charge, indiquant la nature électrostatique de la Lialson hêparine-thrombine. Cependent la variation de densté de charge de ces fractions va de patr avec la variation du pourcentage d'especes moleculalres possedant le ste de liatson t'antithromblne II. De plus une fraction d'héparine de fable affinde pour l'antithrombine tir est depourvue d'action Inhibitrice sur la réaction de formation d'activitë facteur $V_{a}$ plaquettaire catalysëe par la thrombine. Nos resultats suggerent qu" partir d"une prêparation d'hêparine hêtérogène on ne peat isoler de(s) chalne(s) polysaccharldique(s) ayant une action anti-thrombine qui soit exclusivement 1ndépendante de L'antithrombine III.

Un effet nodulateur des composés du systène hémostatique a été décrit sur l'inactivation des enzymes de la coagulation par l'antithrombine Irthêpartne. Cependant le mode d"action fnthbltrice de l'antithrombine III-hepartine sur le facteur $x_{a}$ et la thrombine Lors de la formation de celle-cl par le complexe de la prothrombinase n'est pas clairement etabli. C'est pourquoi nous avons développé une mêthode qui nous permet de determiner L'action de l'antithrombine III-beparine, d'une part sur le facteur $x_{a}$ participant ati complexe de la prothrombinase, d"autre part sur la thrombine formểe par la prothrombinase. Cette action a été comparé a l'inactivation de chaque enzyme puriflé, libre en solution (Chapitre VI). En présence de phospholipides et de facteur $V_{a}$, le facteur $x_{a}$ est protégé de 1" Inactivation par 1'antithrombine III sevle et en presence d'heparine. Par alleurs 1"action Inhibitrice de l'antithrombine III-hêparine sur la thrombine formé est beaucoup moing importante que son action sur la thromblne puriflea (alpha-thrombine). Ce phenomene est observe quelle que sult La composition des complexes de la prochrombtnase. L'expltcation pent en ecre trouvee dans l"étude des prodults d'activation de la prothrombine. I1 semble que l'actulté de la thrombine ainsi formée résulte non seulement de la formation d"alpha-thrombine, mais surtout de la formation de melzothrombine. Contrairement a la thrombine, celle-ci est pratiquement insenstble a l'action de $L^{*}$ antlthrombine TII-héparine.

En conclusion 11 est clair que l'action de l'heparine medlée par L'antithrombine III, sur l'inactivation du facteur $x_{a}$ et de la thrombine puriflés, ne peut pas être extrapolêe a son action étudiée dans des conditions refletant mieux la situation physiologique. 


\section{SAMENVATELNG}

Heparine wordt veelwuldig toegepast bij de behandeling en preventie van veneuze tronbose en trombo-embolisme. Het is bekend dat heparine een bloedstollings-remmende werking heeft. Echter, het verband tussen de antistollings- en antitrombotische werking van heparine 1 s nagenoug onbekend. In het onderzoek naar deze relatle staan twee vragen centraal: welke processen (bloedstollingsteacties) hebben een sleutelpositie in het ontstaan van trombose en op welke wijze werkt theparine in deze redcties. In hoofdstuk I wordt op deze vragen nader Ingegaan.

Omdat trombine, gevormd in de voorlaatste stap van het bloedstollingsproces, middels positieve tegenkoppelingsreacties, een grote rol speelt in zijn elgen vorming, hebben we ons vooral gericht op het bestuderen van een aantal trombine-afhankelijke reacties en het effect wan heparine daarop. Trombine wordt gevormd uit prothrombine door het zogenaamde prothrombinase complex. Dit complex bestaat wit het enzym factor $X_{a}$ en de elwit cofactor factor $V_{a}$, gebonden aan een membraan, een fosfolipide oppervilak. Factor $V_{a}$ wordt gevormd uit en blologisch frnactieve procafactor onder invloed van trombine. De procofactor, factor $V$, is een plasma eiwit, mar het kont ook voor in de alpha-granula van de bloedplaatjes. Trombine is in stat factor $V$ uit de plaatjes te laten treden (release-reactie) waarna factor $v$ vervolgens door trombine wordt ongezet in zijn actieve vorm. Hoofdstuk II beschrijft de kinetiek van de plaatjes factor $v$ release-reactie en de plaatjes factor $V$ activeringreactie. Deze twee, simultaan verlopende, reacties konden apart bestudeerd worden door het gebrulk van een reminer, een semi-synthetische prostacycline analoog, van de release reacte. We vonden dat de actiweringsreactle de snelheidsbeperkende stap in de plat jes factor $V_{\text {a }}$ vormingsreactie 1 .

De hoeveetheid factor $V$ abnwezh in circulerende bloedplaatjes 1 s alechts $10 \%$ van de hoeverthetd factor $V$ aanwezlg in plasma. Dit felt en de waarneming dat plaatjes factor $V$ en plasma factor $V$ in alle opzlchten identlek $z i j n$, roept de vraag op of platejesfactor wel een specifleke fysiologische becekenis heeft, zoals in de literatur gesuggereert wordt.

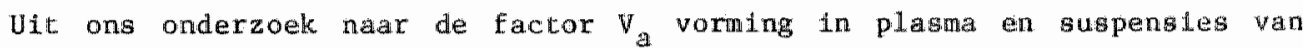
bloedplaatjes van patienten met en exfelijke alpha-granula deficlantie 
(Graly-platelet syndroom) blijkt dat hoeveelteid factor $v_{a}$ die uit hun plaatjes vrijgemakt kan worden hoogut $1 \%$ is van de hoeveelheid te vormen plasma factor $v_{a}$. Interessant ls dat deze patienten desondanks geen errstige bloedingsmelgingen vertonen. Wellicht komt dit door een bijna normal plasma factor $V$ gehalte (Hoofdstuk III).

Het remen van de trombine-gekataliseerde reacties zoals plasma en plat jes factor Va vorming, activeren van factor wII en het activeren van bloedplatijes, kan op het tromboseproces een belangrijke invloed hebben. liminers, op deze manfer wordt de vorming van trombine gereguleerd. In plasma bevindt zich het antitrombine III, een belangrijke remuer van trombine. Hepartne speelt bij deze reactie een catalytische functie. Echter, ook zonder antitrombine III is heparine in staat trombine te inactiveren. De antitrombine IIL-onafhankelijke antistollingselgenschap van heparine is nog nawelifkis bestudeerd. In hoofdstuk IV tonen wij aan dat een aantal troubtne-afhankelifke reactles ook zonder antitromblne III door heparine geremd worden, zoals plasma factor $V$ en plasma factor VIII activering en het induceren van een plaatjes procoagulant oppervlak. Deze heparine werking is het gevolg van de vorming wan een complex tussen trombine en heparine, warbij de trombine zign activitelt t.o.v. natuurlijke, hoog moleculair gewicht, substraten verliest. We vonden dat nlet-gefractioneerde, klinisch toegepaste heparine veed meer effect had dan gefractioneerde, laag moleculair gewicht heparines.

Nader onderzoek nar het effect van heparine fracties verkregen na schelding op een ionenwisselaar, laat zien dat de affinitelt van deze heparine fracties voot trombine en dus hun remende werking, toeneent met de ladingodichtheld van de fractiles (hoofdstuk $v$ ). Wij hebben tevens gevonden dat de fractionerting naar ladingadichtheld geparar gat met een vertifking in antitromblne Iri-bindende heparine fracties. Omgekeerd, waneer heparine gefractioneerd wordt op basts van affinitelt voor antitromblne TII zien we dat de fractes met lage affiniteit voor antitrombine III alet in staat aijn trombine te inactiveren. Hierbij willen we benadrukken dat het antitrombine III en trombine feder hun elgen specifieke bindingsplats heeft op het heparine molecull. Dit betekent dat met, in de trombine-remmende pollysaccharide ketens van een heterogeen heparine preparat, zowel de antitrombine III-afhankelijke als antitrombine 
III-onathankelijke reming van tromblne gevouden kan worden. Met andere worden, er bestaat geen heparine molecuul dat uitsluitend antitrombine III-onafhankelijk werkzaam is.

De rol van hepariue in de hactivering van gezuiverd trombine en factor $x_{a}$ is door veel onderzoekers bestudeerd. In een aantal studies waden hierbij enkele componenten van het hemostase systeeem betrokken. Bchter, de vraag wat is thet effect van heparine op de inactivering van trombine en factor $x_{a}$ door antitrombine III tijdens het proces van de protrombine activering bleef onbeantwoord. Wij hebben een methode ontwikkeld warmee dit probleem zeer goed benaderd kan worden (hoofdstuk $V I$ ). We laten zien dat in tegenstelling tot het vrijkomen factor $x_{a}$, factor $x_{a}$ als onderdeel van het protrombinase complex tijdens de omzetting van protromblne in trombine in aanwzigheid van therapeutische hoeveelheden heparine nagenoeg angevoel. $\mathrm{g}$ is voor de inactivering door antitrombine III. Bovendien vonden we dat de trombine activiteit die gevormd wordt niet gevoelig is voor de stimulerende werking van heparine in de inactivering door antitrombine III. We stellen vast dat gedurende de vroege fase van de protrombine activerlug melzotrombine thet belangrijkste reactieproduct is. In tegenstelling tot trombine, is meizotrombine nauwelijks gevoelig voor de werking van antitromblne IIL/heparine. Waarschijnlijk is dit het gevolg van het feit dat meizotrombin een geringe of geen affindteit heeft voor heparine. Onze conclusile is dat de werking van heparine op de antitrombine ILI-afhankelijke inactivering van gezuiverde trombine en factor $x_{\text {a }}$ niet geextrapoleerd kan worden nar de meer in vivo situatle benaderende conditles. 


\section{ACKNOWLEDGEMENTS}

In writing the last page of this dissertation, I have to realize that a whole period has come to an end and that the time has come co look back over the three years I have spent in Mastricht. Starting in a highly specialized research department as a medical doctor with a mostly theoretical knowledge of biochemistry and no knowledge of the Dutch language would have been a very difficult enterprise without the enormous support and understanding of all those working in the blochemistry department. I cannot thank all these people in person, but I want to speciflcally acknowledge the contributions of those who ande the realization of this thesis possible.

But first of all, I an deeply indebted to professor J. Gaen for helping me to obtain a fellowship from the INSERM (Institut National de la Sante et die la Recherche Medicalle) in his department in the Hôpltal Laribolsiere, in Paris, and for letting me go to Maastricht on a leave of absence. Without his support, my stay would not have been possible. I had many stimulating discussions with him and his co-workers and for these I an very grateful. I would also Ilke to thank him for giving me the opportunity of going to his department in Paris on two occasions to do platelet studies in patients whth a gray platelet syndrome. I am also grateful for his comments on this thesis.

I am equally grateful to prof. H.C. Hemker for accepting me $1 \mathrm{n}$ his department and for directing this thesis. I should like to thank hin for his help and support during the past years.

I would like to express my gratitude especially to Theo lindhout for his daily collaboration. Hils owerwhelming energy, his curlosity and his perseverance, as well as his rigorous method have been prememinent stimulants. Moreover, I apprechated the fact that all his qualitles were expressed in a frlendy and relaxed atmosphere. His contaglous enthusiasti also extended beyond the laboratory, for example 1 in playlng tennts. Finally, $I$ an very griteful for the many kirad invitations to has house.

Hans Soons has been a very faitheul, supportive colleague and frtend. His open mindness made our discussions very stimulating. He was always willing 
to ahare his expertence in many fields of biochemiscry and immonology.

1 am indebted to prof. R. Zwaal for many stinulating dlscussions and for naking new suggestions for the continuation of my work.

I atil equally grateful to Edouard Bevers for his interest in my work and for sharing wh me his expertence in the field of platelets in numerous valuable discugstons.

Jan Rosing is gratefully acknowledged for his help with improving the quality of the work and for his very clear explanations.

I should also like to glve a speclal place to Gerbrand van Dieljen who was a very patient and supportive co-worker during my first year here. He undoubtedly played a major role in my progress in this field. I deeply regret that a very serious 1 Llness prevents him from continuing his work. The referees, Prof. H. Strudjker-Boudier, Prof. M.J. Larrieu and Dr. Y. Legrand are gratefully acknowledged for their interest in my work and their investment of time in reading and criticizing this thesis.

Truug Janssen was a great help in her consclentlous way of working, aspactally ta proceln purtelcatons. She famfliarlzed me with a lot ot technlques and $\mathrm{I}$ am very grateful to her.

Jo Franssen has been a very friendly co-morker during mamy hours of plpetting and proteln purifications. I also want to thank hin for his excellent assistance in making the drawings.

Pleter Schoen"s contribution over the past year has been very valluable, especially in the discussions about kinetics and the practical aspect of the work.

Mary Maclume has been a very patient, llast minute help in improving the

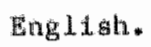

Lynn Alcorn is thanked for her drawing on the front cover.

L an very thankul to Marlet Molendar, Margitta Kampman and Trees Camphuizen, for all their hours of typing. I should like to thank Mariet Molenaar in particular, not only for her enormous support during the last weeks when most work was needed, but also for the way she constantly made me feel at home, from the very first day of my stay in Mastricht.

Flnally, I thank my parents and my friends in Paris and Masitricht very warmly for their understanding and support. The last word is to Riny Rongen, for her support during these last months and in general for the stimulation whlch I recelved from our work together in the women's health center in Maastricht. 
Dominique Baruch was born on August the 2nd, 1954 in suresnes (France). She graduated from high school in 1971 (Lycé Fenelon, Paris). From 1971 tidl 1977 she studied medicine at the university of Medictne Necker-Enfants Malades, Paris. In 1977 she passed the "Concours d.'Internat en Mëdecine des Hôpitaux de Paris" (competitive examination to hospital residency). From 1977 till 1982 she wroked as "interne en médecine" (resident phystcian) in different departments of medicine in Paris, 1ncluding those of internal. medicine (Prof. J. Dormont, Hopital Antoine Bëclere), infectious disease and intensive care (Prof. F. Vachon, Hôpital Claude Bernard), hypertenston (Prof. J. Menard, Hôpital Broussais) and hematology (Prof. R. Zitcoum, Hotel-Dieu; Prof. J. Caen, Hôpital Lariboisiere; Prof. M. Selignann, Hopital Saint-Louis). In 1979 she passed the "Certificat d'Etudes Supérleures de Biologle Humatne d'Hênatologie" and in 1982 the "These pour Le Doctorat en Médecine" (Doctoral Thesis in Medicine) on the subject of renin-secreting tumors (Prof. J. Menard).

In parallel she studied biochemistry at the Faculté des Sciences, Paris from 1977 till 1980. She passed the "Maitrise de Biochimie" in 1979 and in 1980 the "Diplame d'Etudes Approfondies de Biochimie", mention structure et fonction des proteines at the Universite Paris VII, (first year of postgraduate scudies approximately equivalent to a Master in Blochemistry). The "Diplome d"Etudes Approfondles" requires a year of laboratory training. that she did in 1979 in the hematology Laboratory, Faculte de Medecinet Necker-Enfants Malades, directed by Prof. F. Josso, where she wrote a dissertation enttled: "Modifications des conditions physlco-chimlques optimales d'activite de la thrombine par la liaison a l'alpha-2-matroglobuline: exemple du pH".

Since October 1982, she is a recipient of a "poste d"accuell pour internes" from the Institut National de la Sante et de la Recherche Medlcale (fellowship for resident pliysictans) in the Unite de Recherches de Thrombose Experimentale et d"Hemostase, directed by Prof. J. Caen, and on a Leave of absence in the department of Biochenistry, University of Limburg, Madztricht, where this dissertation was prepared. Since october 1985, she 18 a rectplenc of a poste d'aciatil in the croupe de Recherches sur la physiow pathologle de $\mathbb{1}$ Hemostase et de La Thrombose, directed by Dr. D. Meycr. 